\title{
$\sigma$ 1-adaptin - the Small Subunit of the Clathrin Adaptor Complex AP-1
}

\author{
Dissertation \\ zur Erlangung des Doktorgrades \\ der Mathematisch-Naturwissenschaftlichen Fakultäten \\ der Georg-August-Universität zu Göttingen
}

vorgelegt von

Constanze Riel

aus München

Göttingen 2004 
D7

Referent: Prof. Dr. Dr. h.c. Kurt von Figura

Korreferent: Prof. Dr. Ralf Ficner

Tag der mündlichen Prüfung: 25.6.2004 


\section{Contents}

1 Introduction $\quad 1$

1.1 Principles of vesicular transport . . . . . . . . . . . . . . . . 1

1.1.1 Clathrin . . . . . . . . . . . . . . . . 4

1.1.2 Adaptor protein complexes . . . . . . . . . . . 5

1.1.3 Monomeric adaptor proteins . . . . . . . . . . . . . . . . 14

1.2 Sorting pathways involving AP-1 f . . . . . . . . . . 16

1.2.1 Sorting into clathrin-coated vesicles at the TGN . . . . . . 17

1.2.2 Sorting at the endosomal compartment . . . . . . . . . . . 19

1.2.3 AP-1B in polarised epithelial cells . . . . . . . . . . . . . 20

1.3 Aim of the study . . . . . . . . . . . . . . . . . . . . 22

2 Materials and Methods $\quad 23$

2.1 Materials .......................... 23

2.1.1 Specific laboratory equipment . . . . . . . . . . . . 23

2.1.2 Chemicals, plasticware and membranes . . . . . . . . . 23

2.1.3 Kits, spin columns and reagents . . . . . . . . . . . . . . 24

2.1.4 Radioactively labelled substances . . . . . . . . . . . . . . . 24

2.1.5 Enzymes and standards . . . . . . . . . . . . 25

2.1.6 Cell lines and mouse strains . . . . . . . . . . . . . . . 25

2.1.7 Antibodies .................... 26

2.1 .8 Primers . . . . . . . . . . . . . . . . . . 27

2.1 .9 Vectors . . . . . . . . . . . . . . . . . . 28

2.2 Methods . . . . . . . . . . . . . . . . . . . . . 29

2.2.1 Molecular biology . . . . . . . . . . . . . . . . . . . . . 29

2.2.1.1 Culture of E. coli . . . . . . . . . . . . . . . . . . . 29

2.2.1.2 Cloning procedures . . . . . . . . . . . 30

2.2.1.3 Preparation of genomic DNA from mouse tail biopsies 30

2.2.1.4 Preparation of genomic DNA from mouse cells . . . . 30

2.2.1.5 Isolation of RNA from mouse cells or mouse tissue . 31 


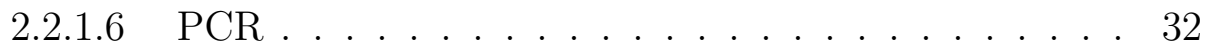

2.2.1.7 Southern blot . . . . . . . . . . . . 34

2.2.1.8 Northern blot . . . . . . . . . . . . . . . 36

2.2.1.9 Microarray ................ 36

2.2 .2 Cell culture . . . . . . . . . . . . . . . . . . . 37

2.2.2.1 Basics . . . . . . . . . . . . . . 37

2.2.2.2 Preparation and immortalisation of mouse embryonic fibroblasts . . . . . . . . . . . . . . . 38

2.2.2.3 Culture of mouse embryonic stem cells . . . . . . . . 38

2.2.2.4 Transfection of mouse embryonic stem cells by electroporation .................. 40

2.2.3 Biochemistry . . . . . . . . . . . . . . . . . . 41

2.2.3.1 Discontinuous SDS-polyacrylamide gel electrophoresis $($ SDS-PAGE) . . . . . . . . . . . . . 41

2.2.3.2 Western blot (semi-dry) . . . . . . . . . . 42

2.2.3.3 Preparation of postnuclear supernatants . . . . . . 43

2.2.3.4 Gelfiltration of cytosol . . . . . . . . . . . . 44

2.2.3.5 Purification of GST-tagged recombinant proteins . . 45

2.2.3.6 Purification of peptides by C18-cartridge . . . . . . . 46

2.2.3.7 Crosslinking of peptides to key limpet hemocyanin $(\mathrm{KLH}) \ldots \ldots \ldots \ldots \ldots$

2.2.3.8 Immunisation of rabbits and serum preparation . . . 47

2.2.3.9 Indirect immunofluorescence of fibroblasts . . . . . . 47

2.2.3.10 Indirect immunofluorescence of cryosections . . . . . 49

2.2.4 Breeding and analysis of mice . . . . . . . . . . . . . . . . . . 49

2.2.4.1 Housing of mice . . . . . . . . . . . . . . . . . 49

2.2.4.2 Perfusion fixation of mice for histology . . . . . . . 49

2.2.4.3 Preparation of T cells and FACS analysis . . . . . . 50

3 Results

3.1 The $\sigma 1$-adaptin family $\ldots \ldots \ldots \ldots \ldots$

3.1.1 Expression analysis of $\sigma 1$ isoforms . . . . . . . . . . 55

3.1 .2 Alternative splicing of $\sigma 1 \mathrm{~B} \ldots \ldots$. . . . . . . . . 60

3.2 Generation of antisera against $\sigma 1$-adaptins and $\gamma 2$-adaptin . . . . . . 65

3.2.1 GST-fusion proteins as antigen . . . . . . . . . . . . 65

3.2.2 Peptides as antigen . . . . . . . . . . . . . . . . 68

$3.3 \sigma 1$ B knock-out mouse model . . . . . . . . . . . . . . . . . . . . 70

3.3.1 Cloning of the targeting construct and ES cell culture . . . . . 70 
3.3.2 Generation of $\sigma 1$ B-deficient mice . . . . . . . . . . 73

3.3.3 Anatomy and histology of $\sigma 1 \mathrm{~B}-/$ - mice . . . . . . . . 77

3.3.4 Analysis of AP-1 in $\sigma 1 \mathrm{~B}-/$ - fibroblasts . . . . . . . . . . . 78

3.3.4.1 Composition of AP-1 . . . . . . . . . . 78

3.3.4.2 Subcellular distribution of AP-1 adaptins . . . . . 81

3.3.5 Analysis of $\sigma 1 \mathrm{~B}-/$ - skeletal muscle . . . . . . . . . . . 87

3.3.5.1 Expression of AP-1 subunits in skeletal muscle . . . 87

3.3.5.2 Localisation of AP-1 . . . . . . . . . . 88

3.3.5.3 Microarray analysis . . . . . . . . . . . . 90

3.3.5.4 Verification of microarray results by northern blot . . 93

3.3.6 FACS-analysis of $\sigma 1 \mathrm{~B}-/-$ T-lymphocytes . . . . . . . . 93

4 Discussion $\quad 97$

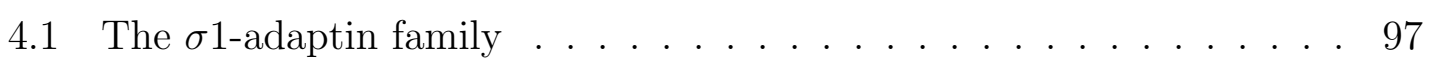

4.2 Generation of antibodies . . . . . . . . . . . . . . . . 99

4.3 Generation and analysis of $\sigma 1 \mathrm{~B}$ deficient mice . . . . . . . . . . 100

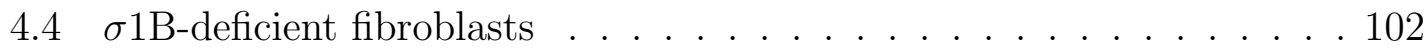

$4.5 \sigma 1 \mathrm{~B}$-deficient muscle . . . . . . . . . . . . . . . . . . . 104

$4.6 \quad \sigma 1 \mathrm{~B}$-deficient T-lymphocytes . . . . . . . . . . . . . . . . 106

4.7 Perspective . . . . . . . . . . . . . . . . . 107

5 Summary 109

$\begin{array}{ll}\text { Bibliography } & 111\end{array}$

$\begin{array}{ll}\text { Appendix } & \mathbf{1 2 5}\end{array}$

Acknowledgements . . . . . . . . . . . . . . . . . . . . 125

Lebenslauf . . . . . . . . . . . . . . . . . . . . . . . 127 


\section{Abbreviations}

ADP adenosine diphosphate

AP-1 "assembly polypeptide", adaptor protein complex 1

ARF ADP-ribosylation factor

ATP adenosine triphosphate

BFA brefeldin A

BLAST basic local alignment search tool

bp basepair(s)

CCV clathrin-coated vesicle

COP coat protein

DMEM Dulbecco's modified Eagle medium

DMSO dimethylsulfoxide

DNA desoxyribonucleic acid

DTT dithiothreitol

E. coli Escherichia coli

EDTA ethylene dinitrilotetraacetic acid

ENTH epsin N-terminal homology

ER endoplasmic reticulum

ES cells embryonic stem cells

EST expressed sequence tag

FACS fluorescence-activated cell sorter

FCS fetal calf serum

fig. figure

FITC fluoresceine-isothiocyanate

GEF GTP-exchange factor 


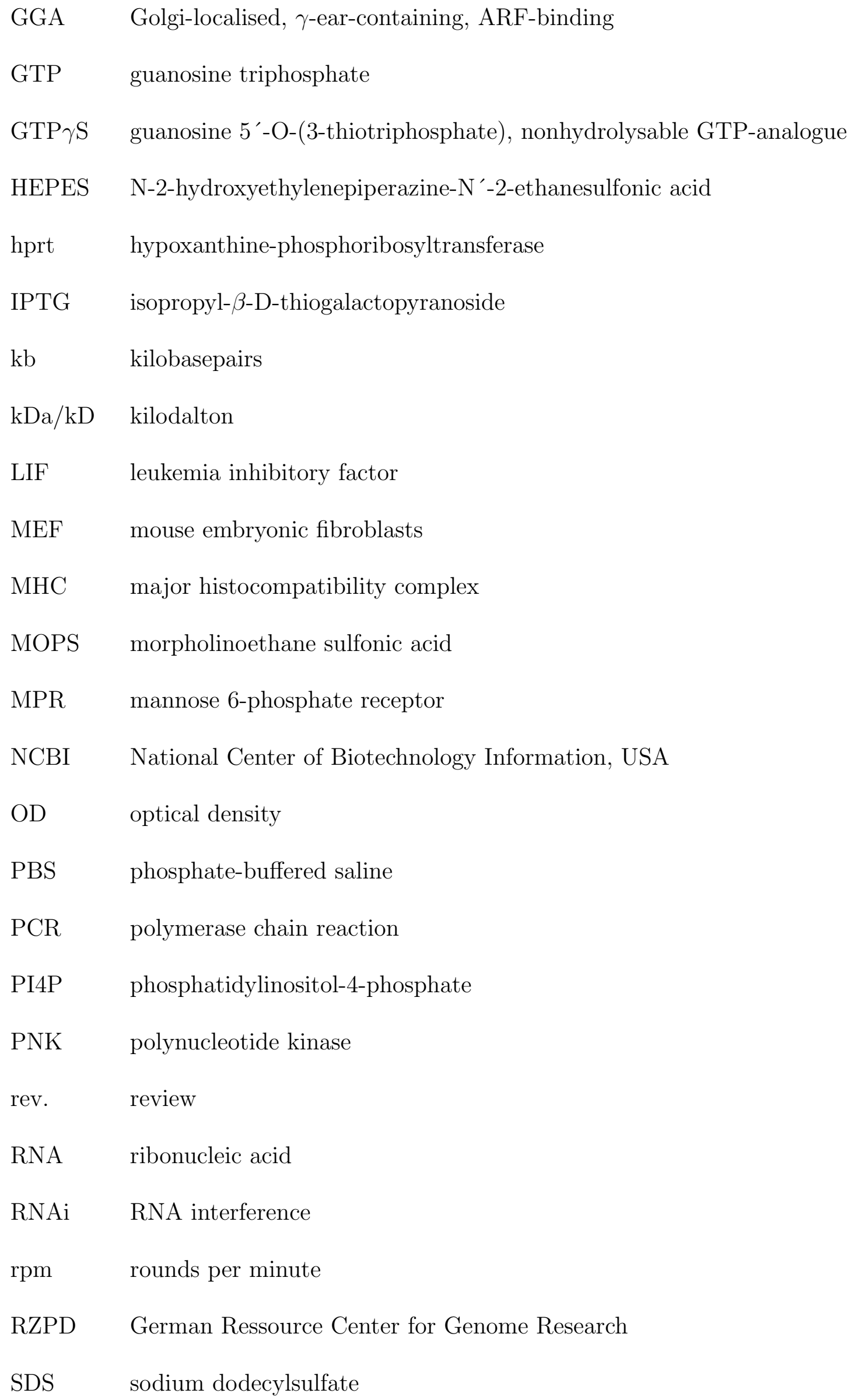


SNARE soluble NSF attachment protein receptor

SSC standard saline citrate

TEMED N, N, N', N'-tetramethyl-ethylene diamine

TGN trans-Golgi-network

Tris tris-(hydroxymethyl)-aminomethane

Vol volume

$\mathrm{Y} 2 \mathrm{H} \quad$ yeast two-hybrid 


\section{Introduction}

Protein sorting between membrane-bound compartments within a eukaryotic cell requires a highly specialised transport network. Following the biosynthetic pathway, proteins travel through the ER and the Golgi apparatus with destination to the endosomal system, the lysosomes, the plasma membrane or to the extracellular lumen. Proteins that are endocytosed at the plasma membrane will reach these compartments taking the opposite direction.

All the trafficking steps are mediated by lipid vesicles and make use of a general mechanism: Initially, the "donor" membrane is curved and formed into a bud, under the influence of a favourable lipid composition and of protein oligomers associated on the cytoplasmic side. The connection to the donor membrane is constricted with the help of associated proteins and disrupted to release a vesicle. Motor proteins recognise the outer surface of the vesicle and move it along a cytoskeletal path. Specific interactions need to be established to dock and fuse the vesicle at the "acceptor" compartment. Thus, the selective targeting of a cargo protein requires an array of high affinity interactions during the transport.

These specific transport events are mediated by "coated vesicles" with a diameter of $60-100 \mathrm{~nm}$. Their formation involves the recruitment of cytoplasmic proteins to the budding site and the concentration of corresponding transmembrane cargo proteins. By initiating a network of associated proteins around the vesicle, the coat constituents account for the correct delivery of the cargo until finally the coat has to be disassembled before the vesicle can fuse with the acceptor membrane.

\subsection{Principles of vesicular transport}

Several types of coated vesicles have been characterised until now (for review see Barlowe, 2000; Bonifacino \& Lippincott-Schwartz, 2003; Bonifacino \& Glick, 2004). Trafficking from the ER to the Golgi complex is mediated by COPII-coated vesicles (fig. 1.1). They assemble on specialised sites of the ER named as "transitional ER" which are devoid of ribosomes and may even play a crucial role in Golgi biogenesis as indicated from studies in yeast (Glick, 2002). COPII consists of two 


\section{Introduction}

dimeric subcomplexes and a small GTPase which is incorporated in stochiometric amounts. COPI-coated vesicles move between different Golgi cisternae or return cargo from the cis-Golgi to the ER. The COPI-complex comprises seven stably associated proteins that are organised into one trimeric and two dimeric subcomplexes. Transport pathways from the ER to the Golgi and in the opposite direction pass by the ER-Golgi intermediate compartment (ERGIC). Finally, clathrin in association with different adaptor complexes maintains transport on the routes between the trans-Golgi-network (TGN) and the plasma membrane (PM). Whereas the different subunits of a COP-complex assemble as two layers of the coat, adaptor complexes constitute the inner and clathrin the outer layer of clathrin-coated vesicles (CCVs). The heterotetrameric adaptor complexes seem to derive from the same ancestor as the two dimeric subcomplexes of COPI (Schledzewski et al., 1999). Moreover, at least one structural element is conserved between clathrin and the trimeric subcomplex of COPI, suggesting common principles for both coats. This question will probably be solved only by the crystal structure of COPI.

Two of the four known adaptor complexes are part of CCVs, namely AP-1 and AP-2. However, the relationship of clathrin and AP-3 is still unclear and the fourth complex AP-4 cannot associate with clathrin. As suggested by electron microscopy, other types of coat proteins remain to be discovered (Hirst et al., 1999).

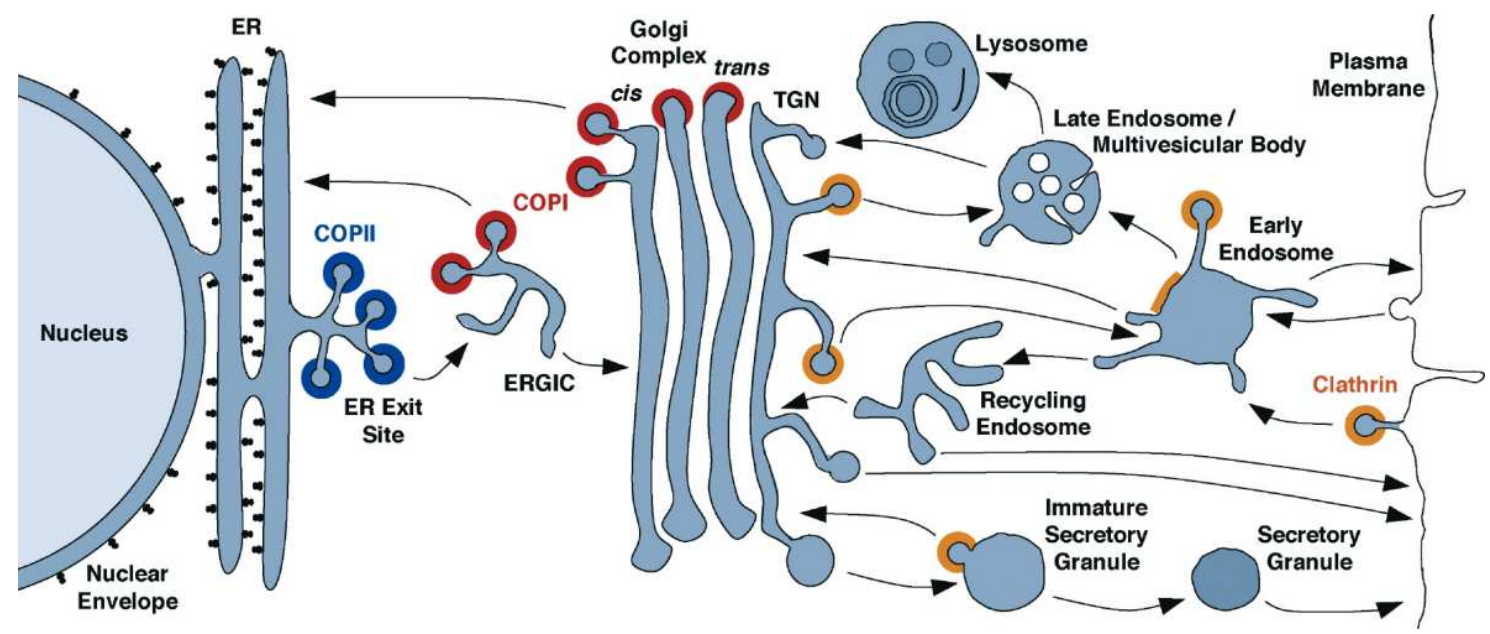

Figure 1.1: Secretory, lysosomal and endocytic compartments in a mammalian cell. Transport steps are indicated by arrows. The known or presumed locations of COPII (blue), COPI (red) and clathrin (orange) are shown in colour. Clathrin coats are heterogeneous and contain different adaptor proteins at different membranes (Bonifacino \& Glick, 2004).

To ensure that coated vesicles bud from a specific site and selectively incorporate cargo proteins, several other factors contribute to their formation (fig. 1.2).

Integral or peripheral membrane proteins present at a particular organelle serve as docking platforms for coat proteins. Membrane properties are also greatly influ- 
enced by a specific phospholipid composition, that is maintained for each cellular compartment with the help of localised biosynthetic enzymes (for rev. see Corvera et al., 1999; Martin, 1997). Many proteins of the vesicular transport machinery contain specific recognition motifs for phosphoinositolphosphates (for rev. see Hurley \& Meyer, 2001).

The recruitment of some of the coat proteins is further regulated by a family of small GTPases, the ARF proteins (for rev. see Chavrier \& Goud, 1999). G-proteins cycle between a GDP-bound form and a GTP-bound form, by tradition named as the "active" state. The GTP-GDP cycle of small GTPases involved in the formation of coated vesicles contributes to spatial and temporal specificity of the budding. On one hand, different GDP-nucleotide exchange factors (GEF) for one GTPase localise to different membranes and give rise to distinct coat populations. GTPase-activating proteins (GAP) or GDP-dissociation inhibitors (GDI), on the other hand, determine the time window needed to establish specific interactions.

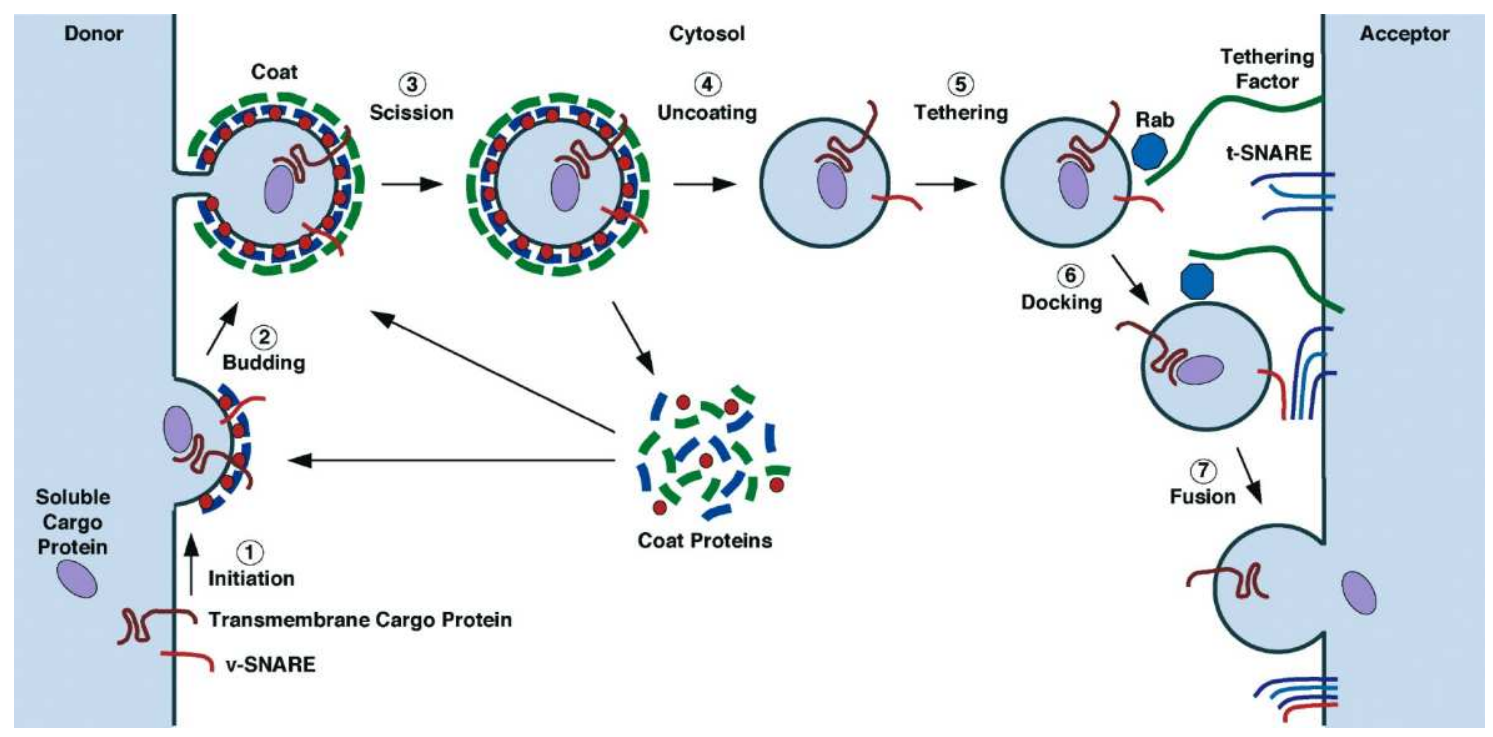

Figure 1.2: Steps of Vesicle Budding and Fusion. Membrane-proximal coat components (blue) are recruited to the donor compartment by binding to a membrane-associated GTPase (red) and/or to a specific phosphoinositide (1). Membrane-distal coat components (green) are added during the progress of budding (2). After scission, uncoating and transport of the vesicle, it is tethered at the acceptor compartment (5). v- and t-SNARE proteins assemble into a four-helix bundle (6) and promote vesicle fusion (7) (Bonifacino \& Glick, 2004).

Some of the proteins, that can classify as cargo proteins during vesicle formation, belong to the transport machinery themselves. Rab proteins, another family of small GTPases, link the vesicles to the cytoskeleton or manage their correct docking at the target membrane. SNARE proteins mediate membrane fusion in the last step of transport (for rev. see Jahn et al., 2003). As assumed for all membrane 


\section{Introduction}

fusion events, SNARE proteins reside on both the vesicle and the target membrane. Specific docking of the vesicle depends on the formation of the correct SNARE complex, which also approaches the two membrane surfaces to prepare for membrane fusion.

According to the focus of this thesis, the following sections will concentrate on the clathrin adaptor complex AP-1.

\subsubsection{Clathrin}

Clathrin-coated vesicles (CCV) mediate one mechanism of endocytosis at the plasma membrane as well as sorting between the trans-Golgi network and the endosomal compartments (for rev. see Kirchhausen, 2000; Brodsky et al., 2001). Soluble clathrin consists of three heavy chains $(190 \mathrm{kD})$ that join their C-termini to form the "vertex" (fig. 1.3), and accommodate three light chains $(25 \mathrm{kD})$. These triskelia polymerise into polyhedral lattices of regular shape, with one unit centered on every edge and its legs lining two sides of a polygon. The N-terminal domains are facing inwards to establish the contact with adaptor molecules that link clathrin to the membrane and which interact with cargo proteins.
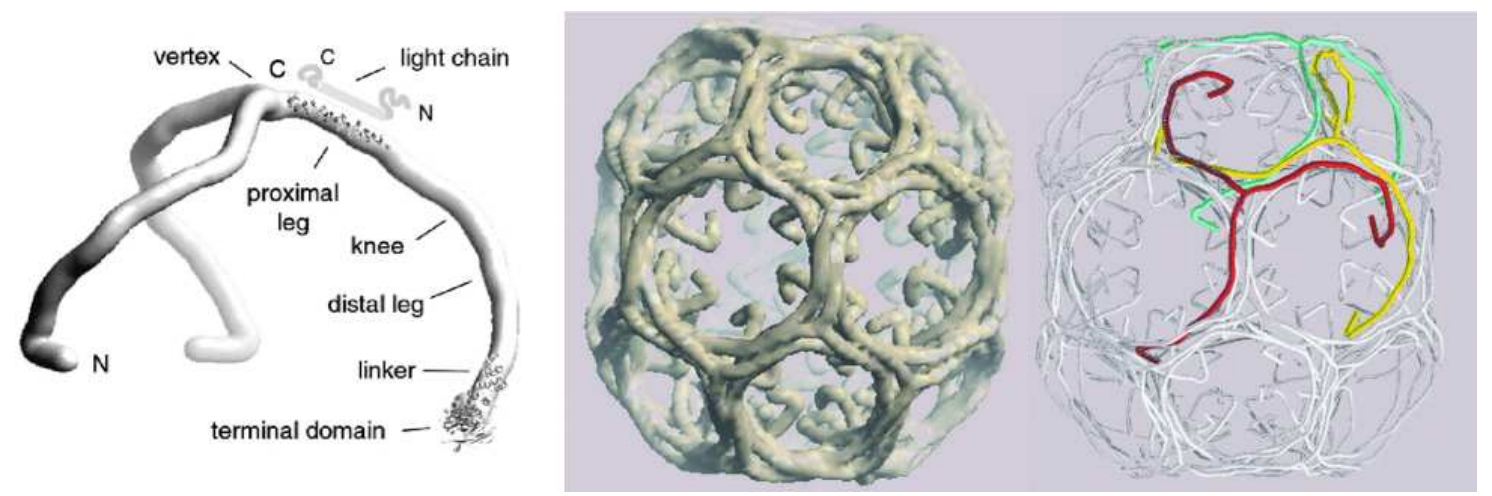

Figure 1.3: Scheme of a clathrin triskelion and its positioning in a clathrin cage (Kirchhausen, 2000).

Electron micrographs established clathrin as an extended protein with a prominent bend in the central part, slight overall curvature and a knob-like N-terminus. Detailed structural information for the clathrin heavy chain was provided by the crystallisation of two fragments: The 330 aminoterminal residues form a propellerlike domain composed of seven $\beta$-sheets, similar to the WD40 repeat fold present in COPI subunits. A peptide of 316 aa was taken from the proximal leg and visualised as a zigzag serie of short antiparallel $\alpha$-helices. About 150 residues in the center of this fragment represent a pattern that is repeated six times covering the whole molecule except the terminal domains. The resulting model of a heavy chain 
monomer turns out to be quite flexible. Along the axis of repeated zigzag motifs, the molecule can be stretched or squeezed like a feather. Due to the curvature of the leg, the distance of the vertex to the membrane is also variable. A polymeric assembly should therefore be able to adjust under pressure from different directions. Purified clathrin can be readily assembled into cage-like structures in vitro at slightly acidic pH (Kirchhausen \& Harrison, 1981). Clathrin light chain exhibits an inhibitory effect on polymerisation in vitro (Liu et al., 1995). Under physiological buffer conditions, the adaptor molecules need to be present and the resulting baskets appear smaller, more regular and of uniform size (Pearse \& Robinson, 1984). In other words, clathrin may inherently tend to assemble but additional contacts are necessary to fix it properly. Electron microscopic images show clathrin assemblies as flat membrane-associated lattices made up of hexagons and as a shell of hexagons and pentagons on curved membrane buds. As it is unlikely from an energetical point of view that hexagons should be transformed into pentagons as part of an existing lattice, the flat arrays may serve to concentrate clathrin at sites of rapid coat-turnover.

Clathrin participates in various transport steps whose distinct properties depend on the specific adaptor protein present.

\subsubsection{Adaptor protein complexes}

Two adaptor protein complexes, AP-1 and AP-2, were originally purified from clathrin-coated vesicles (for rev. see Hirst \& Robinson, 1998; Schu, 2001; Robinson \& Bonifacino, 2001). According to their ability to promote the assembly of clathrin cages in vitro they were named "assembly polypeptides" or adaptins (Pearse \& Robinson, 1984). AP-1 localises to the TGN and to endosomes, whereas AP-2 is found at the plasma membrane. Database searches have identified two more members of the family, AP-3 and AP-4, which are absent from clathrin-coated vesicles. Although AP-3 was initially assigned to a perinuclear region like the TGN and to endosomal structures, recent experiments demonstrate that it is mainly present on endosomal tubules (Dell'Angelica et al., 1997; Simpson et al., 1997; Peden et al., 2004). It was shown to interact and colocalise with clathrin, albeit to a lower extent compared to AP-1, suggesting a function as clathrin adaptor of lower affinity or different assembly properties (Dell'Angelica et al., 1998; Peden et al., 2004). In contrast, AP-4, which has been implicated in sorting at the TGN, obviously does not bind to clathrin (Simmen et al., 2002).

All the adaptor complexes consist of four adaptin proteins. The two large subunits of about $100 \mathrm{kD}, \gamma / \alpha / \delta / \epsilon$ and $\beta 1-4$ for AP1-4, respectively, fold into an aminoterminal 


\section{Introduction}

trunk domain and a carboxyterminal "ear" or appendage domain that are connected by a largely unstructured "hinge". The trunk domains together with the mediumsized subunits, $\mu 1-4$ (about $50 \mathrm{kD}$ ), and the small subunits $\sigma 1-4$ (about $20 \mathrm{kD}$ ) form the core complex. Between AP-1 and AP-2, $\beta$ is the most conserved subunit showing $84 \%$ sequence identity. Whereas the $\mu$ - and $\sigma$-subunits are about $40 \%$ identical, only $25 \%$ of the amino acids are conserved between $\gamma$ and $\alpha$, mostly due to the divergence of the ear domains. Despite the differences in primary sequence, predictions of secondary structure and hydrophilicity profiles indicate that all the four complexes are highly homologous. Thus, the crystal structure of AP-2 can serve as a model for the entire family (see fig. 1.4).

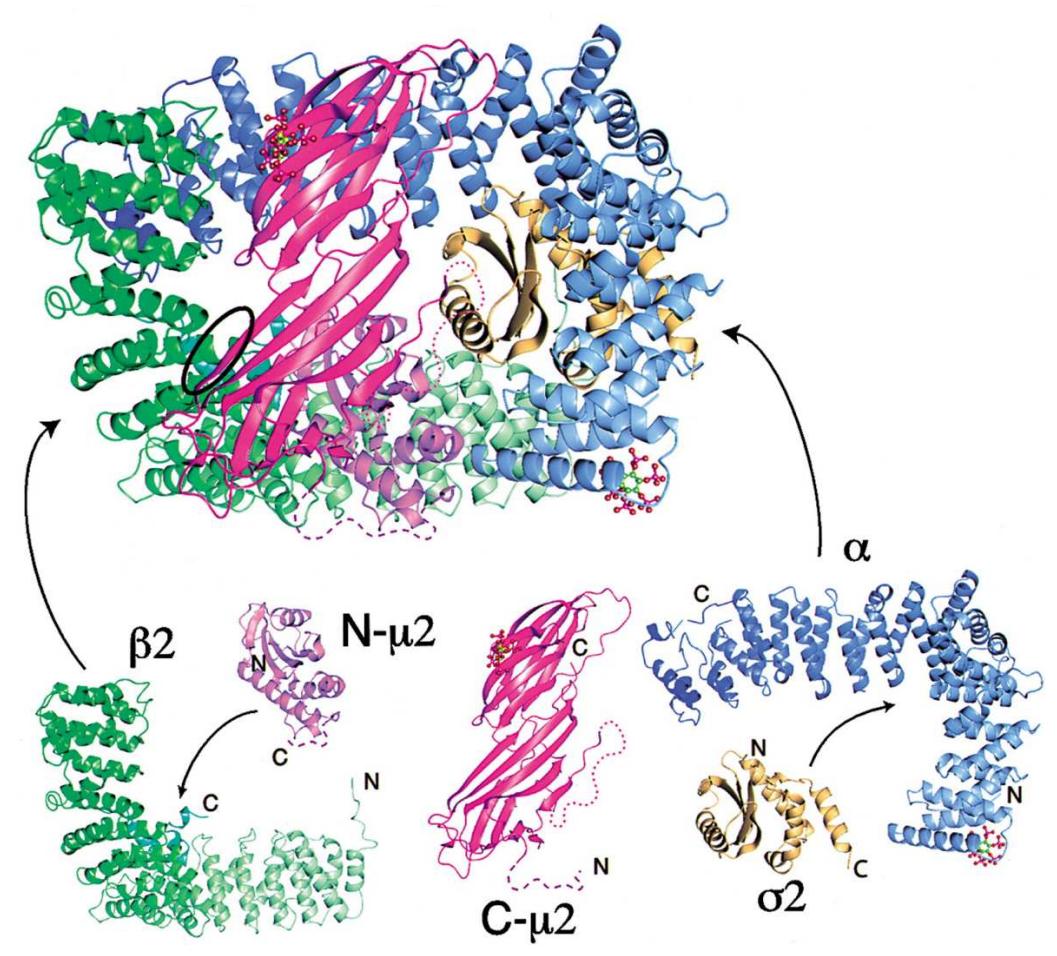

Figure 1.4: Crystal structure and assembly of the AP-2 core complex. The AP-2 subunits $\alpha$ (blue), $\beta 2$ (green), $\mu 2$ (rose and magenta) and $\sigma 2$ (yellow) are shown separately and as an assembled complex. Inositolhexakisphosphate was included for crystallisation to mimick the phosphoinositol headgroup (shown at binding sites near the N-terminus of $\alpha$ and near the C-terminus of $\mu 2$ ). The position of the linker domain between the $\mathrm{N}$-terminal and $\mathrm{C}$-terminal domains of $\mu 2$ is shown with dashed lines, and the dotted line indicates a disordered loop of $\mu 2$. The location of the Tyr-motif binding site in $\mu 2$ is depicted by a black ellipse (Collins et al., 2002).

The large subunits $\alpha$ and $\beta 2$ form curved arrays of $\alpha$-helices, which accommodate the globular $\sigma 2$ and N-terminal $\mu 2$-domains, respectively. $\sigma 2$ and N- $\mu 2$ both contain a central five-stranded $\beta$-sheet surrounded by $\alpha$-helices. $\mathrm{N}-\mu 2$ is connected to the 
all- $\beta$ sheet by a 23 -residue loop. All the subunits contact each other to some extent, but stronger interactions link $\alpha$ to $\sigma 2$ as well as $\beta 2$ to $\mu 2$. In fact, these two dimers show significant similarity on the amino acid level and their folds can be matched onto each other, particularly for the N-terminal domain of $\mu 2$ and $\sigma 2$ and for the aminotermini of the large subunits. $\sigma 2$ is related to the N-terminal domain of $\mu 2$ even at the primary sequence level, whereas the C-terminal domain of $\mu 2$, that associates loosely on the surface of the core complex, was probably acquired later in evolution. COPI seems to derive from the same ancestor, which is supposed to be a dimeric complex of one large and one small subunit (Schledzewski et al., 1999). The AP-2 core complex harbours two phosphoinositide binding sites, one in the C$\mu 2$ domain and one at the N-terminus of $\alpha$ (as indicated by a ball-stick model in fig. 1.4). Sequence alignment of AP-2 and AP-1 counterparts indicates that these binding sites are basically conserved.

Whereas the core complex measures about $100 \AA$ x $80 \AA$, the hinge regions of the two large subunits can probably stretch about 200-300 $\AA$ away from the core, since they have no significant secondary structure. In consequence, the ear domains are able to act at a long distance.

For many of the adaptor subunits, several genes are known in mammals. $\gamma 2$-adaptin is about $60 \%$ identical to $\gamma 1$-adaptin, being shortened in the hinge region. In contrast to $\gamma 1$, it does not interact with $\beta 1$ in the yeast two-hybrid system, which indicates that they will not form a complex in vivo. Three genes are known for the $\sigma 1$-subunit, named $\sigma 1 \mathrm{~A},-\mathrm{B}$ and $-\mathrm{C}$ that are about $70-80 \%$ identical to each other. $\sigma 1 \mathrm{~A}$ and $\sigma 1 \mathrm{~B}$ apparently bind to both $\gamma 1$ and $\gamma 2$ in vitro (Takatsu et al., 1998, 2001). In addition to the ubiquitous subunit $\mu 1 \mathrm{~A}, \mu 1 \mathrm{~B}$ is selectively expressed in polarised cells and assembles into the variant complex AP-1B (Ohno et al., 1999; Fölsch et al., 1999; Eskelinen et al., 2002).

$\alpha$-adaptin exists as two different proteins, $\alpha \mathrm{A}$ and $\alpha \mathrm{C}$, which are $80 \%$ identical (Ball et al., 1995). In addition to a ubiquitous alternative for $\sigma 3(\sigma 3 \mathrm{~B})$, neuron-specific variants are known for $\mu 3$-adaptin $(\mu 3 \mathrm{~B})$ and $\beta 3$-adaptin $(\beta$-NAP) and they have been shown to form a variant neuronal AP-3B complex (Faúndez et al., 1998). No additional genes for AP-4 have been described.

\section{Formation of a clathrin-coated vesicle via AP-1}

Regarding the mechanism of coat formation, AP-1 and AP-2 were extensively examined. During the initial studies in order to define the absolute prerequisites for their membrane recruitment, they apparently differed at a very basic level. The treatment with Brefeldin A, a fungal metabolite, that inhibits the ARF family of small GT- 


\section{Introduction}

Pases via their GEF proteins, caused AP-1 to dissociate from the membrane whereas it had no obvious effect on AP-2 (Robinson \& Kreis, 1992). Further experiments identified ARF1 as the GTPase required for AP-1 membrane binding (Stamnes \& Rothman, 1993). AP-2 membrane localisation could as well be modulated by activated ARF1, but, in contrast to the influence on AP-1, this effect was attributed to regulation of phospholipid metabolism by ARF1 (West et al., 1997). Supporting a strong impact of membrane lipids on the function of AP-2 in contrast to AP-1, AP-2 was shown to interact with phosphoinositides, namely phosphoinositol-4,5bisphosphate $\left(\mathrm{PI} 4,5 \mathrm{P}_{2}\right)$ via the $\alpha$ and $\mu 2$ subunits (Gaidarov \& Keen, 1999; Rohde et al., 2002).

However, the idea of two entirely different mechanisms of membrane recruitment operating for AP-1 and AP-2 has been challenged later on. Some GEF acting on ARF proteins can not be inhibited by Brefeldin A, i.e. small GTPases could well be involved in AP-2 membrane recruitment. Indeed, the plasma membrane-resident ARF6 directly binds and activates PIPKI $\gamma$ to generate PI4,5P 2 and initiate the formation of coated pits in neurons (Krauss et al., 2003). Consistently, AP-1 was shown to bind directly to the phosphoinositide PI4P (Wang et al., 2003). Thus, ARF GTPases and phosphoinositides seem to regulate the membrane assembly of both AP-1 and AP-2, even though their contribution to high affinity membrane binding is not equally strong regarding the two processes. This can probably be extended to the AP-3 and AP-4 complexes which associate with the membrane in a BFA-sensitive mode. The mechanism of vesicle formation will be discussed in more detail for AP-1.

Coat formation is thought to be initiated by recruitment of ARF1 to the membrane where it is converted into the GTP-bound form upon interaction with a BFA-sensitive GEF, that is peripherally associated with the membrane. Among the various GEF proteins identified for ARF1, BIG2 is a good candidate as its overexpression was shown to prevent the effect of BFA on AP-1 but did not influence COPI (Shinotsuka et al., 2002). Activated ARF1 binds directly to $\gamma$ - adaptin as well as to $\beta 1$-adaptin (fig. 1.5, step 1), however, the latter can as well assemble with other ARFs (Austin et al., 2000, 2002).

AP-1 recognises sorting motifs in the cytoplasmic domain of cargo proteins in order to concentrate and package them (fig. 1.5, step 2). Tyr-based signals bind to the $\mu 1$-subunit, most likely after its phosphorylation which is assumed to trigger a conformational change that opens access to the Tyr-motif binding pocket (Ricotta et al., 2002; Collins et al., 2002; Ghosh \& Kornfeld, 2003b). The candidate kinase, auxilin-2, associates with AP-1 via the $\gamma$-ear domain (Umeda et al., 2000). $\beta 1$ - or 


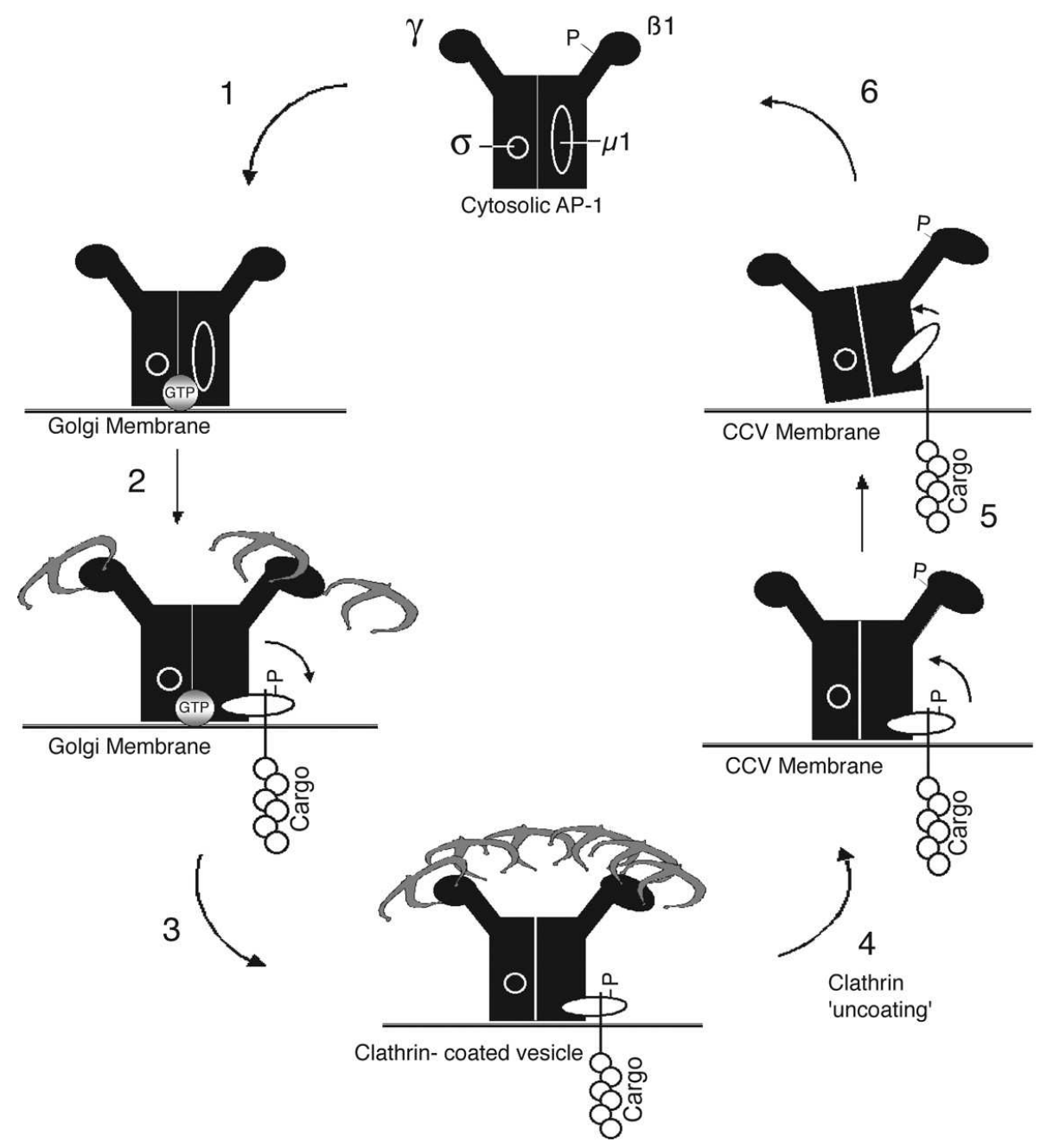

Figure 1.5: Membrane association of AP-1 is regulated by phosphorylation. Cytosolic AP-1 contains a phosphorylated $\beta 1$ hinge, whereas $\mu 1$ is dephosphorylated. (1) Recruitment of AP-1 onto the membrane stimulates dephosphorylation of $\beta 1$, which allows clathrin assembly $(2,3)$. Concurrently, $\mu 1$ is phosphorylated, inducing a conformational change that exposes the $\mu 1$ ligand binding site (2). (4) After budding, clathrin is uncoated, maybe facilitated by the phosphorylation of $\beta 1$. (5) Dephosphorylation of $\mu 1$ decreases the avidity of AP-1 for cargo signals and releases AP-1 into the cytosol (Ghosh \& Kornfeld, 2003b). 


\section{Introduction}

$\mu 1$-adaptin as well as a dimer of $\gamma$ and $\sigma 1$-adaptin have been proposed as binding partners for Leu-based motifs (Rapoport et al., 1998; Bremnes et al., 1998; Janvier et al., 2003).

Since cargo proteins and ARF1 localise to several membrane compartments in vivo, they cannot determine the site-specificity of coat formation. In addition to these interactions, a direct association of AP-1 with phosphoinositides, namely PI4P, and its necessity for AP-1 localisation in vivo have recently been discovered (Wang et al., 2003). In analogy to AP-2, phosphoinositide interaction could be mediated by $\gamma$ and $\mu 1$ (Collins et al., 2002). The composition of phospholipids, namely phosphoinositides, is an individual and dynamic property of each compartment, because the enzymes that generate and degrade them are specifically targeted and their activity is regulated on many levels. For instance, PI4,5 $\mathrm{P}_{2}$ plays an important role at the plasma membrane whereas PI3P and PI4P are enriched at endosomes and at the Golgi apparatus, respectively (for rev. see Martin, 1997; DeMatteis et al., 2002). Therefore, membrane binding of AP-1 is probably stabilised by several components, but it is not known until now, if there is a specific sequence of interactions. ARF1 and clathrin have both been implicated in regulation of phosphoinositide metabolism, suggesting a mechanism of feedback activation (Godi et al., 1999; Gaidarov et al., 2001).

In vitro studies showed that purified AP-1 can be assembled onto defined liposomes dependent on the phospholipid composition and the presence of activated ARF1 (Zhu et al., 1999; Crottet et al., 2002). In addition, the presence of cytosol was required for membrane recruitment of AP-1 (Zhu et al., 1999). A different group reported, that cytosolic components were not necessary, but the phospholiposomes were coupled to peptides containing sorting motifs in their assay (Crottet et al., 2002). These data suggest that several factors can independently contribute to bind AP-1 with high affinity to the membrane.

Clathrin is recruited to the coated pit upon interaction with the two large subunits of AP-1 (fig. 1.5, step 3). Each hinge region contains two "clathrin box" motifs of the sequence $\mathrm{LL}(\mathrm{N} / \mathrm{D}) \mathrm{L}(\mathrm{D} / \mathrm{L})$ which promote clathrin assembly in vitro (ter Haar et al., 2000; Doray \& Kornfeld, 2001). These motifs bind to the N-terminal domain of clathrin. Additional binding sites for clathrin were described for the $\gamma 1$ - and $\beta 1$-appendage domains, suggesting multivalent association of clathrin and adaptors (Owen et al., 2000; Doray \& Kornfeld, 2001). However, in the assembled coat, adaptins interact only with the globular N-terminus of clathrin (Keen et al., 1991; Murphy \& Keen, 1992). Further steps of budding are not known in great detail, although Golgi-localised dynamin-2 probably participates in fission of the coated 
vesicle, as shown for dynamin-2 and endocytic vesicles. Uncoating involves the phosphorylation of $\beta 1$ to disturb its interaction with clathrin (Wilde \& Brodsky, 1996; Ghosh \& Kornfeld, 2003b). Finally, the chaperone Hsc70 plays a crucial role, in association with PP2A that dephosphorylates the $\mu 1$-subunit, thereby decreasing its affinity for sorting motifs (Hannan et al., 1998; Doray \& Kornfeld, 2001). During the next round of membrane association, $\beta 1$ will be dephophorylated by a protein phosphatase $2 \mathrm{~A}$ isoform.

\section{Recognition of sorting motifs}

At least three types of sorting signals have been characterised in the context of APmediated trafficking (for rev. see Bonifacino \& Traub, 2003). Best understood are the Tyr-based motifs of the consensus $\operatorname{Yxx} \phi$ ( $\phi$ for a bulky hydrophobic residue) which are selectively recognised by the medium subunits. Cocrystallisation of the $\mu 2$-adaptin C-terminal domain with peptides containing a Tyr-motif confirmed the precise interaction site (Owen \& Evans, 1998). Yxx $\phi$ motifs function in various transport pathways including endocytosis, lysosomal targeting or sorting to the basolateral plasma membrane (Marks et al., 1996; Bonifacino \& Traub, 2003). Consistently, all the four $\mu$-adaptins bind to $\mathrm{Yxx} \phi$ sequences in vitro with distinct preferences for specific motifs (Ohno et al., 1998). The surrounding residues obviously contribute to this specificity as well as the exact spacing of the motif within the cytoplasmic domain of the protein. Most solely endocytic motifs are found at 10-40 amino acid distance from the transmembrane domain, but not at the C-terminus of the protein. In contrast, motifs for lysosomal targeting are often located only 6-9 residues from the transmembrane domain and close to the C-terminus. As shown for the lysosomal protein Lamp-1, changing the distance of the GYQTI signal from the membrane interfered with sorting to lysosomes, but not with internalisation from the plasma membrane (Rohrer et al., 1996).

Another Tyr-based motif with the consensus FxNPxY functions exclusively in clathrin-mediated endocytosis. Peptides comprising this signal can interact with the Nterminal domain of clathrin heavy chain as well as with purified AP-2 in vitro, but it is still unclear if these mediate the sorting in vivo. Moreover, a group of proteins that were initially known for recognition of phosphotyrosine residues and implicate in downstream signalling of tyrosine-kinase receptors, show a remarkable affinity for unphosphorylated FxNPxY and are localised in coated pits by various interactions with AP-2, phospholipids and clathrin (see 1.1.3).

Leu-based motifs were identified as sorting determinants from the plasma membrane and from the TGN to endosomes and lysosomes. Apparently, there are two 


\section{Introduction}

different classes. (D,E)xxxL(L,I) signals, like $\mathrm{Yxx} \phi$, bind to adaptor complexes with preference for specific complexes and are found close to transmembrane domain as well as to the C-terminus. The acidic residue at the first position is not strictly required although favoured. Competition experiments with Tyr- and Leu-based motifs demonstrated that they are recognised by independent binding sites (Marks et al., 1996). Until now, several subunits have been proposed to contain this site, namely $\mu$, as inferred from several in vitro studies, and $\beta$, which was crosslinked to peptides (Rapoport et al., 1998; Hofmann et al., 1999). Recently, Y2H experiments reported an interaction between $(\mathrm{D}, \mathrm{E}) \mathrm{xxxL}(\mathrm{L}, \mathrm{I})$ signals and a $\gamma 1-\sigma 1$ - or $\delta$ - $\sigma 3$-dimer, whereas none of the AP-1 or AP-3 subunits alone bound the motif (Janvier et al., 2003). The other class of Leu-based signals, DxxLL seems to be required for transport between TGN and endosomes. Because the leucines are generally preceeded by several acidic residues, these motifs are also named acidic-cluster-dileucine motifs. In this case, the $\mathrm{D}$ residue cannot be replaced. In contrast to $(\mathrm{D}, \mathrm{E}) \mathrm{xxxL}(\mathrm{L}, \mathrm{I})$ signals, DxxLL does not bind to AP complexes in vitro, but to the monomeric adaptor group of GGA proteins (Zhu et al., 2001; Puertollano et al., 2001).

Another family of sorting motifs consists of a stretch of acidic amino acids containing one to three phosphorylation sites for casein kinase II (CKII). This motif is present in a number of transmembrane proteins that cycle between the TGN and endosomes, and phosphorylation of the CKII sites is particularly required for retrieval from endosomes to TGN. A protein called PACS-1 (phosphofurin acidic cluster sorting protein 1) was shown to bind to phosphorylated acidic clusters, as well as to the adaptor complexes AP-1 and AP-3. Remarkably, the binding interface to AP-1 was mapped to $\mu 1$ and $\sigma 1$ (Wan et al., 1998; Crump et al., 2001).

\section{AP-1 connections to accessory proteins}

Additional interaction partners have been described that are thought to create a specific environment to an AP-1 CCV. Most of these proteins, which are referred to as "accessory proteins", bind to the appendage domains of the two large subunits of AP-1. Since these domains are the least conserved among all the large adaptins, they establish highly specific connections in vivo (Lui et al., 2003).

In fact, the $\gamma 1$-ear domain contains a discontinuous motif of basic amino acids that was shown to interact with several proteins, i.e. $\gamma$-synergin, Eps15, EpsinR, Rabaptin-5, Snx9 and ARF1 GAP1 (Page et al., 1999; Kent et al., 2002; Hirst et al., 2003). Their respective binding site to $\gamma$-adaptin was found to conform more or less to the stretch DFxDF (Mills et al., 2003; Duncan et al., 2003).

$\gamma$-synergin associates with cytosolic and membrane-bound AP-1 and is enriched in 
CCVs. Both a GTPase and AP-1 are necessary to recruit it onto the membrane. It further contains an "Eps15-homology" (EH) domain, a common fold among endocytic proteins that binds to the tripeptidyl sequence motif "NPF", suggesting a function as linker protein (Page et al., 1999; Hirst et al., 2003).

Eps15 was mainly characterised in the context of clathrin-mediated endocytosis. Although it shows a BFA-sensitive perinuclear immunostaining, it remains unknown if Eps15 interacts with AP-1 in vivo (Kent et al., 2002).

EpsinR (synonymous to Enthoprotin / Clint) belongs to a group of proteins that interact with phosphoinositides via their "epsin N-terminal homology" or ENTH domain, in this case preferentially with PI4P (Mills et al., 2003; Hirst et al., 2003). Surprisingly, the crystal structure of the related epsin1 ENTH domain in the presence of phospholipid molecules visualised an additional amphipathic $\alpha$-helix compared to the lipid-free structure (Ford et al., 2002). When incubated with liposomes, this ENTH domain generated thin tubules. According to these observations, it was proposed that ENTH proteins can insert an amphipathic helix into the membrane and thereby promote membrane curvature. Even if epsinR seems to bind to lipids with less affinity, the versatile helix region is well conserved. Similar to $\gamma$-synergin, epsinR is enriched in CCVs and localises to the membrane in an ARF-dependent manner, but it does not require AP-1. Moreover, it directly interacts with clathrin (Mills et al., 2003) and the SNARE protein Vti1b (Chidambaram et al., 2004), supporting a role as tethering and stabilising factor in coat formation.

Rabaptin-5, which binds to the ear domains of $\gamma 1$ and $\gamma 2$ in vitro, functions as a divalent linker between Rab4 and Rab5, GTPases involved in endosomal trafficking (Stenmark et al., 1995). It has been shown to interact with a dimeric $\gamma 1$ - $\sigma 1$-adaptin complex on endosomes and to connect it to Rab4 (Deneka et al., 2003). However, it is not known whether this occurs during coat formation or at a later stage of transport. As for ARF1 GAP and the sorting nexin 9 (Snx9), their physiological role as AP-1 binding partners remains to be demonstrated.

The ear domain of $\gamma 1$ further associates with GGA proteins in vitro, homologous monomeric adaptor proteins that will be described later. It was shown very recently that a WxxF sequence of GGA1 competes for the same binding site as DFxDF motifs.

Providing a link to the cytoskeleton, $\gamma 1$-adaptin was proposed to attach to microtubuli, but the binding site has not been precisely defined (Orzech et al., 2001).

Although the critical residues of $\gamma 1$ for interaction with DFxDF motifs are conserved in the ear domain of $\gamma 2$, binding to $\gamma 1$-ear-partners has not been examined until now except for rabaptin-5. The only specific interaction for the $\gamma 2$-ear domain with respect to the $\gamma 1$-ear domain was reported with the large envelope protein of 


\section{Introduction}

hepatitis B virus (Hartmann-Stühler \& Prange, 2001).

Consistent with the homology between the large subunits, some of the accessory proteins described for the $\gamma 1$-appendage interact also with the $\beta 1$-appendage domain in vitro (Owen et al., 2000; Lundmark \& Carlsson, 2002), but these interactions have not yet been confirmed in vivo. In addition, KIF13A, which is a plus-end directed motor protein on microtubules, bound to both the $\beta$-adaptins with a preference for $\beta 1$. Indeed, overexpression of KIF13A caused AP-1 to redistribute to the cell periphery (Nakagawa et al., 2000).

\subsubsection{Monomeric adaptor proteins}

Similar to adaptor complexes, monomeric adaptor proteins are defined by their ability to recruit clathrin to the membrane contributing to coat stability and to recognise the cargo for coated vesicles. They are generally modular proteins, combining several conserved protein-protein or protein-lipid interaction domains. Various proteins seem to participate in clathrin-coat assembly at the plasma membrane (for rev. see Traub, 2003). Most of them serve to recruit very specific cargo proteins into coated pits, such as activated $\mathrm{G}$ protein-coupled receptors that bind to $\beta$-arrestin and as proteins with the sorting motif FxNPxY that bind to ARH (autosomal recessive hypercholesteremia), Dab2 or numb. In the case of AP180, which associates with $\mathrm{PI} 4,5 \mathrm{P}_{2}$ via its ANTH domain (related to ENTH) as well as with AP-2 and clathrin, an interaction with cargo proteins has not been demonstrated until now, suggesting that it serves mainly to stabilise and shape the coat. It is believed that these endocytic monomeric adaptors would probably function without AP-2 or alone, though not very efficient compared to the concerted activity (Hinrichsen et al., 2003; Motley et al., 2003). For example, AP180 promotes clathrin assembly onto a lipid monolayer in vitro and influences the size of coated vesicles in vivo (Zhang et al., 1998). However, AP-2 needs to participate to drive bud formation and the combination of AP180 and AP-2 works more efficiently in this respect than AP-2 alone.

The monomeric GGA proteins (Golgi-localised, $\gamma$-ear-containing, ARF-binding proteins) take part in clathrin-coated vesicle formation at the TGN, in some aspects similar to AP-1. Moreover, it was proposed recently that they are also involved in sorting of ubiquitinylated proteins at endosomes, where they could cooperate with another monomeric clathrin adaptor, Hrs (hepatocyte growth factor-regulated tyrosine kinase-receptor substrate). 


\section{GGA proteins}

The GGA proteins were identified and extensively studied by several groups during the last few years in the context of sorting at the TGN (for rev. see Bonifacino, 2004). In addition, they localise to early endosomes. Three genes are known in mammals, encoding for GGA1, GGA2 and GGA3, and the family is conserved among eukaryotes as supported by two homologues in yeast. The GGA proteins consist of several domains that they share with other proteins:

At the N-terminus they contain a common interaction module in vesicular traffic, the VHS domain (named after the first family members Vps27p, Hrs and STAM), followed by the GAT domain (which is also present in TOM1=target of Myb1), a rather unstructured linker and the C-terminal GAE ( $\gamma$-adaptin-ear-homologous) domain. These domains convey properties which are very similar to AP-1. By means of the GAT domain, GGAs bind to ARF1 and ARF3 which is sufficient for their targeting to the TGN. Sorting signals of the DxxLL type, including a cluster of acidic residues aroung the essential aspartate and and an upstream serine residue whose phosphorylation enhances sorting efficiency, are recognised by the VHS domain. Clathrin binds to clathrin box motifs in the linker region and to an additional site within GGA1-GAE. In analogy to the adaptins, the GAE domain accounts for recruitment of accessory proteins, displaying preferential affinity to p56, a protein of currently unknown function. Whereas p56 and $\gamma$-synergin bind to ear domains of both $\gamma 1$-adaptin and GGA in vitro, p56 colocalises with GGA and $\gamma$-synergin with AP-1 in vivo and membrane association depends on the presence of GGA or AP-1, respectively (Lui et al., 2003). Rabaptin-5 associates with GGA proteins via the GAT and GAE domains and is involved in their endosomal targeting (Mattera et al., 2003).

Despite the similarity of the three GGAs, they are probably not completely redundant: Crystal structures of the VHS domains revealed that GGA2 differs significantly from GGA1 and GGA3 in that region. In contrast to GGA2, the two latter proteins are regulated by phosphorylation which induces a conformational change. Phosphorylation of a serine residue adjacent to an internal acidic-cluster-dileucine motif in the linker region enables this motif to occupy the cargo binding site in the VHS domain. Since other interaction sites, namely for ARF and cargo proteins, become buried by this fold, this is the "closed", cytosolic form of GGA1 and GGA3. Membrane association probably occurs after dephosphorylation by PP2A, whereas phosphorylation can be mediated by CKII, a kinase associated with AP-1 (Doray et al., 2002; Ghosh \& Kornfeld, 2003a). It was shown recently that all the GGAs colocalise in coated pits at the TGN and that their membrane-bound pools interact 


\section{Introduction}

with each other via multiple domains. Depletion of any GGA protein resulted in increased degradation of the other two (Ghosh et al., 2003b).

Although GGA proteins exhibit the basic properties of adaptors and localise to clathrin-coated pits and/or CCVs by EM (Doray et al., 2002), they have not been detected in purified CCVs until now. They play an essential part during sorting events at the TGN and may cooperate with AP-1, but their function has not been clearly defined.

Surprisingly, recent data demonstrate that GGAs bind to ubiquitinated proteins in vitro (Puertollano \& Bonifacino, 2004).

Ubiquitination of endocytosed proteins targets them to lysosomes for degradation. Cargo selection occurs at early endosomes and involves the ESCRT machinery as well as specialised clathrin-coated membrane patches initiated by the monomeric adaptor Hrs (Raiborg et al., 2001a). In contrast to other coated pits, this region does not generate coated vesicles, but probably clusters the components which should be present in the internal vesicles of a multivesicular body (Sachse et al., 2002).

Like the GGA proteins, Hrs contains a VHS domain, followed by a FYVE module, which is a zinc finger fold that binds specifically to PI3P. A ubiquitin-interacting motif (UIM) serves to sequester ubiquitinated proteins destined for degradation in lysosomes. There are further two coiled-coil regions present and a functional clathrin box motif at the C-terminus. The endosomal localisation of Hrs depends on a functional FYVE domain together with the coiled-coil domains (Raiborg et al., $2001 b)$.

All the GGA proteins were shown to interact with ubiquitin, but GGA3 displayed the highest affinity. Depletion of GGA3 by RNAi significantly delayed the degradation of EGF in lysosomes in addition to endosomal membrane reorganisation. As GGA3 binds to a subunit of the ESCRT complex as well, a role in ubiquitin sorting seems possible and has to be addressed by further experiments (Puertollano \& Bonifacino, 2004).

\subsection{Sorting pathways involving AP-1}

AP-1 localises to clathrin-coated pits at the TGN as well as to endosomal compartments as shown by immunofluorescence and immunoelectronmicroscopy.

The TGN as the exit point of the Golgi apparatus displays a highly tubulated and branched morphology. According to the model of maturing Golgi cisternae, the whole "organelle" would be steadily dispersed towards the plasma membrane and the endocytic compartments, except for some components being retrieved to medial 
Golgi elements, and would be regenerated by the following cisterna. Transport routes from the TGN include constitutive and regulated secretion into the plasma membrane and delivery to lysosomes via endosomes. The endosomal compartment consists of vesicular and tubular elements that continuously fuse and separate to integrate inputs from the plasma membrane and the TGN. Stable microdomains defined by specific Rab proteins and their effectors probably play a crucial role in endosomal sorting.

Tracing the trafficking steps of AP-1 by means of fluorescently labeled subunits demonstrated that AP-1 leaves the TGN in vesicular or tubular structures and that similar carriers can be observed, although less frequent, on return to the TGN (Huang et al., 2001; Waguri et al., 2003).

Despite the high conservation of AP-1 from yeast to mammals, depletion of adaptors, even of all known adaptor-like proteins, does not cause a severe phenotype in $S$. cerevisiae (Yeung et al., 1999). In contrast, AP-1 deficient mice die early in embryonic development (Zizioli et al., 1999; Meyer et al., 2000). Disruption of $\gamma 1$-adaptin interferes with development even before nidation of the blastocyste, whereas the mice deficient for $\mu 1 \mathrm{~A}$-adaptin survive until day 13.5 of embryonic development. In conclusion, AP-1 functions are essential for the development of a multicellular organism. Apparently, $\gamma 2$-adaptin cannot replace the $\gamma 1$ subunit, whereas $\mu 1 \mathrm{~B}$ maintains viability for an extended period, either because AP-1B is crucial at that time of development, or due to some overlapping functions of $\mu 1 \mathrm{~A}$ and $\mu 1 \mathrm{~B}$.

\subsubsection{Sorting into clathrin-coated vesicles at the TGN}

Several cargo proteins which are sorted into clathrin-coated vesicles at the TGN, have been shown to interact with AP-1, such as for example the mannose 6-phosphate receptors (MPRs), the lysosomal membrane proteins lamp-1 and limp-II, the SNARE protein Vamp4 and the viral glycoprotein gp48 (Reusch et al., 2002). Among these, mannose 6-phosphate receptors are the best-characterised.

Both MPRs, named MPR46 and MPR300 according to their molecular weight, mediate the sorting of soluble lysosomal hydrolases from the TGN to endosomes (for rev. see Hille-Rehfeld, 1995; Ghosh et al., 2003a). Along the biosynthetic route, the enzymes acquire a mannose 6-phosphate (M6P) modification in the Golgi, which is recognised by MPR46 and MPR300. The receptors cycle at a high rate between the TGN and endosomes, where they release the enzymes due to acidic pH before returning to the TGN. In addition, about $10 \%$ of both MPRs are found at the PM at steady state. The luminal domain of MPR46 harbours one M6P-binding site, whereas MPR300 contains 15 homologous ligand binding modules two of which 


\section{Introduction}

bind to M6P. In contrast to MPR46, MPR300 is able to internalise M6P-containing ligands from the extracellular lumen. Moreover, it is essential for the clearance of IGF-II during embryonic development and probably endocytoses a variety of yet unidentified ligands. The cytoplasmic tails of the MPRs comprise several motifs for phosphorylation, palmitoylation and Tyr- and Leu-based sorting signals, which ensure their transport along several intracellular routes as well as their endocytosis. MPRs were shown by immunoelectronmicroscopy to exit the TGN in clathrin-coated vesicles containing AP-1 (Klumperman et al., 1993). In vitro studies demonstrated that AP-1 binds to several independent sequence determinants in the cytoplasmic domain of both receptors (Höning et al., 1997). One of them, an acidic-clusterDxxLL sorting motif close to the C-terminus of the cytoplasmic tails, revealed to be important for sorting of lysosomal enzymes (Johnson \& Kornfeld, 1992). Whereas especially the mutation of the leucine residues interfered with efficient sorting, it did not affect the binding of AP-1 (Höning et al., 1997). However, the conflict could be resolved after the discovery of the GGA proteins. These monomeric adaptors were observed in clathrin-coated buds at the TGN together with AP-1 and MPR300 (Doray et al., 2002) and bind to the DxxLL motif in the cytoplasmic tail of MPRs dependent on the leucine residues (Puertollano et al., 2001; Zhu et al., 2001). Since GGA proteins could not be detected in preparations of CCVs until now, but associate and colocalise with AP-1, it seems likely that both act sequentially during the vesicle formation (Doray et al., 2002). Considering the multiple interaction motifs of the MPR cytoplasmic tail, GGA proteins and AP-1 could simultaneously bind to one MPR molecule. It has been proposed that cooperation of GGA1 and GGA3 with AP-1 involves casein kinase-II, which colocalises with AP-1 and converts the GGAs to an inactive conformation by phosphorylation (Ghosh \& Kornfeld, 2003a). Consistent with this model, MPRs that do not bind to GGA proteins, are less efficiently incorporated into CCVs and overexpression of a truncated GGA that cannot bind to AP-1, prevents exit of MPRs from the TGN (Doray et al., 2002; Puertollano et al., 2001).

Studies on $\mu 1 \mathrm{~A}$-deficient fibroblasts confirmed the role of AP-1 in lysosomal sorting, showing that aberrant secretion of lysosomal enzymes like Cathepsin D is significantly enhanced. However, MPRs do not accumulate at the TGN under these conditions but instead are redistributed to early endosomes (Meyer et al., 2000). Interestingly, depletion of GGA proteins by RNA interference or mutation of the critical leucine residues to alanine affected the localisation of MPRs in a similar way (Ghosh et al., 2003b; Tikkanen et al., 2000). Taken together, AP-1 and GGA proteins probably cooperate in the formation of clathrin-coated vesicles at the TGN. In contrast to MPRs, the lysosomal sorting of lamp-1 depends on a Tyr-based motif 
in its cytoplasmic tail. The corresponding peptide was shown to bind to AP-1 in vitro and lamp-1 was detected in AP-1-positive membranes and vesicles in the TGN region (Höning et al., 1996; Ohno et al., 1998). Mutation of the critical tyrosine residue in lamp-1 equally abolished the interaction with AP-1 and the colocalisation with AP-1 on CCVs, supporting the idea that AP-1 is required for sorting of lamp-1 at the TGN. Surprisingly, lamp-1 was correctly targeted to lysosomes via intracellular pathways in $\mu 1 \mathrm{~A}$-deficient cells (Meyer et al., 2000). This is probably due to compensation of the AP-1 defect by an unknown parallel transport pathway from the TGN. Otherwise, the assignment of lamp-1/AP-1-positive membranes to the TGN may be ambiguous because other vesicular compartments are found in close vicinity.

Gp48 is a transmembrane glycoprotein from mouse cytomegalovirus which is targeted to lysosomes using the nonconventional sorting motif EplarLL, and stably associates with MHCI (Reusch et al., 1999). Cytomegalovirus infection therefore results in the degradation of MHCI. In AP-1-deficient cells, trafficking of gp48 via the plasma membrane is enhanced in addition to a significant delay in lysosomal targeting and degradation of the gp48/MHCI complex (Reusch et al., 2002). These observations indicate that AP-1 participates in sorting of gp48 at the TGN.

\subsubsection{Sorting at the endosomal compartment}

Directly after the internalisation of cell surface proteins, the transport vesicles reach "early endosomes" of a luminal pH of 6-6.5. Early endosomes can be further classified as "sorting endosomes", from which certain components are redirected to the plasma membrane via "recycling endosomes". Other proteins advance to "late endosomes" of $\mathrm{pH}$ 5.5. During this transformation, vesicles eventually bud into the endosome, generating a "multivesicular body" (MVB). This mechanism probably serves to target membrane proteins for degradation, as late endosomes or MVBs fuse with lysosomes reaching $\mathrm{pH}$ 5, where luminal components are degraded by hydrolases. Concerning this pathway, there is still some uncertainty about whether early/late endosomes and lysosomes represent different stages of one membrane carrier that matures by constant vesicular input from later stages or alternatively earlier carriers fuse sequentially with advanced ones thereby acquiring their properties. Transport carriers from the TGN can probably fuse with early as well as with late endosomes. Similarly, recycling pathways from both types of endosomes are postulated back to the TGN.

While AP-1 had been classified as clathrin adaptor at the TGN, the analysis of $\mu 1 \mathrm{~A}-$ deficient fibroblasts led to surprising observations. In the absence of a functional AP-1, both the MPRs were shifted from the TGN to early endosomes at steady state, as shown by colocalisation with early-endosomal-antigen-1 (EEA1) (Meyer 


\section{Introduction}

et al., 2000). Similarly, the proprotein convertase furin was displaced from its main localisation at the TGN to peripheral structures, which did not overlap with EEA1 (Meyer et al., 2001). These data suggested that AP-1 could participate in retrograde transport from endosomes to the TGN. In fact, AP-1 was localised to clathrin-coated endosomal membranes by immunoelectronmicroscopy (Mallard et al., 1998; Peden et al., 2004).

In order to address the role of AP-1 in retrograde transport of MPR46 directly, an in vitro assay was established using membrane and cytosol preparations from mouse fibroblasts. AP-1-deficient cytosol promoted transport between wt membranes as efficiently as wt cytosol, suggesting that cytosolic AP-1 is not required for vesicle formation. But transport using AP-1-deficient membranes was very inefficient compared to wt membranes, indicating that the lack of a functional AP-1 changes the organisation of early endosomal membranes (Medigeshi \& Schu, 2003).

Furin is a membrane-anchored enzyme which cycles between the TGN, endosomes and the PM (for rev. see Thomas, 2002). The retrieval of furin to the TGN depends on an acidic cluster in its cytoplasmic tail that can be phosphorylated by CKII. AP1 associates with furin via the adaptor molecule PACS-1 that recognises the acidic cluster motif of furin and other cargo proteins including MPR46 and Vamp 4 (Wan et al., 1998; Crump et al., 2001) .

Furin is also involved in the generation of secretory granules, which are specialised organelles in neuroendocrine cells. Immature secretory granules (ISGs) are formed from TGN membranes and undergo further maturation, during which the final granule components have to be separated from for example contaminating Golgi molecules or enzymes only needed at an early stage. In addition to furin, PACS-1, AP-1, ARF-1, MPR46 and MPR300, Syntaxin 6 and Vamp 4 have been implicated in the formation of CCVs from ISGs (Dittié et al., 1997; Klumperman et al., 1998). The dependence of this transport pathway on PACS-1 and AP-1 suggests that it follows a similar mechanism as retrograde transport from ubiquitous endosomes.

\subsubsection{AP-1B in polarised epithelial cells}

In polarised epithelial cells, cargo proteins have to be correctly delivered to two separate regions of the plasma membrane, the apical and the basolateral side. AP$1 \mathrm{~B}$ which incorporates the variant subunit $\mu 1 \mathrm{~B}$ mediates basolateral targeting of a subset of proteins such as the low density lipoprotein (LDL)-receptor (Fölsch et al., 1999). Interestingly, some of the cargo proteins require a $\operatorname{Yxx} \phi$ motif for correct delivery, whereas others depend on nonconventional motifs (Sugimoto et al., 2002). 
Besides AP-1B, AP-4 seems to mediate basolateral sorting of an overlapping subset of cargo proteins, and probably also in cell types where AP-1B is not expressed (Simmen et al., 2002). AP-1B localises to the TGN and to endosomes, but there is no colocalisation with AP-1A in polarised cells. Consistently, $\mu 1 \mathrm{~B}$ can substitute $\mu 1 \mathrm{~A}$ in fibroblasts regarding the transport of MPRs and lysosomal enzymes, but most probably it cannot associate with furin (Fölsch et al., 2001; Eskelinen et al., 2002). Although AP-1B was found in clathrin-coated buds in the TGN region similar to AP$1 \mathrm{~A}$, it is unclear at present if the basolateral sorting via AP-1B occurs at the TGN or at an endosomal level. For instance, polarised epithelial cells are presumed to contain two separate early endosomal pools which merge at the level of late endosomes. A mutant LDL-receptor which cannot be internalised was shown to reside mainly at the basolateral plasma membrane even in the absence of AP-1B, whereas the wildtype LDL-receptor was missorted in AP-1B-deficient cells. This observation strongly suggests that AP-1B functions in sorting of endocytosed proteins at early endosomes (Gan et al., 2002). Recent data demonstrated the association of Rab8 and the exocyst complex, which have been implicated in tethering of secretory vesicles in yeast, with AP-1B-containing membranes (Fölsch et al., 2003; Ang et al., 2003). Since expression of only one variant subunit, $\mu 1 \mathrm{~B}$, gives rise to the complex AP-1B, which differs significantly from AP-1A in localisation and sorting functions, these changes are all attributed to $\mu 1 \mathrm{~B}$. However, it is not known if $\mathrm{AP}-1 \mathrm{~B}$ contains $\sigma 1 \mathrm{~A}$ or $\sigma 1 \mathrm{~B}$ or both. Their ubiquitous expression indicates that none functions exclusively with AP-1B. Still, a preferential assembly with one of them is possible and could influence the properties of the complex. 


\section{Introduction}

\subsection{Aim of the study}

The adaptor complex AP-1 participates in clathrin-mediated transport between the TGN and endosomal compartments. Each subunit contributes to the performance of AP-1 by establishing specific connections to membrane recruitment factors, sorting signals, clathrin or accessory proteins. However, the role of $\sigma 1$-adaptin is unclear. At the beginning of this study, $\sigma 1 \mathrm{~A}$ and $\sigma 1 \mathrm{~B}$ were known as isoforms of $\sigma 1$ and had been found to be co-expressed in a number of tissues (Ohno et al., 1998).

First of all, we wanted to confirm and extend this expression analysis to a broader range of tissues. The gene for $\sigma 1 \mathrm{C}$-adaptin was identified by genomic sequencing during the course of this study and was subsequently included in the analysis.

Second, while the generation of a mouse knock-out for $\sigma 1 \mathrm{~A}$ was already in progress, this project intended to disrupt the gene for $\sigma 1 \mathrm{~B}$ in mouse, in order to finally obtain a mouse strain deficient for both $\sigma 1 \mathrm{~A}$ and $\sigma 1 \mathrm{~B}$. This would enable us to study the specific properties of the AP-1 populations containing either $\sigma 1 \mathrm{~A}$ or $\sigma 1 \mathrm{~B}$ as well as the function of $\sigma 1$-adaptin in general.

Another important goal of the project was the generation of isoform-specific antibodies to study the endogenous proteins in vivo. 


\section{Materials and Methods}

\subsection{Materials}

\subsubsection{Specific laboratory equipment}

Confocal Laser Scanning Microscope

Leica, Bensheim

Leica TCS SP2 AOBS

(Ar: 488, 514 nm; He/Ne: 543 nm;

63x Oil Objective)

Electroporator 1000 (used for bacteria)

Stratagene, USA

FACScan flow cytometer

Gene Pulser ${ }^{\text {TM }}$ (used for ES cells)

Becton Dickinson, Heidelberg

BioRad, München

Gene quant II, RNA/DNA calculator

Pharmacia Biotech, UK

Intelligent Dark Box II, LAS-1000+

Fuji, Japan

Phosphoimager Fujix BAS1000

Fuji, Japan

Ultra-turrax T8

SMART System for HPLC

IKA Labortechnik, Staufen

(column: Superdex 200 PC 3.2/30)

Amersham Pharmacia Biotech,

Mastercycler gradient

Sweden

Eppendorf, Hamburg

\subsubsection{Chemicals, plasticware and membranes}

Chemicals

Cell culture media, sera and supplements

Cell culture plasticware

Nitrocellulose membrane

Hybond-N Nylon membrane
Boehringer/Roche, Mannheim;

Merck, Darmstadt;

Roth, Karlsruhe;

Serva, Heidelberg;

Sigma, Deisenhofen

Gibco BRL, Eggenstein;

PAA Laboratories, Cölbe

Greiner, Frickenhausen;

Nalge Nunc International, Denmark

Schleich and Schüll, Dassel

Amersham Biosciences, UK 


\subsubsection{Kits, spin columns and reagents}

\section{DNA, RNA:}

Atlas SMART Fluorescent Probe Amplification Kit HiSpeed Plasmid Midi kit

Omniscript Reverse Transcription kit

PCR purification kit

QIAprep Spin Miniprep kit

QIAquick Gel Extraction kit

LabelStar Array kit

Rapid-hyb hybridisation buffer

rediprime ${ }^{\mathrm{TM}}$ II labelling system

RNAlater RNA Stabilisation Reagent

RNase inhibitor RNase Out

RNeasy Mini and Midi Kit

TA Cloning Kit

\section{Protein:}

Bio-Rad Protein Assay

DAKO fluorescent mounting medium

ECL Plus

GSH-Sepharose 4B

Protease Inhibitor Cocktail

PD-10 Sephadex G-25 M column

Sep-Pak C18 Cartridge

Stimune Adjuvant

Supersignal Chemiluminescence Kit

Titermax Gold Adjuvant

Vivapure $^{\mathrm{TM}}$ ion exchange columns

Vivaspin
BD Biosciences

Qiagen

Qiagen

Qiagen

Qiagen

Qiagen

Qiagen

Amersham Pharmacia Biotech

Amersham Pharmacia Biotech

Qiagen

Invitrogen

Qiagen

Invitrogen

Bio-Rad

DakoCytomation, USA

Amersham Biosciences

Amersham Biosciences

Sigma

Amersham Pharmacia Biotech

Waters, USA

Cedi Diagnostics B. V., Netherlands

Pierce, USA

Sigma

Vivascience, Göttingen

Vivascience, Göttingen

\subsubsection{Radioactively labelled substances}

$\begin{array}{ll}\alpha_{-}{ }^{32} \text { P-dCTP } & \text { Hartmann Analytics, Braunschweig } \\ \gamma_{-}{ }^{32} \text {-P-dATP } & \text { Hartmann Analytics, Braunschweig }\end{array}$ 


\subsubsection{Enzymes and standards}

Restriction endonucleases

Klenow DNA polymerase

Taq DNA polymerase

Alkaline phosphatase

$1 \mathrm{~kb}$ DNA ladder

Ultrapure dNTP Set

DNase I

RNase

Proteinase K

Lysozyme

SDS-PAGE Protein Standard
New England Biolabs

New England Biolabs

Amersham Pharmacia Biotech

Boehringer

Invitrogen

Amersham Pharmacia Biotech

Amersham Pharmacia Biotech

Amersham Pharmacia Biotech

Roth

Merck

Bio-Rad

\subsubsection{Cell lines and mouse strains}

\begin{tabular}{|c|c|c|}
\hline \multicolumn{3}{|c|}{ bacterial strains: } \\
\hline XL1-Blue & $\begin{array}{l}\text { recA1, endA1, gyrA96, thi-1, } \\
\text { hsdR17, supE44, relA1, } \\
\text { lac }[F, \text { proAB, laclqZ } \Delta \mathrm{M} 15, \\
\text { Tn10(Tetr)]c }\end{array}$ & Stratagene \\
\hline BL21(DE3) & $\begin{array}{l}\mathrm{F}^{-} \text {ompT }, \mathrm{dcm}^{+}, \operatorname{hsdS}_{\mathrm{B}}\left(\mathrm{r}_{\mathrm{B}}{ }^{-} \mathrm{m}_{\mathrm{B}}{ }^{-}\right) \\
\text {Tet }^{\mathrm{r}}, \operatorname{gal} \lambda(\mathrm{DE} 3), \text { endA, } \\
\text { Hte }\left[\mathrm{pT}-\operatorname{Trx} \mathrm{Cam}^{\mathrm{r}}\right]\end{array}$ & Yasukawa et al., 1995 \\
\hline \multicolumn{3}{|c|}{ mouse cell lines: } \\
\hline E14-1 ES cells & $\begin{array}{l}\text { established from blastocysts of } \\
\text { the mouse } 129 / \text { Ola strain }\end{array}$ & Hooper et al., 1987 \\
\hline $\begin{array}{l}\text { neomycin- } \\
\text { resistant MEF }\end{array}$ & $\begin{array}{l}\text { established from a } \\
\text { neomycin-resistant mouse strain } \\
\text { in this institute }\end{array}$ & Müller et al., 1991 \\
\hline$\mu 1 \mathrm{~A}-/-\mathrm{MEF}$ & $\begin{array}{l}\text { established from the } \mu 1 \mathrm{~A}-/- \\
\text { mouse strain } \\
\text { (mixed C57 BL/6J : } 129 / \text { Ola } \\
\text { background) }\end{array}$ & Meyer et al., 2000 \\
\hline$\sigma 1 \mathrm{~B}-/-\mathrm{MEF}$ & $\begin{array}{l}\text { established from the } \sigma 1 \mathrm{~B}-/- \\
\text { mouse strain S1B111 (mixed C57 } \\
\text { BL/6J : 129/Ola background) }\end{array}$ & this study \\
\hline
\end{tabular}




\begin{tabular}{|l|l|l|}
\hline \multicolumn{2}{|l|}{ mouse strains: } \\
\hline \hline C57 BL/6J & inbred strain, black colour & BRL, Switzerland \\
\hline $129 \mathrm{SV} / \mathrm{J}$ & inbred strain, agouti colour & BRL, Switzerland \\
\hline
\end{tabular}

\subsubsection{Antibodies}

\section{Primary antibodies:}

\begin{tabular}{|c|c|c|c|}
\hline antigen, charge, epitope & type & reference & $\begin{array}{l}\text { western } \\
\text { blot }\end{array}$ \\
\hline $\begin{array}{l}\gamma 1 \text {-adaptin } 100.3, \\
\text { mouse } \gamma \text {-adaptin hinge }\end{array}$ & $\begin{array}{l}\text { mouse } \\
\text { mAb, } \\
\text { purified }\end{array}$ & $\begin{array}{l}\text { Transduction } \\
\text { Laboratories }\end{array}$ & $1: 5000$ \\
\hline $\begin{array}{l}\mu 1 \mathrm{~A} \text {-adaptin } 144, \\
\text { mouse } \mu 1 \mathrm{~A} \text { residues } 295-310\end{array}$ & rabbit $\mathrm{pAb}$ & $\begin{array}{l}\text { Meyer et al., } \\
2000\end{array}$ & $1: 1000$ \\
\hline $\begin{array}{l}\gamma 2 \text {-adaptin, } \\
\text { mouse } \gamma 2 \text { residues } 577-791\end{array}$ & rabbit $\mathrm{pAb}$ & this study & $1: 250$ \\
\hline $\begin{array}{l}\sigma 1 \mathrm{~B} \text {-adaptin, } \\
\text { GST fused to full length rat } \sigma 1 \mathrm{~B}\end{array}$ & rabbit $\mathrm{pAb}$ & this study & $1: 250$ \\
\hline $\begin{array}{l}\alpha \text {-adaptin, } \\
\text { mouse } \alpha \text {-adaptin, residues } 38-215\end{array}$ & $\begin{array}{l}\text { mouse } \\
\text { mAb, } \\
\text { purified }\end{array}$ & $\begin{array}{l}\text { Transduction } \\
\text { Laboratories }\end{array}$ & 1: 1000 \\
\hline dihydrofolate reductase (DHFR) & rabbit $\mathrm{pAb}$ & M. Horst & $1: 500$ \\
\hline $\begin{array}{l}\text { MPR46, MSC } 1 \text {, } \\
\text { cytoplasmic tail of MPR46 }\end{array}$ & rabbit $\mathrm{pAb}$ & $\begin{array}{l}\text { Klumperman } \\
\text { et al., } 1993\end{array}$ & - \\
\hline MPR300, I 5, rat MPR300 & rabbit $\mathrm{pAb}$ & $\begin{array}{l}\text { Claussen et al., } \\
1995\end{array}$ & - \\
\hline TGN38 & rabbit $\mathrm{pAb}$ & $\begin{array}{l}\text { Transduction } \\
\text { Laboratories }\end{array}$ & - \\
\hline CD4, PE-conjugate & rat $\mathrm{mAb}$ & BD Biosciences & - \\
\hline CD8a, FITC-conjugate & rat $\mathrm{mAb}$ & BD Biosciences & - \\
\hline CD5, PE-conjugate & rat $\mathrm{mAb}$ & BD Biosciences & - \\
\hline
\end{tabular}

Secondary antibodies were purchased from Dianova, Germany. 


\subsubsection{Primers}

\begin{tabular}{|c|c|c|c|}
\hline name & sequence & description & $\begin{array}{l}\text { Tm used } \\
\text { for PCR }\end{array}$ \\
\hline PSS1-6 & $\begin{array}{l}\text { CGGGATCCTGCAGGA } \\
\text { TGATGCGATTCATGCT }\end{array}$ & $\begin{array}{l}\sigma 1 \mathrm{~A} \text { cDNA, reverse, } \\
\text { BamHI }\end{array}$ & $60^{\circ} \mathrm{C}$ \\
\hline PSS1-535 & $\begin{array}{l}\text { CGGGATCCTGACGGG } \\
\text { GCTATGCCAGGCCC }\end{array}$ & $\begin{array}{l}\sigma 1 \mathrm{~A} \text { cDNA, reverse, } \\
\text { BamHI }\end{array}$ & $60^{\circ} \mathrm{C}$ \\
\hline PSRS1-1 & $\begin{array}{l}\text { CGGGATCCCCGCGGC } \\
\text { CCGCAGCCGCC }\end{array}$ & $\begin{array}{l}\sigma 1 \mathrm{~B} \text { cDNA, forward, } \\
\text { BamHI }\end{array}$ & $60{ }^{\circ} \mathrm{C}$ \\
\hline PSRS1-640 & $\begin{array}{l}\text { CGGGATCCGGAGGAC } \\
\text { AGTTATGTCAGTCC }\end{array}$ & $\begin{array}{l}\sigma 1 \mathrm{~B} \text { cDNA, reverse, } \\
\text { BamHI }\end{array}$ & $60^{\circ} \mathrm{C}$ \\
\hline $\mathrm{s} 1 \mathrm{bD} 2 / 2$ & $\begin{array}{l}\text { GTTTATGTTGCTTTT } \\
\text { TAGTCGC }\end{array}$ & $\begin{array}{l}\sigma 1 \mathrm{~B} \mathrm{cDNA}, \\
\text { forward }\end{array}$ & $60^{\circ} \mathrm{C}$ \\
\hline s1bU8 & $\begin{array}{l}\text { TTCAGCTTCCTCCTG } \\
\text { CAGG }\end{array}$ & $\begin{array}{l}\sigma 1 \mathrm{~B} 1 \mathrm{cDNA}, \\
\text { reverse }\end{array}$ & - \\
\hline s1bU4 & $\begin{array}{l}\text { CAGCTTCTTTTGCAT } \\
\text { CCTCCTG }\end{array}$ & $\begin{array}{l}\sigma 1 \mathrm{~B} 2 \mathrm{cDNA}, \\
\text { reverse }\end{array}$ & - \\
\hline s1bU5 & $\begin{array}{l}\text { CCTCCCCATTCTTCA } \\
\text { TTCTGGC }\end{array}$ & $\begin{array}{l}\sigma 1 \mathrm{~B} 3 \mathrm{cDNA}, \\
\text { reverse }\end{array}$ & $60^{\circ} \mathrm{C}$ \\
\hline $\mathrm{s} 1 \mathrm{cD} 2 \mathrm{~B}$ & $\begin{array}{l}\text { CTCTGGATCCGGGGC } \\
\text { CATGATACATTTCATC }\end{array}$ & $\begin{array}{l}\sigma 1 \mathrm{C} \text { cDNA, forward, } \\
\text { BamHI }\end{array}$ & $60^{\circ} \mathrm{C}$ \\
\hline s1cU2SX & $\begin{array}{l}\text { CCTCGAGTCGACTGT } \\
\text { ACACTTAAAACG }\end{array}$ & $\begin{array}{l}\sigma 1 \mathrm{C} \text { cDNA, reverse, } \\
\text { SalI, XhoI }\end{array}$ & $60^{\circ} \mathrm{C}$ \\
\hline g2RTd2B & $\begin{array}{l}\text { GGATCCAAGTATAAC } \\
\text { ACACTCTTCC }\end{array}$ & $\begin{array}{l}\text { PCR of } \gamma 2 \text { hinge-ear, } \\
\text { forward, BamHI }\end{array}$ & $53^{\circ} \mathrm{C}$ \\
\hline g2RTu2S & $\begin{array}{l}\text { GTCGACACGTGGGTC } \\
\text { TGTTATTTCCG }\end{array}$ & $\begin{array}{l}\text { PCR of } \gamma 2 \text { hinge-ear, } \\
\text { reverse, }\end{array}$ & $53^{\circ} \mathrm{C}$ \\
\hline hprt_f & $\begin{array}{l}\text { CCTGCTGGATTACAT } \\
\text { TAAAGCACTG }\end{array}$ & $\begin{array}{l}\text { PCR of hypoxanthin- } \\
\text { ribosyltransferase, } \\
\text { forward }\end{array}$ & $60^{\circ} \mathrm{C}$ \\
\hline hprt_r & $\begin{array}{l}\text { GTCAAGGGCATAGCC } \\
\text { AACAACAAAC }\end{array}$ & $\begin{array}{l}\text { PCR of hypoxanthin- } \\
\text { ribosyltransferase, re- } \\
\text { verse }\end{array}$ & $60^{\circ} \mathrm{C}$ \\
\hline PS1BMd & $\begin{array}{l}\text { GCTATTGAGGATCCG } \\
\text { GACAATG }\end{array}$ & $\begin{array}{l}\text { mutagenesis of } \sigma 1 \mathrm{~B} \\
\text { exon } 3\end{array}$ & $50^{\circ} \mathrm{C}$ \\
\hline PS1BMu & $\begin{array}{l}\text { CATTGTCCGGATCCT } \\
\text { CAATAGC }\end{array}$ & $\begin{array}{l}\text { mutagenesis of } \sigma 1 \mathrm{~B} \\
\text { exon } 3\end{array}$ & $50^{\circ} \mathrm{C}$ \\
\hline
\end{tabular}




\begin{tabular}{|l|l|l|l|}
\hline name & sequence & description & $\begin{array}{l}\mathbf{T}_{\mathbf{m} \text { used }} \\
\text { for PCR }\end{array}$ \\
\hline s1bti1 & $\begin{array}{l}\text { TGAAGTTGCCACTGG } \\
\text { ATAGC }\end{array}$ & $\begin{array}{l}\text { genomic } \sigma 1 \mathrm{~B} \text { locus, } \\
\text { upstream of targeting } \\
\text { construct, forward }\end{array}$ & $58^{\circ} \mathrm{C}$ \\
\hline PS1Bu3 & $\begin{array}{l}\text { CACACTGCCAAAATA } \\
\text { CTTGTC }\end{array}$ & $\begin{array}{l}\text { genomic } \sigma 1 \mathrm{~B} \text { locus, } \\
\text { downstream of exon 3, } \\
\text { reverse }\end{array}$ & $48^{\circ} \mathrm{C}$ \\
\hline NeoD2 & $\begin{array}{l}\text { CCGTGATATTGCTGA } \\
\text { AGAGC }\end{array}$ & $\begin{array}{l}\text { neomycin cDNA, for- } \\
\text { ward }\end{array}$ & $48-58^{\circ} \mathrm{C}$ \\
\hline UFPR & $\begin{array}{l}\text { TGTAAAACGACGGCC } \\
\text { AGT }\end{array}$ & $\begin{array}{l}\text { forward universal se- } \\
\text { quencing primer }\end{array}$ & - \\
\hline URPR & $\begin{array}{l}\text { GAAACAGCTATGACC } \\
\text { ATG }\end{array}$ & $\begin{array}{l}\text { reverse universal se- } \\
\text { quencing primer }\end{array}$ & - \\
\hline pGEX3 & $\begin{array}{l}\text { GGAGCTGCATGTGTC } \\
\text { AGAGG }\end{array}$ & $\begin{array}{l}\text { forward sequencing } \\
\text { primer for pGEX-2T }\end{array}$ & \\
\hline pGEX5 & $\begin{array}{l}\text { CTGGCAAGCCACGTT } \\
\text { TGGTG }\end{array}$ & $\begin{array}{l}\text { reverse sequencing } \\
\text { primer for pGEX-2T }\end{array}$ & \\
\hline
\end{tabular}

\subsubsection{Vectors}

\begin{tabular}{|l|l|}
\hline name & source \\
\hline \hline pCR2.1 & Invitrogen \\
\hline pBluescript KS or SK & Stratagene \\
\hline pBSK(Neo2xKpnI) & P. Schu, modified from pMC1neo (Stratagene) \\
\hline pGEX-2T & Pharmacia Biotech \\
\hline
\end{tabular}




\subsection{Methods}

\subsubsection{Molecular biology}

\subsubsection{Culture of $E$. coli}

Luria Bertani (LB) medium: $\quad 0.5 \%$ yeast extract, $1 \%$ trypton, $0.5 \% \mathrm{NaCl}$

LB plates:

ampicillin:

chloramphenicol:

SOC medium:
LB medium, 1,5\% Agar

$25 \mathrm{mg} / \mathrm{ml}$ in water

(final concentration $100 \mu \mathrm{g} / \mathrm{ml}$ )

$10 \mathrm{mg} / \mathrm{ml}$ in methanol

(final concentration $20 \mu \mathrm{g} / \mathrm{ml}$ )

$2 \%$ trypton, $0.5 \%$ yeast extract, $0.06 \% \mathrm{NaCl}$,

$0.02 \% \mathrm{KCl}, 0.2 \% \mathrm{MgCl}^{*} 6 \mathrm{H}_{2} \mathrm{O}$

E. coli cultures were grown according to standard protocols in LB medium supplemented with ampicillin or chloramphenicol if needed for selection of plasmids.

Preparation of electrocompetent cells: A $10 \mathrm{ml}$ culture of XL1-Blue was grown in LB medium over night, diluted 1:100 into fresh medium and incubated up to an OD of 0.3-0.35 (after about $4 \mathrm{~h}$ ). The cells were cooled on ice for 15-30 min (all the following steps were done at $4^{\circ} \mathrm{C}$ ), centrifuged for $15 \mathrm{~min}$ in a JA-10 Rotor at $5000 \mathrm{rpm}$, washed with $1 \mathrm{l}$ of cold sterile water first, with $0.5 \mathrm{l}$ of cold sterile water second and finally resuspended in $20 \mathrm{ml}$ of cold sterile-filtered $10 \%$ glycerol. Again, the suspension was centrifuged in a JA-20 Rotor at $6000 \mathrm{rpm}$ for $15 \mathrm{~min}$ and resuspended in $2 \mathrm{ml}$ of $10 \%$ glycerol. $40 \mu \mathrm{l}$ aliquots were frozen on dry ice and stored at $-80^{\circ} \mathrm{C}$.

Transformation with plasmid DNA by electroporation: An aliquot of electrocompetent cells was thawed on ice and mixed with a maximum of $5 \mu \mathrm{l}$ of DNA solution by pipetting. The sample was transferred into a cold sterile electroporation cuvette and subjected to a $1800 \mathrm{~V}$ pulse in the electroporator. Immediately, the cells were diluted in $500 \mu \mathrm{l}$ of SOC medium and incubated at $37^{\circ} \mathrm{C}$ for $20-40 \mathrm{~min} .1 / 5$ and $4 / 5$ of the sample were spread onto selective LB plates to grow over night at $37^{\circ} \mathrm{C}$.

Preparation of glycerol stocks: $0.5 \mathrm{ml}$ of a logarithmic E. coli culture was mixed with $0.5 \mathrm{ml}$ of $65 \%$ (v/v) glycerol, $0.1 \mathrm{M} \mathrm{MgSO}_{4}, 25 \mathrm{mM}$ Tris $\mathrm{pH} 8$ and stored at $-80^{\circ} \mathrm{C}$. 


\subsubsection{Cloning procedures}

Standard protocols (Ausubel et al., 1994) or instructions of the manufacturer were followed for the isolation of plasmid DNA from E. coli (Qiaprep Kit), for the digestion or modification of DNA by enzymes, for the analysis of DNA by agarose gelelectrophoresis in TAE buffer and for the purification of DNA fragments from agarose gels (Qiaspin Gel extraction Kit).

10x DNA loading dye: $0.25 \%(\mathrm{w} / \mathrm{v})$ bromphenol blue, $40 \%$ saccharose in $1 \mathrm{x}$ TAE

50x TAE buffer: $\quad 2 \mathrm{M}$ Tris base, $5.7 \%(\mathrm{w} / \mathrm{v})$ acetic acid, $50 \mathrm{mM}$ EDTA pH 8.0

ethidium bromide: $\quad 10 \mathrm{mg} / \mathrm{ml}$ stock (final concentration $0.5 \mu \mathrm{g} / \mathrm{ml})$

\subsubsection{Preparation of genomic DNA from mouse tail biopsies}

lysis buffer: $\quad 100 \mathrm{mM}$ Tris pH 8, $50 \mathrm{mM}$ EDTA, 0.5\% SDS, $200 \mathrm{mM} \mathrm{NaCl}$ proteinase $\mathrm{K}: 100 \mu \mathrm{g} / \mathrm{ml}$ (stock solution $10 \mathrm{mg} / \mathrm{ml}$ )

At the age of 3-7 weeks, 0.5 to $0.7 \mathrm{~cm}$ of tail was cut from the tail-tip of the mice. It was incubated with proteinase $\mathrm{K}$ in a total volume of $500 \mu \mathrm{l}$ in a shaking incubator at $56^{\circ} \mathrm{C}$ and $700 \mathrm{rpm}$ over night. The lysate was centrifuged for $10 \mathrm{~min}$ at $13000 \mathrm{rpm}$. After decanting the supernatant into a new cup, the DNA was precipitated by addition of 1 volume isopropanol. The cup was inverted several times during 5-10 min and left standing at room temperature in between until a cloudy precipitate formed. The DNA was captured with a curved pasteur pipet and placed into $500 \mu \mathrm{l}$ $70 \%$ ethanol for $1 \mathrm{~min}$. After that wash, the DNA was air-dried on the pipet and finally dissolved in 50-200 $\mu \mathrm{l}$ of $\mathrm{H}_{2} \mathrm{O}$ over night at $37^{\circ} \mathrm{C}$.

\subsubsection{Preparation of genomic DNA from mouse cells}

lysis buffer: $\quad$ see 2.2.1.3

proteinase $\mathrm{K}: \quad 20 \mu \mathrm{g} / \mathrm{ml}$ (stock solution $2 \mathrm{mg} / \mathrm{ml}$ )

PCI: $\quad$ phenole : chloroform : isoamylalcohol $=25: 24: 1$

CI: $\quad$ chloroform : isoamylalcohol $=24: 1$

A cell pellet of up to $50 \mu \mathrm{l}$ was digested in a total volume of $500 \mu \mathrm{l}$ lysis buffer containing proteinase $\mathrm{K}$ as described above. If the solution still contained visible debris after the incubation, fresh proteinase $\mathrm{K}$ was added to digest for another 4-5 h. Eventually, remaining fragments were pelleted by centrifugation at $13000 \mathrm{rpm}$ for 10 min. 1 Vol of PCI was added to the supernatant and mixed by careful shaking for 
$1 \mathrm{~min}$. After centrifugation at $13000 \mathrm{rpm}$ for $5 \mathrm{~min}$, the aequous upper phase was transferred into a new cup. The extraction was repeated with $1 \mathrm{Vol}$ of CI. Again, the upper phase was transferred. To precipitate the DNA, 2-3 Vol of ethanol (1 ml) were added. The DNA was fished and processed as described in 2.2.1.3. If no precipitate could be seen, the cup was incubated at $-20^{\circ} \mathrm{C}$ over night and centrifuged. The pellet was washed with $70 \%$ ethanol, air-dried and resuspended in $50 \mu \mathrm{l}$ of $\mathrm{H}_{2} \mathrm{O}$.

\subsubsection{Isolation of RNA from mouse cells or mouse tissue}

All the preparations were done according to the RNeasy protocol (Qiagen) with the following details:

For isolation of total RNA from cells, they were grown to confluency on a $10 \mathrm{~cm}$ culture dish and lysed directly on the plate. The lysate was eventually stored at $-80^{\circ} \mathrm{C}$. For isolation of total RNA from tissue, the organs were excised from a mouse and immediately either frozen in liquid nitrogen for storage at $-80^{\circ} \mathrm{C}$ or immersed in RNAlater reagent $(10 \mathrm{ml} / \mathrm{g}$ tissue $)$ for storage at $4^{\circ} \mathrm{C}$ or at lower temperature. An appropriate amount of tissue was cut into mm-sized pieces and homogenised with an ultra-turrax. For tissues with a low yield of RNA such as brain, heart etc., about twice the recommended tissue weight could be successfully loaded onto one column, if the volume of lysis buffer and subsequent buffers was doubled as well.

RNA preparation from fibrous tissues as skeletal or heart muscle and spleen included the recommended additional digestion with proteinase $\mathrm{K}$ as given in the special protocol.

A special protocol was also used to process adipose tissue (see Vidal et al., 1997). Frozen tissue was smashed on ice under liquid nitrogen using a mortar and a pestle. 100-200 mg of powder (melting fast) were transferred into a tube and mixed with $600 \mu \mathrm{l}$ buffer RLT from RNeasy kit. After homogenisation with a rotor-stator homogeniser, the suspension was centrifuged for 3 min at 8,000xg (10,000 rpm) at room temperature. Lipid material floated as a separate phase on top and was carefully removed. $500 \mu \mathrm{l}$ the of aequous phase was transferred to a new tube and mixed with the same volume of $70 \%$ ethanol. The pellet was resuspended in $350 \mu \mathrm{l}$ RLT buffer and again homogenised. Finally, the alcoholic solutions were pooled and loaded onto an RNeasy Mini spin column. The subsequent steps were done according to the standard protocol. 


\subsubsection{PCR}

\begin{tabular}{|c|c|c|}
\hline & stock concentration & $\begin{array}{l}\text { amount per } 50 \mu \mathrm{l} \\
\text { reaction }\end{array}$ \\
\hline Taq DNA polymerase & $5 \mathrm{U} / \mu \mathrm{l}$ & $0.5 \mu \mathrm{l}$ \\
\hline $\begin{array}{l}\text { Taq polymerase } \\
\text { buffer }(10 x)\end{array}$ & $\begin{array}{l}500 \mathrm{mM} \quad \mathrm{KCl}, \quad 15 \mathrm{mM} \\
\mathrm{MgCl}_{2}, \\
100 \mathrm{mM} \text { Tris-HCl, } \mathrm{pH} 9.0\end{array}$ & $5 \mu \mathrm{l}$ \\
\hline dNTP Mix & $1.25 \mathrm{mM}$ each dNTP & $\begin{array}{l}1 \mu \mathrm{l}(2 \mu \mathrm{l} \text { for } 1.5 \mathrm{~kb} \\
\text { products })\end{array}$ \\
\hline $\begin{array}{l}\text { oligonucleotide } \\
\text { primers }\end{array}$ & $5 \mathrm{pmol} / \mu \mathrm{l}$ & $2.5 \mu \mathrm{l}$ \\
\hline
\end{tabular}

\section{PCR programs}

Genomic PCR: $100 \mathrm{ng}-1 \mu \mathrm{g}$ genomic DNA was used as template DNA. $\sigma 1 \mathrm{~B}$ wt locus was detected with primers s1bti1 and PS1Bu3 at $48^{\circ} \mathrm{C}, \sigma 1 \mathrm{~B}$ knock-out locus with primers s1bti1 and NeoD2 at $58^{\circ} \mathrm{C}$ (for primer sequences see 2.1.8).
1. $1 \min 94^{\circ} \mathrm{C}$
2. $30 \sec 94^{\circ} \mathrm{C}$
3. $30 \mathrm{sec} 48-58^{\circ} \mathrm{C}$
4. $4 \min 72^{\circ} \mathrm{C}$
repeat 2.-4. $29 \mathrm{x}$

5. $8 \min 72^{\circ} \mathrm{C}$

PCR using cDNA, plasmid DNA or DNA fragments as template DNA:

To generate cDNA, reverse transcription reaction was set up according to the Omniscript RT Kit protocol (Qiagen), using 1-2 $\mu \mathrm{g}$ RNA. $2.5 \mu \mathrm{l}$ of the $20 \mu \mathrm{l}$ reaction served as template for further PCR. In the case of DNA fragments or plasmids, 50-100 ng were included in a PCR reaction.

1. $40 \sec 95^{\circ} \mathrm{C}$

2. $40 \mathrm{sec} 48-58^{\circ} \mathrm{C}$

3. $30 \mathrm{sec} 72^{\circ} \mathrm{C}$ (per 500 bp product size)

repeat 1.-3. $29 \mathrm{x}$ 


\section{Colony PCR using bacteria as template:}

This protocol was used to select positive colonies without preparation of plasmid DNA. 1-2 $\mu \mathrm{l}$ of a $2 \mathrm{ml}$ bacterial culture, grown for $4 \mathrm{~h}$ or overnight, was added to a PCR reaction setup.

1. $1 \min 96^{\circ} \mathrm{C}$

2. $15 \sec 96^{\circ} \mathrm{C}$

3. $30 \sec 48^{\circ} \mathrm{C}$

4. $1 \min 72^{\circ} \mathrm{C}$

repeat $2 .-4.29 \mathrm{x}$

5. $8 \min 72^{\circ} \mathrm{C}$

\section{Sequencing PCR:}

\begin{tabular}{|l|l|}
\hline Sequencing premix & $2 \mu \mathrm{l}$ \\
\hline \hline Primer & 10 pmol $(1 \mu \mathrm{l})$ \\
\hline DNA template & $200-500 \mathrm{ng}($ plasmid DNA) \\
\hline HPLC- $\mathrm{H}_{2} \mathrm{O}$ & ad $10 \mu \mathrm{l}$ \\
\hline
\end{tabular}

1. $10 \sec 96^{\circ} \mathrm{C}$

2. $5 \sec 50^{\circ} \mathrm{C}$

3. $4 \min 60^{\circ} \mathrm{C}$

repeat $1 .-3.24 \mathrm{x}$

Sequencing products were precipitated at room temperature by addition of $1 / 5$ Vol of $3 \mathrm{M} \mathrm{NaAc}$ pH 5.2 and $5 \mathrm{Vol}$ of $95 \%$ ethanol, vortexing and incubating for 10 min. DNA was pelleted by 20 min centrifugation at full speed, washed once with

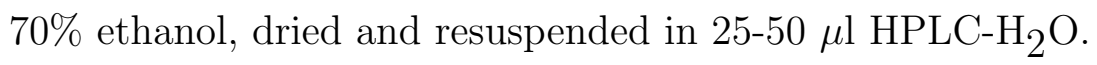

Sequencing of repetitive genomic sequences: A modified program was used for sequencing of genomic intron regions. Decreasing or increasing the amount of sequencing premix improved the result as well.

1. $30 \sec 98^{\circ} \mathrm{C}$

2. $30 \mathrm{sec} 50^{\circ} \mathrm{C}$

3. $4 \min 60^{\circ} \mathrm{C}$

repeat $1 .-3.24 \mathrm{x}$ 


\subsubsection{Southern blot}

$\begin{array}{ll}\text { denaturating solution: } & 1.5 \mathrm{M} \mathrm{NaCl}, 0.5 \mathrm{M} \mathrm{NaOH} \\ \text { renaturating solution: } & 0.5 \mathrm{M} \mathrm{NaCl}, 1 \mathrm{M} \text { Tris } \\ \text { 20x SSC: } & 3 \mathrm{M} \mathrm{NaCl}, 0.34 \mathrm{M} \mathrm{Na-Citrat,} \mathrm{pH} 7.0 \\ \text { salmon sperm DNA (SSP): } & 10 \mathrm{mg} / \mathrm{ml} \\ \text { TE buffer: } & 10 \mathrm{mM} \text { Tris-HCl pH } 7.5,1 \mathrm{mM} \text { EDTA } \\ { }_{\alpha-}{ }^{32} \mathrm{P}-\mathrm{dCTP}: & 10 \mu \mathrm{Ci} / \mu \mathrm{l} \\ \gamma_{-}{ }^{32} \mathrm{P}-\mathrm{dATP}: & 5 \mu \mathrm{Ci} / \mu \mathrm{l}\end{array}$

Restriction digest. For genotyping of genomic DNA, 10-15 $\mu \mathrm{g}$ of DNA were digested with $60 \mathrm{U}$ of restriction enzyme in a volume of $50 \mu \mathrm{l}$ overnight at $37^{\circ} \mathrm{C}$. If the DNA preparation was too dilute, the volume could be increased up to $100 \mu \mathrm{l}$. After the incubation, $2 \mu \mathrm{l}$ of the digest were loaded on an agarose gel to check the degree of digestion. If needed, 1-2 $\mu$ l of enzyme were added again and the DNA was incubated for further digestion.

Agarose gel. Finally, the entire DNA samples were loaded on a $0.7 \%$ agarose gel and run at $45-55 \mathrm{~V}$ for at least 10-12 h or overnight. The volume of DNA ladder was twice as usual because of the weak staining intensity after the run.

PCR samples were loaded on a 1.5\% agarose gel and run for 1-2 h at about $100 \mathrm{~V}$, just as any other agarose gel.

DNA transfer to nylon membrane. After cutting the gel to the required size and taking a picture including a scale, it was washed twice in denaturing solution for 15 min in order to separate the DNA strands, twice 15 min in renaturing solution and finally about $15 \mathrm{~min}$ in 20x SSC for equilibration. Every time before applying a different solution the gel was rinsed briefly with water. For overnight transfer of the DNA to a nylon membrane the setup was as follows:

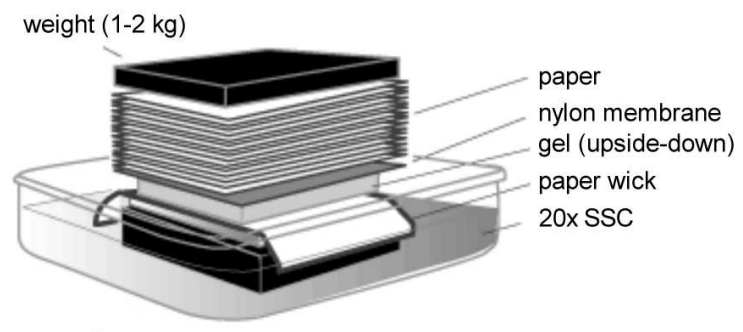

The membrane was afterwards dried at room temperature, exposed to UV light for $15 \mathrm{~s}$ to crosslink the DNA to the membrane and incubated at $60^{\circ} \mathrm{C}$ for $1 \mathrm{~h}$. At this point, the membrane can be stored for a long time at a dark, dry place. It was rolled and placed into a $50 \mathrm{ml}$ Falcon tube. 
Radioactive labelling of DNA fragment. Approximately $25 \mathrm{ng}$ of DNA fragment were diluted up to $45 \mu \mathrm{l}$ in TE buffer. After 5 min at $95^{\circ} \mathrm{C}$ and 5 min on ice, the solution was transferred to a cup containing rediprime random DNA labelling kit lyophilisate, on ice. $30-50 \mu \mathrm{Ci}$ of $32 \mathrm{P}$-dCTP were added, dependent on the calibration date of the radioactivity, and the lyophilisate was resuspended by pipetting. The labelling reaction mix was incubated at $37^{\circ} \mathrm{C}$ for $15 \mathrm{~min}$. Qiaspin nucleotide removal kit was used to purify the labelled DNA and 1/100 of the eluate was measured in a scintillation counter using Cerenkov radiation. 2-15 $\mu \mathrm{Ci}$ were used for one membrane.

\section{Radioactive labelling of oligonucleotides.}

\begin{tabular}{|l|c|}
\hline $10 \mathrm{x}$ PNK buffer & $2 \mu \mathrm{l}$ \\
\hline$\gamma_{-}{ }^{32} \mathrm{P}-d A T P$ & $5 \mu \mathrm{l}$ \\
\hline oligonucleotide $(1 \mathrm{pmol} / \mu \mathrm{l})$ & $3 \mu \mathrm{l}$ \\
\hline poly-nucleotide kinase $(10 \mathrm{U} / \mu \mathrm{l})$ & $2 \mu \mathrm{l}$ \\
\hline $\mathrm{H}_{2} \mathrm{O}$ & $8 \mu \mathrm{l}$ \\
\hline
\end{tabular}

The reaction mix was incubated at $37^{\circ} \mathrm{C}$ for 60 min and purified by Qiaspin column. About $4 \mu \mathrm{Ci}$ were added to one membrane.

Hybridisation. To prepare the membrane for hybridisation, salt was removed by washing the membrane with water twice for $5 \mathrm{~min}$. Water was removed, especially inside the screwcap, to prevent leaking of hybridisation buffer. Prehybridisation was done in $3 \mathrm{ml}$ Rapid-hyb hybridisation buffer $(5 \mathrm{ml}$ if the membrane was rolled in more than one layer) for at least $1 \mathrm{~h}$ at $65^{\circ} \mathrm{C}$. After labelling the probe, SSP was boiled for 10-15 min. $10 \mu \mathrm{l}$ of $\mathrm{SSP} / \mathrm{ml}$ hybridisation buffer were added to the radioactive DNA solution, the mixture was boiled for 5 min and added dropwise to the hybridisation buffer. The tube was double-sealed in a plastic bag and incubated overnight at $65^{\circ} \mathrm{C}$ a rolling hybridisation oven.

The membrane was washed with $0.1 \%$ SDS in $2 \mathrm{x}$ SSC for 15 min at room temperature and with $0.1 \% \mathrm{SDS}$ in $0.2 \mathrm{x} \mathrm{SSC}$ for $15 \mathrm{~min}$ at $65^{\circ} \mathrm{C}$. Further washes were done eventually after the first exposure to a phosphoimager screen, depending on the signal/background relationship.

Stripping of the membrane. The membrane was added to just boiled $0.1 \%$ SDS or $0.1 \% \mathrm{SDS}$ in $0.2 \mathrm{x} \mathrm{SSC}$ and left to cool in that solution. The remaining signal was detected by overnight exposure and the procedure repeated up to 3 times. 


\subsubsection{Northern blot}

To prevent RNase contamination, all surfaces, instruments and containers used were cleaned extensively in advance as described in the Qiagen RNeasy Kit manual.

10x MOPS buffer:

$200 \mathrm{mM}$ MOPS, $50 \mathrm{mM}$ NaAc,

10 mM EDTA, pH 7.0

1x MOPS gel running buffer: 1x MOPS buffer, $0.74 \%$ formaldehyde (FA)

5x RNA loading dye: $\quad 4$ mM EDTA pH 8.0, $2.7 \%$ FA, $20 \%$ glycerol,

$31 \%$ formamide, $4 x$ MOPS buffer,

bromphenol blue

Solutions were prepared according to the Qiagen RNeasy Kit Manual. For the agarose gel, agarose was boiled in 1x MOPS buffer and left to cool until about $50^{\circ} \mathrm{C}$. Formaldehyde was then added to a concentration of $0.7 \%$ as well as ethidium bromide, before pooring the gel. RNA samples were mixed with $5 \mathrm{x}$ dye, incubated at $65^{\circ} \mathrm{C}$ for $5 \mathrm{~min}$ and kept on ice to cool for $5 \mathrm{~min}$.

The gel was run at 50-70 $\mathrm{V}$ for 4-7 h. To prepare for transfer, it was briefly washed with water and equilibrated in 20x SSC. All the following steps were done as described for Southern blot (see 2.2.1.7).

\subsubsection{Microarray}

Hybridisation buffer: $50 \%$ formamide, $5 x$ SSC (2.2.1.7), 0.1\% SDS, $5 \mathrm{x}$ Denhardt's reagent

This experiment was done in collaboration with Dr. Jobst Landgrebe from the Microarray facility at the medical department. The DNA chips that were used had been spotted with 22,000 clones from the RZPD Mus musculus Unigene Set II.

Two RNA preparations, labelled with the fluorescent dyes Cy3 and Cy5, were hybridised to each chip, and the ratio of both signals was used for calculation. Since the total amount of RNA obtained from the mice was not sufficient for hybridisation, the remaining part was substituted by cDNA which was synthesised from the RNA preparations and amplified.

DNase treatment and clean up. To remove contaminating DNA, RNA eluates

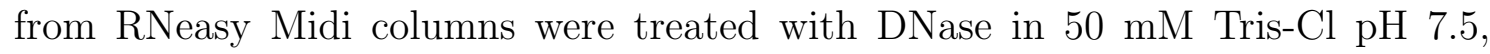
$10 \mathrm{mM} \mathrm{MgCl} 2$ containing 20-40 U DNase I and 20-40 U RNase Inhibitor for $20 \mathrm{~min}$ at $37^{\circ} \mathrm{C}$. The reaction was then cleaned up by extraction with 1 Vol PCI (2.2.1.4). After centrifugation of the mixture, the aequous upper phase was transferred to a new cup and mixed with $1 \mathrm{Vol}$ of isopropanol and 1/10 Vol of $3 \mathrm{M} \mathrm{NaAc} \mathrm{pH} 4.8$ to precipitate the RNA. It was pelleted by centrifugation at $13,000 \mathrm{x}$ g for $15 \mathrm{~min}$ at $4^{\circ} \mathrm{C}$ 
and washed twice with $70 \%$ ethanol. The RNA pellet was dried and resuspended in RNase-free water by incubation at $42^{\circ} \mathrm{C}$ and vortexing. Concentration and purity of the RNA solution was determined and adjusted to $50 \mu \mathrm{g}$ per $18 \mu \mathrm{l}$.

Amplification of RNA and labelling. cDNA amplification was done according to the Atlas SMART protocol (BD Biosciences) using $1 \mu \mathrm{g}$ total RNA for reverse transcription. Each PCR sample contained $100 \mathrm{ng}$ of first strand cDNA as template. Aliquots were taken after each cycle between 15 and 20 cycles, and the reaction was finally performed for a number of cycles where the amount of cDNA amplified increased still linearly.

Both cDNA and RNA were labelled using LabelStar Array Kit (Qiagen) according to the instructions supplied with the following changes: cDNA was denatured for $5 \mathrm{~min}$ at $95^{\circ} \mathrm{C}$ before labelling. QIAquick PCR purification columns were used for clean up instead of MinElute columns, including one additional wash step with $750 \mu \mathrm{l}$ $35 \%$ guanidine- $\mathrm{HCl}$ solution and one repetition of the wash step with buffer PE. Elution was done in buffer EB.

Hybridisation. Cy3- and Cy5-labelled probes for one specific array were pooled and reduced to a volume of $2 \mu \mathrm{l}$ at $30^{\circ} \mathrm{C}$ under vacuum and protection from light. They were resuspended in $37 \mu \mathrm{l}$ of hybridisation buffer, which had been prewarmed at $42^{\circ} \mathrm{C}$, and supplemented with $1 \mu \mathrm{l}$ of mouse Cot- 1 DNA and $2 \mu \mathrm{l}$ of poly(dA) to decrease unspecific binding. The mix was denatured at $94^{\circ} \mathrm{C}$ for $3 \mathrm{~min}$, cooled on ice for $1 \mathrm{~min}$, briefly centrifuged and transferred onto a $24 \mathrm{x} 60 \mathrm{~mm}^{2}$ glass coverslip. It was assembled with the array glass slide and enclosed with $15 \mu \mathrm{l}$ extra buffer in a hybridisation chamber, which was submersed in a $42^{\circ} \mathrm{C}$ waterbath overnight. The array was afterwards washed at RT for 10 min each in $2 \mathrm{x}$ SSC/0.2\% SDS, in $2 \mathrm{x}$ SSC and in $0.2 \mathrm{x}$ SSC. It was then quickly dried with compressed air and stored in a dark box at RT until scanning.

\subsubsection{Cell culture}

\subsubsection{Basics}

fibroblast growth medium:

DMEM, $10 \%$ fetal calf serum, Pen-Strep

trypsin-EDTA solution: $0.5 \mathrm{~g} / 1$ Trypsin, $0.2 \mathrm{~g} / 1$ EDTA

phosphate-buffered saline (PBS): $150 \mathrm{mM} \mathrm{NaCl}, 120 \mathrm{mM} \mathrm{KCl}$, $10 \mathrm{mM} \mathrm{Na}_{2} \mathrm{HPO}_{4} / \mathrm{KH}_{2} \mathrm{PO}_{4} \mathrm{pH} 7.4$

freezing medium: $10 \%$ DMSO in fibroblast growth medium

Passaging by trypsinisation. Fibroblasts were passaged every 2-7 days depending on the growth rate. After two washes with PBS, $0.5 \mathrm{ml}$ trypsin solution per $25 \mathrm{~cm}^{2}$ 
was added to the cell layer. The cells were incubated at $37^{\circ} \mathrm{C}$ for $5 \mathrm{~min}$, then singled by tapping to the dish and resuspended in medium. To concentrate, wash or harvest cells, centrifugation was always done at 500xg for $5 \mathrm{~min}$.

Freezing cells for stock maintenance. Usually, cells from a confluent $35 \mathrm{~cm}^{2}$ flask were frozen as 2-4 vials. Cells were pelleted after trypsinisation, resuspended in $1 \mathrm{ml}$ freezing medium per vial, immediately placed on ice and stored at $-80^{\circ} \mathrm{C}$ overnight. The vials were transferred to the liquid nitrogen container the following day.

Thawing cells. The frozen vial was taken out of liquid nitrogen, the cap was carefully loosened to release pressure and the vial was thawed in $70 \%$ ethanol at $37^{\circ} \mathrm{C}$, until the suspension had almost completely melted. Under the hood, the cells were then transferred to a tube containing $5 \mathrm{ml}$ chilled cell culture medium. The cells were pelleted, resuspended in prewarmed culture medium and transferred to a culture flask. Medium was replaced on the next day.

\subsubsection{Preparation and immortalisation of mouse embryonic fibroblasts}

A pregnant mouse was anaesthetised with $\mathrm{CO}_{2}$ and killed by cervical dislocation at day 13.5 after fertilisation (determined by vaginal plug control). The embryos were prepared with their amnion coat from the uterus and washed in sterile PBS. First, the amnion coat was removed and put aside for DNA preparation as well as the head of the embryos. However, the amnion may be contaminated with cells from the mother and were therefore regarded as a minor DNA source. Second, organs of the body cavity were removed from the embryos. The remainings were torn into small pieces and transferred to a small Erlenmeyer flask containing glass beads for digestion with $5 \mathrm{ml}$ of trypsin solution for on a shaking incubator at $37^{\circ} \mathrm{C}$. After $15 \mathrm{~min}$ of incubation, the suspension was homogenised by pipetting and undigested pieces were left in the flask as far as possible. The cells were centrifuged at $500 \mathrm{xg}$ for $5 \mathrm{~min}$, resuspended in fibroblast growth medium and plated onto a $10 \mathrm{~cm}$ culture dish.

Primary fibroblasts proliferate very rapidly and were usually passaged 1:3 every third day.

\subsubsection{Culture of mouse embryonic stem cells}

Embryonic stem (ES) cells were grown on a fibroblast monolayer and in the presence of leukemia inhibitory factor (LIF) to prevent differentiation. LIF factor was 
produced by the cell line CHO 720 LIF, whose culture supernatant served as supplement for ES cell medium. To preserve their totipotent state, the cells were cultured for 10-15 passages at most.

ES cell medium:

DMEM-high glucose, 15\% FCS (Boehringer),
non-essential aa, $1 \mathrm{mM}$ Na-pyruvate,
$2 \mathrm{mM}$ L-Gln, $100 \mathrm{U} / \mathrm{ml}$ Pen/Strep (Gibco),
$0.1 \mathrm{mM} \beta$-mercaptoethanol,
$1 \%$ LIF-culture supernatant
fibroblast medium (see 2.2 .2 .1 )
$20 \%$ DMSO, $20 \%$ FCS (Boehringer)
in DMEM
DMEM-high glucose, $15 \%$ FCS (Gibco),
non-essential aa, $1 \mathrm{mM} \mathrm{Na-pyruvate,}$
$2 \mathrm{mM} \mathrm{L-Gln,} 100 \mathrm{U} / \mathrm{ml}$ Pen/Strep (Gibco),
$0.1 \mathrm{mM} \beta$-mercaptoethanol
$1 \mathrm{mg} / \mathrm{ml}$ in $5 \%$ DMSO, PBS

mitomycin C: $1 \mathrm{mg} / \mathrm{ml}$ in 5\% DMSO, PBS

Feeder layers. ES cells were cultivated on confluent monolayers of a neomycinresistant fibroblast cell line. To arrest proliferation of the fibroblasts, confluent plates were treated with mitomycin $\mathrm{C}(1: 100)$ for $2-3 \mathrm{~h}$ at $37^{\circ} \mathrm{C}$. Cells were then washed 3 times with PBS, trypsinised, and seeded at a density of $4 \times 10^{6}$ cells per $10 \mathrm{~cm}$ dish or $6 \times 10^{6}$ cells per 24 well plate. To ensure extended adherence of the cells, culture dishes were coated with $0.1 \%$ gelatine for at least $30 \mathrm{~min}$ and washed 2-3 times before plating of the inactivated fibroblasts. ES cells could be seeded after a minimum of $4 \mathrm{~h}$.

Cultivation. Undifferentiated ES cells grow as regular, round colonies on top of the feeder layer. Medium was changed about twice a week. ES cells were passaged every 4-10 days as described in 2.2.2.1, depending on the colony density and the condition of the feeder layer.

Separation of ES cells from feeder cells and differentiation. After trypsinisation, the cells were resuspended 1:1 in ES medium and incubated at $37^{\circ} \mathrm{C}$ in a normal culture dish. The spreading of fibroblasts was surveyed under the microscope and after 30-90 min or when most of them had adhered, the supernatant containing ES-cells was transferred to a new tube and pelleted by centrifugation. The cells were resuspended in DNA-ES medium and plated on a normal culture dish. In the absence of LIF, ES cells will differentiate and grow as adherent cells for several passages. These cells can be used to prepare DNA, RNA or cell extracts.

Freezing and thawing ES cells. $5 \times 10^{6}-10^{7}$ cells should be frozen per aliquot. After trypsinisation, ES and feeder cells were pelleted and resuspended in $4^{\circ} \mathrm{C}$-cold 
ES-medium at $0.5 \mathrm{ml}$ per aliquot. The same amount of ES freezing medium was added dropwise and mixed by pipetting. $1 \mathrm{ml}$ per vial was transferred to cryotubes that were placed immediately on ice and stored at $-80^{\circ} \mathrm{C}$. The next day, the tubes were transferred to a liquid nitrogen container.

Frozen vials were kept at room temperature for about $1 \mathrm{~min}$, then warmed in a vessel with $70 \% \mathrm{EtOH}$ at $37^{\circ} \mathrm{C}$, until they were thawed almost completely. The cell suspension was diluted into $5 \mathrm{ml}$ of cold medium, centrifuged, resuspended in $5 \mathrm{ml}$ of warm medium and seeded onto a feeder layer.

\subsubsection{Transfection of mouse embryonic stem cells by electroporation}

DNA can be introduced into eukaryotic cells by application of an electric pulse which transiently destabilises the plasma membrane, similar to the method used for bacteria.

EB buffer:

$10 \mathrm{mM}$ Tris $\mathrm{pH} 8.5$

geneticin G418 (neomycin analogue): $25 \mathrm{mg} / \mathrm{ml}$ in DMEM

ES cells from a confluent $10 \mathrm{~cm}$ dish were trypsinised and separated from feeder cells by incubation for about $30 \mathrm{~min}$. The supernatant cells were counted, pelleted and resuspended at $10^{7}$ cells/900 $\mu \mathrm{l}$ in EB buffer. 20-35 $\mu \mathrm{g}$ of linearised DNA in $45 \mu \mathrm{l}$ of EB buffer were added and mixed by pipetting. The suspension was transferred to an electroporation cuvette, subjected to an electric pulse of $240 \mathrm{~V}$ and $500 \mu \mathrm{F}$ at a time constant of 5.4-5.7 $\mathrm{s}$ and incubated for further $10 \mathrm{~min}$ in the same position before plating on a $15 \mathrm{~cm}$ feeder dish. An aliquot of untransfected cells was plated on a $6 \mathrm{~cm}$ dish as negative control for selection. After $48 \mathrm{~h}$, the ES medium was changed to ES medium containing $335 \mu \mathrm{g} / \mathrm{ml}$ G418. About seven days after electroporation, half of the medium was replaced by fresh ES/G418 medium, with care not to disturb the feeder layer.

ES cell colonies were picked 8-10 days after selection. In advance, five 24 well plates were coated with feeder cells to seed the clones. To process many clones in reasonable time, a multipet was used for pipetting. For practical reasons, boxes with yellow pipet tips were prepared such that only every second place of a row was filled, and only every second well of a 96 well plate was used, according to the spacing of a 24 well plate. The selection dishes were first washed with PBS, covered with PBS and placed under the microscope. Around each colony, the feeder layer was detached using a pipet with yellow tip, was then taken up by the pipet in $30 \mu$ l and mixed with $50 \mu$ l trypsin solution, that had been aliquoted just before in a 96 well plate. About six clones were isolated, $50 \mu \mathrm{l}$ of medium was added to every well to stop 
trypsinisation and the cells were transferred to one row of a 24 well plate. About 120 clones should be picked to obtain at least one positive clone.

The ES cell clones were cultured in ES/G418 medium, supplemented with fresh medium at least every week, for about 20 days or until the cells covered most of the well. After trypsinisation, half of the cell suspension was frozen for storage and the other half was seeded onto the same plates in DNA-ES medium which allows adherence and differentiation. Dependent on the density and growth rate, either all the cells were frozen as pellet at $-20^{\circ} \mathrm{C}$ or only $3 / 4$ of the cells were frozen and $1 / 4$ plated again, until a sufficient amount was obtained to isolate genomic DNA (equivalent to a confluent well).

\subsubsection{Biochemistry}

\subsubsection{Discontinuous SDS-polyacrylamide gel electrophoresis (SDS-PAGE)}

4x stacking gel buffer:

$4 \mathrm{x}$ resolving gel buffer:

acrylamide (AA) solution:

ammonium peroxodisulfate (APS):

5x sample buffer:

5x anode buffer:

5x cathode buffer:

Coomassie stain:

Coomassie destain:
$0.5 \mathrm{M}$ Tris- $\mathrm{Cl} \mathrm{pH} \mathrm{6.8,} \mathrm{0.4 \%} \mathrm{SDS}$

1.5 M Tris-Cl pH 8.8, 0.4\% SDS, 0.4\% APS

$30 \%(\mathrm{w} / \mathrm{v})$ acrylamide,

$0.8 \%(\mathrm{w} / \mathrm{v})$ bisacrylamide

$10 \%$ solution in water

0.225 M Tris-Cl pH 6.8, 50\% glycerol, $5 \%$ SDS, $0.05 \%$ bromphenol blue, $0.1 \mathrm{M}$ DTT $50 \mathrm{mM}$ Tris base, $192 \mathrm{mM}$ glycine

$0.5 \%$ SDS in anode buffer

0.5\% Coomassie blue, $50 \%(\mathrm{v} / \mathrm{v})$ methanol, $1 \%(\mathrm{v} / \mathrm{v})$ acetic acid

$50 \%(\mathrm{v} / \mathrm{v})$ methanol, $10 \%(\mathrm{v} / \mathrm{v})$ acetic acid

Glass plates were cleaned with $70 \%$ EtOH before use. Polymerising solutions were prepared as follows for one minigel $(8 \mathrm{~cm} \mathrm{x} 7 \mathrm{~cm} \mathrm{x} 1.5 \mathrm{~mm})$ :

\begin{tabular}{|c|c|c|}
\hline & Resolving gel $(8 \mathrm{ml})$ & Stacking gel $(3 \mathrm{ml})$ \\
\hline \hline $4 \mathrm{x}$ gel buffer & $2 \mathrm{ml}$ & $0.45 \mathrm{ml}$ \\
\hline AA solution & $1 \mathrm{ml} / 3.75 \%$ & $0.45 \mathrm{ml}$ \\
\hline water & $5.9 \mathrm{ml}-\mathrm{V}(\mathrm{AA})$ & $1.77 \mathrm{ml}$ \\
\hline TEMED & $8 \mu \mathrm{l}$ & $3 \mu \mathrm{l}$ \\
\hline $10 \%$ APS & $80 \mu \mathrm{l}$ & $30 \mu \mathrm{l}$ \\
\hline
\end{tabular}

For a large gel the amounts indicated were adjusted to total volumes of $30 \mathrm{ml}$ (resolving gel) and $10 \mathrm{ml}$ (stacking gel). Proteins of 20-50 kDa were separated best 
on a $15 \%$ AA gel, those between 50 and $100 \mathrm{kDa}$ on a $10 \% \mathrm{AA}$ gel, and $7.5 \% \mathrm{AA}$ resulted in good resolution in the range of 75-150 kDa.

Samples were mixed with sample buffer to a $1 \mathrm{x}$ concentration, incubated at $95^{\circ} \mathrm{C}$ for $5 \mathrm{~min}$ and cooled to room temperature before loading onto the gel. The gel was placed in a tank with either $1 \mathrm{x}$ cathode buffer (for a one-buffer-system) or $1 \mathrm{x}$ cathode/anode buffer (for a two-buffer-system) and run at 30-40 mA until the dye front passed the bottom of the gel.

After removal of the stacking gel, proteins were either stained with Coomassie blue (fresh stain for $1 \mathrm{~h}$, destain 16-48 h) or the gel was processed for Western blotting.

\subsubsection{Western blot (semi-dry)}

cathode buffer

anode buffer

Tris-buffered saline (TBS)

TBST

blocking buffer

glycine stripping solution

SDS stripping solution
$40 \mathrm{mM} \epsilon$-aminocaproic acid, $20 \mathrm{mM}$ Tris-Cl, $20 \%$ (v/v) methanol, pH 9.0 ( $\mathrm{pH}$ was adjusted with free Tris base before addition of methanol) 75 mM Tris-Cl, 20\% (v/v) methanol, pH 7.4

$10 \mathrm{mM}$ Tris-Cl pH 7.4, $150 \mathrm{mM} \mathrm{NaCl}$ $0.1 \%(\mathrm{v} / \mathrm{v})$ Tween-20 in TBS

$5 \%$ milk powder in TBST

$0.2 \mathrm{M}$ glycine $\mathrm{pH} 2.8,0.5 \mathrm{M} \mathrm{NaCl}$

$16 \mathrm{mM}$ Tris- $\mathrm{Cl} \mathrm{pH}$ 6.8, 2\% SDS,

$0.1 \mathrm{M} \beta$-mercaptoethanol

Six pieces of $3 \mathrm{~mm}$ Whatman paper and one piece of nitrocellulose membrane were cut to the size of the SDS gel. Gel and membrane were equilibrated for 5-15 min in cathode buffer. The blot was assembled without air bubbles according to the following scheme:

cathode (-)

$3 \mathrm{x}$ paper in cathode buffer

gel membrane

$3 \mathrm{x}$ paper in anode buffer anode $(+)$

For transfer, the current was set to $1 \mathrm{~mA} / \mathrm{cm}^{2}$ gel size for $45-60 \mathrm{~min}$. The membrane was then briefly washed with TBST and incubated in blocking buffer for one hour at room temperature. Decoration with the primary antibody diluted in blocking buffer occurred overnight at $4^{\circ} \mathrm{C}$. After three 10-15 min washes with blocking buffer, the 
membrane was incubated with horse radish peroxidase(HRP)-coupled secondary antibody, diluted 1:10 000 in blocking buffer, for one hour at room temperature. The blot was washed three times 10-15 min with TBST and incubated with chemiluminescence substrate solution. Intelligent Dark Box II Camera was used for signal detection.

Stripping of nitrocellulose membranes. Removal of antibodies from a blot was done under mild conditions, if it should serve to reduce the background for incubation with another primary antibody, either from a different species or for a protein of clearly distinct size than in the first decoration. After washing the membrane in TBST, it was incubated 5-20 min in glycine stripping solution. The solution was neutralised with $1 \mathrm{M}$ Tris- $\mathrm{Cl} \mathrm{pH} 8.5$, followed by several washes in TBST.

If it was crucial to remove antibodies completely, the blot was incubated in SDS stripping solution for $30 \mathrm{~min}$, tightly closed, on a wheel at $50^{\circ} \mathrm{C}$, followed by several washes in TBST.

Decoration of the membrane was done as described above, starting from the blocking step again.

\subsubsection{Preparation of postnuclear supernatants}

phosphate-buffered saline (PBS): $10 \mathrm{mM} \quad \mathrm{Na}_{2} \mathrm{HPO}_{4} / \mathrm{NaH}_{2} \mathrm{PO}_{4} \quad \mathrm{pH} \quad$ 7.4, $0.09 \% \mathrm{NaCl}$

\section{Protease inhibitors:}

PMSF

Leupeptin

Pepstatin

Iodoacetamide (IAA)
$200 \mathrm{mM}$ stock in DMSO (used 1:200)

$0.5 \mathrm{mg} / \mathrm{ml}$ stock in water (used 1:1000)

$1 \mathrm{mM}$ stock in DMSO (used 1:1000)

$0.5 \mathrm{M}$ stock in water (used 1:100)

Fibroblast cells were washed twice with PBS after harvesting. The samples were subsequently kept on ice during the whole procedure. According to the volume of the cell pellet, $1 \mathrm{Vol}$ of PBS containing protease inhibitors was added to resuspend the cells. If the pellet volume was $\leq 100 \mu$, the cells were lysed by sonification for $3 \times 10$ sec. Above $100 \mu \mathrm{l}$ pellet volume, the cell suspension was passed smoothly about 20 times through a $23 \mathrm{G}$ needle. Afterwards, the homogenate was centrifuged for $5 \mathrm{~min}$ at $500 \mathrm{xg}$ or $3500 \mathrm{rpm}$ in a tabletop centrifuge. The supernatant was collected in a new tube and is referred to as total cell extract or postnuclear supernatant, as it contains all the cellular material except nuclei. The pellet was again resuspended in PBS for a second round of lysis. Finally, the protein concentration of the extracts was determined using the Bradford method, before they were diluted 
at least 4:5 in 5x SDS-Page sample buffer and boiled for 5 min at $95^{\circ} \mathrm{C}$.

Tissue extracts were prepared essentially in the same way. About $150 \mathrm{mg}$ tissue (corresponding to $0.5 \mathrm{~cm}^{3}$ ) were homogenised with the ultra-turrax in $1 \mathrm{ml} \mathrm{PBS}$ containing protease inhibitors. The homogenate was centrifuged at $3500 \mathrm{rpm}$ for 5 min and the supernatant was used for protein estimation.

Estimation of protein concentration using Bradford reagent. An appropriate volume of the sample as well as 2, 4, 8, 12 and $16 \mu \mathrm{l}$ of $1 \mathrm{mg} / \mathrm{ml}$ bovine serum albumine for the standard values were adjusted to $800 \mu \mathrm{l}$ with water and mixed by vortexing. $200 \mu \mathrm{l}$ of Bradford reagent were added to every cup and mixed. After 5-45 min, absorption at $595 \mathrm{~nm}$ was measured and the concentration of the samples calculated according to the standard values.

\subsubsection{Gelfiltration of cytosol}

Sephadex 200, the chromatographic support used, consists of hollow and porous beads that allow the entry of particles of an appropriate size. Larger molecules that are excluded from the beads will pass the column with the flow-through, whereas the other particles will equilibrate between the mobile buffer phase and the internal bead volume.

cytosol buffer: $20 \mathrm{mM}$ HEPES pH 7.4, $150 \mathrm{mM} \mathrm{NaCl}, 2 \mathrm{mM} \mathrm{MgCl}_{2}$

Cells were washed and lysed as described in 2.2.3.3, but using cytosol buffer instead of PBS. The postnuclear supernatant was then further centrifuged at 100,000xg for $1 \mathrm{~h}$ (44,000 rpm in a TLA 45 rotor). In this step, all the membraneous components are pelleted. Protein concentration of the supernatant cytosol was estimated using Bradford reagent.

All the solutions used for HPLC were filtered and degased. Protein samples were centrifuged at $13,000 \mathrm{xg}$ before loading to avoid clogging of the column by protein aggregates. The Superdex 200 column, which is a composite of dextran and crosslinked agarose with an exclusion limit of $1,300 \mathrm{kDa}$, was equilibrated with at least one column volume $(2.4 \mathrm{ml})$ of cytosol buffer. The column was calibrated using a protein standard solution composed of the following proteins: thyreoglobulin (669 kDa), ferritin $(440 \mathrm{kDa})$, aldolase $(158 \mathrm{kDa})$, BSA $(67 \mathrm{kDa})$ and cytochrome c $(12 \mathrm{kDa})$. Up to $250 \mu \mathrm{g}$ of cytosolic proteins, but a maximal volume of $50 \mu \mathrm{l}$ was loaded onto the column at a flow rate of $40 \mu \mathrm{l} / \mathrm{min}$. Fractions of $40 \mu \mathrm{l}$ were collected starting 20 min after load. 


\subsubsection{Purification of GST-tagged recombinant proteins}

buffer A:

buffer B:

buffer C:

buffer D:
$10 \%$ sucrose and protease inhibitors (2.2.3.3) in buffer B

$25 \mathrm{mM}$ Tris-Cl pH 7.5, 0.5 mM EDTA, 1 mM DTT

$1 \%$ Triton $\mathrm{X}-100$ in buffer $\mathrm{B}$

$50 \mathrm{mM}$ Tris- $\mathrm{Cl} \mathrm{pH}$ 8.0, $25 \mathrm{mM}$ glutathione, adjusted to $\mathrm{pH}$ 8-8.5 with $\mathrm{NaOH}$ (prepared freshly)

regeneration buffer A: $\quad 0.1 \mathrm{M}$ Tris-Cl, $0.5 \mathrm{M} \mathrm{NaCl}$, pH 8.5

regeneration buffer $\mathrm{B}$ : $\quad 0.1 \mathrm{M} \mathrm{NaAc}, 0.5 \mathrm{M} \mathrm{NaCl}, \mathrm{pH} 4.5$

A bacterial clone expressing the GST-fusion protein under the control of an inducible promoter was grown in a $20 \mathrm{ml} \mathrm{LB}$ preculture overnight. The culture was diluted 1:20 in fresh LB medium and grown for $3 \mathrm{~h}$ up to an optical density of 0.5-0.8 (600 nm). Protein expression was induced by adding $0.1 \mathrm{mM}$ IPTG to the culture, which was further grown for $3-5 \mathrm{~h}$ at $30^{\circ} \mathrm{C}$. The cells were harvested at $(6,000 \mathrm{rpm}$ in a JA 10 rotor) and washed once with cold PBS. All the following steps were performed on ice. The pellet was resuspended in $4 \mathrm{ml}$ buffer $\mathrm{A}$, transferred to a $50 \mathrm{ml}$ falcon tube and mixed with $4 \mathrm{ml}$ buffer A containing $2 \mathrm{mg} / \mathrm{ml}$ lysozyme. After $15 \mathrm{~min}$ of digestion, the volume was made up to $20 \mathrm{ml}$ with buffer A. The suspension was sonicated with a immersing tip twice for $30 \mathrm{sec}$. To reduce the viscosity of the homogenate, it was treated with $10 \mu \mathrm{g} / \mathrm{ml}$ RNase and $5 \mu \mathrm{g} / \mathrm{ml}$ DNase for $15 \mathrm{~min}$. The lysate was finally supplemented with Triton X-100 to a concentration of $1 \%$ to increase the solubility of its components. The insoluble fraction was pelleted by centrifugation at 11,000xg $(12,000 \mathrm{rpm}$ in a JA 20 rotor) and the supernatant transferred to a new tube.

$260 \mu \mathrm{l}$ of glutathione-coupled sepharose beads (75\% suspension), corresponding to a bead volume of $200 \mu \mathrm{l}$, were centrifuged at $1000 \mathrm{rpm}$ for $5 \mathrm{~min}$ in a tabletop centrifuge and washed twice with $2 \mathrm{ml}$ of each buffer $\mathrm{B}$ and $\mathrm{C}$. The beads were incubated with the soluble lysate fraction on a wheel at $4^{\circ} \mathrm{C}$ overnight. On the next day, the sepharose was washed twice with buffer $\mathrm{C}$ and twice with buffer B. While buffers A-C contains DTT at pH 6-7.5 to prevent oxidisation of glutathione, the elution is facilitated at $\mathrm{pH} 8-8.5$ without addition of DTT. GST-fusion protein was eluted from the beads by adding $200 \mu \mathrm{l}$ of buffer D and incubating the sample for $15 \mathrm{~min}$ at room temperature or on ice for $1 \mathrm{~h}$ up to overnight. Elution was repeated at least 2 times.

The glutathione-sepharose was cleaned by three cycles of washes with 10 bed volumes of regenerating buffer A and B, followed by neutralisation with PBS. It was stored in $20 \%$ ethanol at $4^{\circ} \mathrm{C}$ and reused for the same fusion protein. 


\title{
2.2.3.6 Purification of peptides by C18-cartridge
}

C18-sepharose is a hydrophobic material suitable to purify oligopeptide preparations. Peptides bind to the column in the hydrophilic solution $\mathrm{A}$ and are released by the hydrophobic solution B. The solubility of a peptide should be tested in advance with small aliquots. Most peptides dissolve readily in solution A. If not, addition of acetonitril up to $30 \%$ or other volatile (!!) buffer systems such as $\mathrm{NH}_{4}$ Ac may help.

Lyophilised peptides should be handled without gloves and rather quickly to minimise electrostatic forces.

solution A: $0.1 \%$ tri-fluoro-acetic acid (TFA) in $\mathrm{H}_{2} \mathrm{O}$

solution B: $70 \%$ acetonitril in solution A

All solutions were applied to the cartridge by $5 \mathrm{ml}$ or $1 \mathrm{ml}$ syringes at slow and steady pressure, avoiding air bubbles.

The cartridge was first washed with $2 \mathrm{ml}$ of solution B and equilibrated with $5 \mathrm{ml}$ of solution A. $10 \mathrm{mg}$ peptide, dissolved in $1 \mathrm{ml}$ solution A or a different suitable buffer solution, was applied, followed by washing with $30 \mathrm{ml}$ solution A. $3 \mathrm{ml}$ of this washing volume were collected as flow-through. The peptide was eluted with $5 \mathrm{ml}$ solution B and collected in 10 fractions of $0.5 \mathrm{ml}$ each.

Peptides containing aromatic residues can be detected at $280 \mathrm{~nm}$, others should be measured at $215 \mathrm{~nm}$ against solution A. Pooled eluates were concentrated about 5fold in the speed vac, lyophilised, resuspended in $\mathrm{H}_{2} \mathrm{O}$, lyophilised again and stored at $-20^{\circ} \mathrm{C}$.

\subsubsection{Crosslinking of peptides to key limpet hemocyanin (KLH)}

\author{
MBS (m-maleimidobenzoic acid N-hydrosysuccinimideester) Sigma \\ KLH (keyhole limpet hemocyanin) Sigma
}

This procedure uses the bifunctional crosslinker MBS to attach peptides to KLH via a terminal cysteine residue, resulting in a specific orientation (Schneider et al., 1983). Internal cysteine or terminal lysine, arginine, serine or threonine can also be linked.

$10 \mathrm{mg}$ KLH per peptide were diluted up to $1 \mathrm{ml}$ with PBS pH 6. $1.5 \mathrm{mg}$ MBS were dissolved in $50 \mu 1$ DMSO and added below the surface of the KLH suspension while this was vigorously shaking on an incubator. The mixture was stirred at room temperature for further $30 \mathrm{~min}$. A sephadex column was equilibrated in $\mathrm{PBS} \mathrm{pH} 7$ and loaded with the KLH suspension. 10 fractions of about $500 \mu 1$ were collected and their protein concentration estimated by Bradford assay. Three fractions containing 
the eluate peak were pooled.

$5 \mathrm{mg}$ of the peptide was dissolved in a minimum volume of 200-500 $\mu \mathrm{l} \mathrm{PBS} \mathrm{pH} 7$ (if not dissolved, 5-25 $\mu \mathrm{l} 5 \mathrm{~N} \mathrm{NaOH}$ or 100-500 $\mu$ l DMSO can help). Under vigorous shaking of the peptide solution, the KLH pool was added and the mixture was incubated for $1 \mathrm{~h}$ on a wheel at room temperature. Aliquots of $300 \mu \mathrm{g}$ and $150 \mu \mathrm{g}$ peptide were stored at $-20^{\circ} \mathrm{C}$.

\subsubsection{Immunisation of rabbits and serum preparation}

Rabbits were housed by the animal facility of the medical faculty.

\section{Preparation of antigen emulsions for immunisation:}

As for eluates from GST-sepharose, aliquots containing 250-300 $\mu \mathrm{g}$ and 100-150 $\mu \mathrm{g}$ full-length protein were emulsified for the first injection and subsequent booster injections, respectively. In the case of KLH-coupled peptides, aliquots of $300 \mu \mathrm{g}$ and $150 \mu \mathrm{g}$ peptide were used. Stimune or Titermax Gold served as adjuvant.

\section{Preparation of serum from blood samples:}

Blood samples were incubated for $4 \mathrm{~h}$ at room temperature or overnight at $4^{\circ} \mathrm{C}$ to allow for clot formation and centrifuged for $15 \mathrm{~min}$ at $13,000 \mathrm{xg}$ and $4{ }^{\circ} \mathrm{C}$. The supernatant was carefully transferred into new tubes. Small aliquots were either frozen at $-20^{\circ} \mathrm{C}$, mixed 1:1 with glycerol or with sodium azide up to $0.01 \%$ and tested on western blot. The storage procedure which did not affect the quality of the antibodies was used to store the serum as small aliquots.

\subsubsection{Indirect immunofluorescence of fibroblasts}

Cells were seeded on round coverslips in a 24-well plate 1-2 days in advance and grown to 50-70\% confluency. All the incubation steps given were performed by filling the wells with $0.5-1 \mathrm{ml}$ of the respective solution unless indicated otherwise. Solutions were changed carefully for the cells should neither be washed away nor become dry. The lid of the cell culture plate was closed during prolonged incubations and upon application of the secondary, fluorescent antibody the samples were protected from light.

Fixation with para-formaldehyde: PFA reacts with nitrogen-containing groups and in effect crosslinks the proteins in a cell. 
4\% para-formaldehyde (PFA): The required amount of PFA was suspended in $1 / 5$ of the final volume, mixed with $50 \mu \mathrm{l}$ of $1 \mathrm{M} \mathrm{NaOH} / \mathrm{g}$ PFA and dissolved by incubation at $60^{\circ} \mathrm{C}$ for about $1 \mathrm{~h}$. The solution was stored for $1-2$ weeks at $4^{\circ} \mathrm{C}$.

$0.5 \%$ saponin-PBS: $10 \%$ stock solution, stored at $-20^{\circ} \mathrm{C}$

Cells were washed twice with $37^{\circ} \mathrm{C}$-warmed PBS and fixed with $4 \%$ PFA either for 30-40 min at room temperature or overnight at $4^{\circ} \mathrm{C}$. After two washes with PBS, $50 \mathrm{mM} \mathrm{NH}_{4} \mathrm{Cl}$ served to block unspecific ionic interactions. The cells were washed twice with PBS and permeabilised $3 \times 5$ min with $0.5 \%$ saponin in PBS. The primary antibody was diluted 1:100 in saponin-PBS ( $\alpha$-Lamp1 1:200). One 20-30 $\mu$ l drop of the dilution was added to the center of the coverslip and the plate was incubated with closed lid for $1 \mathrm{~h}$ at room temperature. To remove excess antibody, the cells were washed $3 \times 5$ min with saponin-PBS. To block unspecific binding sites, $200 \mu \mathrm{l}$ of $10 \%$ goat serum in PBS were applied for 20 min at RT (substituted by fetal calf serum, if the primary antibody was raised in goat). The cells were incubated with a dilution of the secondary antibody in saponin-PBS (1:400 for cyanine-coupled antibodies, 1:100 for all others), for 45-60 min at RT. Finally, the wells were washed 3 x 5 min with saponin-PBS, twice with PBS and once with water. The coverslips were carefully taken out with a forceps, dried from excess water and adhered upside-down to a drop of DAKO mounting medium on a glass slide. The slides were protected from light to dry overnight and sealed with nail-polish the next day.

Fixation with methanol-acetone: These reagents cause the precipitation of proteins due to dehydration and mediate fixation as well as permeabilisation of cells.

Cells were washed twice with PBS and cooled on ice. Both methanol and acetone were stored at $-20^{\circ} \mathrm{C}$ and taken out directly before use. Methanol was applied to the cells for $3 \mathrm{~min}$ on ice, followed by acetone for $30 \mathrm{sec}$ on ice. The cells were then washed twice with PBS at RT. In order to block unspecific interactions, PBS was supplemented with $5 \%$ fetal calf serum (FCS) in the following steps. After $3 \times 5 \mathrm{~min}$ incubation of the cells with FCS-PBS, the primary antibody was applied as 1:100 dilution in FCS-PBS for $1 \mathrm{~h}$. The cells were washed $3 \times 5$ min with FCS-PBS and blocked with $10 \%$ goat serum for $20 \mathrm{~min}$, before incubation with the secondary antibody diluted 1:100-1:400 in FCS-PBS. After 3 x 5 min washes with FCS-PBS, two washes with PBS and one wash with water, the coverslips were embedded as described for PFA-fixation. 


\subsubsection{Indirect immunofluorescence of cryosections}

glycine buffer: $\quad 0.1 \mathrm{M}$ glycine, adjusted to $\mathrm{pH} 7.4$

with Tris-base

blocking buffer: $15 \%$ goat serum, $3 \%$ Triton X-100,

$20 \mathrm{mM} \mathrm{NaP}$ i pH 7.2, $0.45 \mathrm{M} \mathrm{NaCl}$

Cryosections were taken from the $-20^{\circ} \mathrm{C}$ freezer and dried at room temperature for $15 \mathrm{~min}$. The embedding material was removed and the sections surrounded by nail-polish. Glycine buffer was applied for $30 \mathrm{~min}$ first, followed by blocking buffer for $1 \mathrm{~h}$. The slides were transferred to a moist chamber and incubated with the primary antibody (mAb $\gamma 1$-adaptin) diluted 1:30 in blocking buffer overnight at room temperature. After several washes with blocking buffer for $30 \mathrm{~min}$ in total, the secondary antibody ( $\alpha$-mouse, Cy2-conjugate) was applied diluted 1:100 in blocking buffer for 2-3 hrs. The sections were again washed in blocking buffer for 30 min with several changes, washed in $0.05 \mathrm{M} \mathrm{Na}-\mathrm{P}_{\mathrm{i}}, \mathrm{pH} 7.2$ for 30 min with several changes and embedded in DAKO fluorescent mounting medium.

\subsubsection{Breeding and analysis of mice}

\subsubsection{Housing of mice}

Mice were kept in the animal facility of the medical faculty (C57 BL/6J strain) and in the animal rooms of the biochemistry II department (129/Sv strain). Conditions were according to conventional standards, with a temperature of $21-23^{\circ} \mathrm{C}$ and $45-$ $60 \%$ air moisture. The "day phase" lasted from 6-18 h, and midnight was generally assumed as time of mating.

\subsubsection{Perfusion fixation of mice for histology}

(protocol acquired from PD Dr. Michael Rickmann, Institute of Anatomy, University of Göttingen)

perfusion solution: $0.9 \% \mathrm{NaCl}$

anaesthetic: $\quad 0.8 \%$ Rompun (contains xylazine-Cl), $20 \mathrm{mg} / \mathrm{ml}$ Ketavet (contains ketamin-Cl), $0.9 \% \mathrm{NaCl}$ (can be stored for about one week at $4^{\circ} \mathrm{C}$ )

fixation solution: $\quad 2 \%$ para-formaldehyde, $2 \%$ glutaraldehyde, $0.1 \mathrm{M} \mathrm{NaP}_{\mathrm{i}} \mathrm{pH} 7.4$ The mouse was anaesthetised by intraperitoneal injection of $0.2 \mathrm{ml}$ narcotic per $10 \mathrm{~g}$ body weight (only half of the volume is needed in case of transient anaesthesia). After several minutes, the mouse should by unable to move. Its pain sensitivity was 
tested by pinching the tail or the feet and by fixing the feet with needles. If the mouse still reacted to one of these treatments, another $50 \%$ dose of anaesthetic was injected. Increasing amounts of the agent may lead to an early death of the mouse, which is directly preceeded by gasping.

A strip of about $1 \mathrm{~cm}$ of the ventral skin and muscle was cut to access the peritoneum. Lifting the sternum, the diaphragm was dissected from the ribs and the thorax was opened and bent aside.

A small cut was applied to the right atrium of the heart as an exit for the blood. A winged perfusion set, connected to a $10 \mathrm{ml}$ syringe with $0.9 \% \mathrm{NaCl}$, was introduced into the left ventricle, at about $0.5 \mathrm{~cm}$ depth and without damaging the inner wall. The mouse was perfused by manual injection at about $1-2 \mathrm{ml} / \mathrm{min}$ flow. Dark-red blood should exit the heart and the mouth and the liver should become pale. The syringe was replaced, without introducing air bubbles into the tube, and perfusion was continued with 20-30 ml fixative, until the neck and body of the mouse were stiff.

For further microscopical analysis by Prof. Lüllmann-Rauch (University of Kiel), the complete mice were shaved and sealed in plastic bags filled with fixative.

For preparation of cryosections by Susanne Lausmann (MPI of biophysical chemistry, Göttingen), organs were excised post-mortem and incubated in fixation solution for $24 \mathrm{~h}$ with two changes.

\subsubsection{Preparation of $\mathrm{T}$ cells and FACS analysis}

FACS (fluorescence-activated cell sorting) analysis serves to determine the fraction of cells in a population that contains specific surface proteins. Cells are sorted according to their light scattering properties, which differ between viable and dead cells, and according to the fluorescent staining. A prominent application of this technique is the analysis of T-lymphocytes, which display CD4 or CD8 or both on their surface depending on their developmental stage.

buffered DMEM: $\quad 4 \mathrm{ml}$ DMEM, $1 \mathrm{ml} 25 \mathrm{mM}$ HEPES pH 7.4

lysis buffer for erythrocytes: $150 \mathrm{mM} \mathrm{NH}_{4} \mathrm{Cl}, 1 \mathrm{mM} \mathrm{KHCO}_{3}$,

$0.1 \mathrm{mM}$ Na-EDTA, pH 7.4

Mice were anaesthetised in a $\mathrm{CO}_{2}$-saturated chamber, killed by cervical dislocation and dissected. Spleen and thymus were explanted, weighed and submersed in $10 \mathrm{ml}$ PBS or $5 \mathrm{ml}$ buffered DMEM, respectively. The spleen was injected with $10 \mathrm{ml}$ PBS via a $22 \mathrm{G}$ needle, which flushes the cells out of the organ wheras the complete thymus was minced in a potter-homogeniser and the cell suspension was decanted 
leaving tissue debris in the potter. Cells were collected from both suspensions by centrifugation at $1200 \mathrm{rpm}$ for $10 \mathrm{~min}$. All pellets were resuspended in lysis buffer and incubated at $37^{\circ} \mathrm{C}$ for $5 \mathrm{~min} .10 \mathrm{ml}$ DMEM was then added to stop the reaction. Cells were pelleted again, washed twice with PBS, resuspended in 5-10 ml PBS and counted in a Neubauer cell chamber. The cell density was adjusted to $10^{7} / \mathrm{ml}$ and $100 \mu \mathrm{l}$ aliquots of the samples were transferred to 96-well plates with round bottom.

For fluorescent labelling of cell surface antigens, $1 \mu \mathrm{l}$ of antibody solution was added to each well. Plates were incubated on ice and protected from light for $1 \mathrm{~h}$, washed twice with $100 \mu \mathrm{l}$ cold PBS, resuspended in $200 \mu \mathrm{l}$ cold PBS and transferred to round-bottom polystyrene tubes with $300 \mu$ l cold PBS provided.

10,000 cells were analysed by FACS to determine the amount of stained T-lymphocytes. 
2 Materials and Methods 


\section{Results}

\subsection{The $\sigma$-adaptin family}

$\sigma 1$-adaptins are well conserved from yeast to humans, with about $30 \%$ of amino acid identity and $53 \%$ similarity between yeast $\sigma 1$ (Aps1p) and human $\sigma 1 \mathrm{~A}$. But yeast cells possess only one $\sigma 1$-adaptin gene, while there are three different genes in humans.

We wanted to know about the conservation of genes for $\sigma 1$-adaptin among eukaryotic organisms. Sequences for $\sigma 1 \mathrm{~A}$ and $\sigma 1 \mathrm{~B}$ are well confirmed for man and mouse, whereas $\sigma 1 \mathrm{C}$ sequence entries still contain some conflicts since it was identified only recently during genomic sequencing. In addition to the sequences from model organisms like S. cerevisiae, A. thaliana, C. elegans and D. melanogaster, translated expressed sequence tag (EST) sequences of various organisms were aligned to mouse $\sigma 1$-adaptin proteins by BLAST search (at NCBI; Altschul et al., 1990). Only sequences supported by at least one complete EST entry including the $3^{\prime}$-untranslated region were selected for further analysis. Each protein sequence was confirmed by searching the EST database against several peptides from that sequence to sort out low-quality entries. Finally, a selection of $\sigma 1$ sequences was submitted to Clustalw (Higgins et al., 1994) for phylogenetic evaluation. All the matrices provided by that program, which use different ways of calculation, generated the same alignment (fig. 3.1) and phylogenetic tree (fig. 3.2).

$\sigma 1 \mathrm{~A}$ and $\sigma 1 \mathrm{~B}$ are $100 \%$ conserved between human, mouse, rat, cow and pig. As for $\sigma 1 \mathrm{C}$, the sequences of these organisms differ only in a few residues. Therefore, only the mouse proteins are shown. Chicken, frog and zebrafish possess three genes similar to mammals. In contrast, only one type of mRNA was found from fly, worm, and yeast. The plant $A$. thaliana probably contains two $\sigma 1$-adaptin proteins encoded by different genes, but they only differ in four amino acid residues, which do not help to attribute them to the gene families A, B or C. Thus, only one sequence, s1-I, was included. The alignment illustrates that about 10 amino acids at the Nterminus and the region from aa 60-120 are almost identical in all the proteins. This part is the most homologous to other $\sigma$-adaptin proteins as well and can be found 


\section{Results}

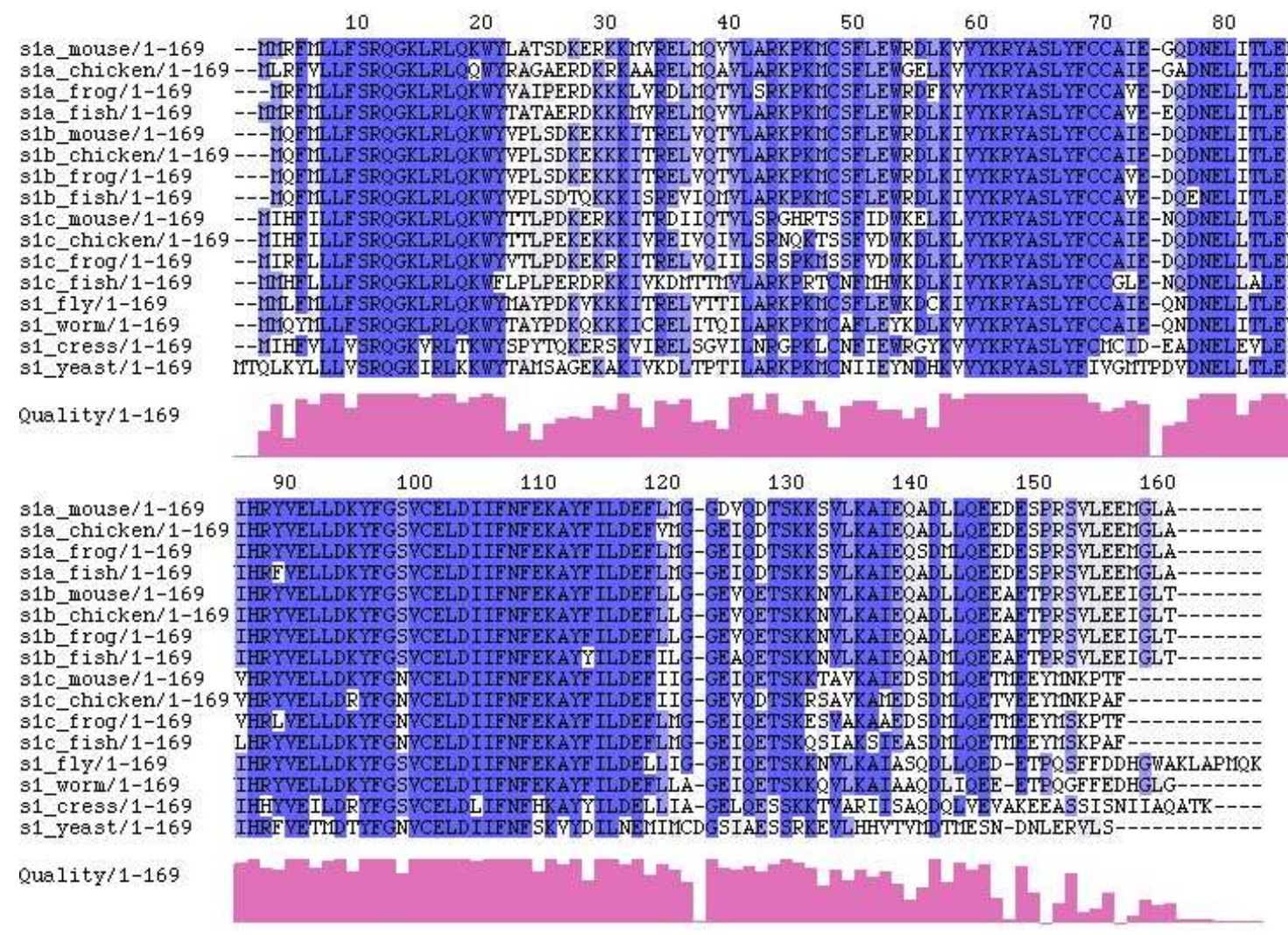

Figure 3.1: Alignment of $\sigma$ 1-adaptin proteins. Residues are coloured according to their degree of conservation. S43 of frog $\sigma 1 \mathrm{C}$ is supported by 2 EST sequences, whereas one, otherwise identical, entry contains N43. mouse: Mus musculus, chicken: Gallus gallus, frog: Xenopus laevis, fish: Danio rerio, fly: Drosophila melanogaster, worm: Caenorhabditis elegans, cress: Arabidopsis thaliana, yeast: Saccharomyces cerevisiae. 
as "clathrin adaptor complex small chain" domain (pfam 01217) in the conserved domain database CDD (Marchler-Bauer et al., 2003).

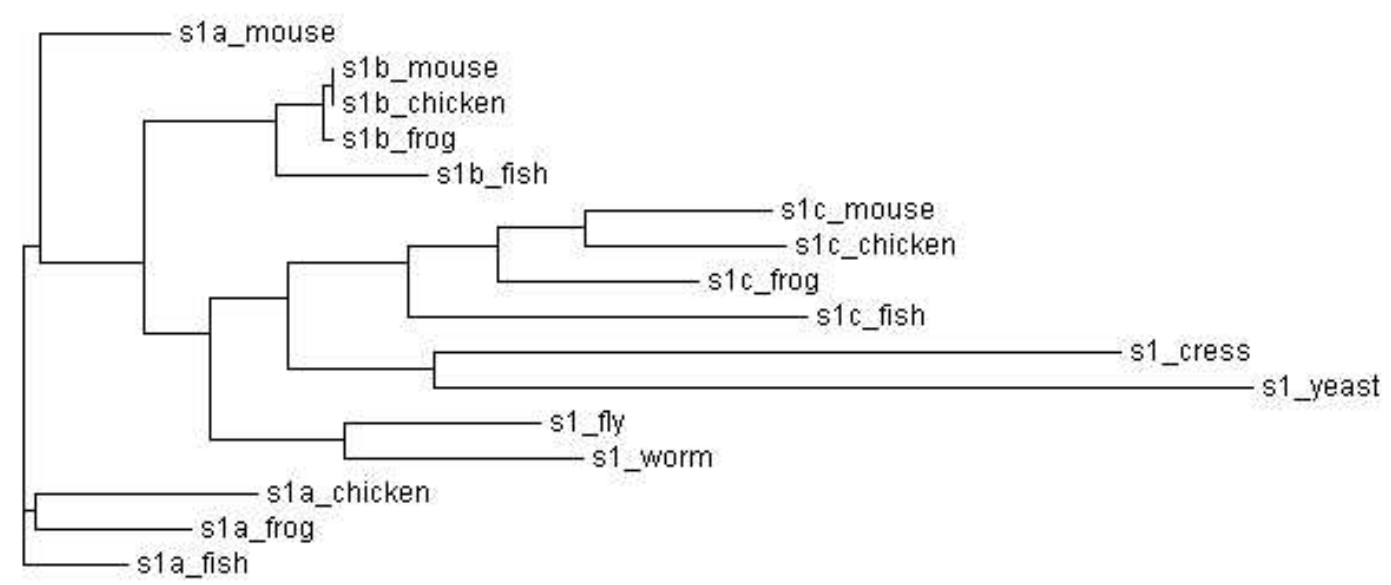

Figure 3.2: Phylogenetic tree of $\sigma$ 1-adaptin proteins. The horizontal length of a branch is proportional to the time of evolution.

Consistent with the sequence alignment, $\sigma 1 \mathrm{C}$ seems to be the most divergent within vertebrates and the most related of the three genes to lower eukaryotes. $\sigma 1 \mathrm{~B}$ shows the least variability within vertebrates. According to this tree, gene diversification occurred during the evolution of vertebrates. The tree is in line with the evolutionary overview of the adaptin family (Boehm \& Bonifacino, 2001).

\subsubsection{Expression analysis of $\sigma 1$ isoforms}

Upon cloning and characterisation of $\sigma 1 \mathrm{~A}$ and $\sigma 1 \mathrm{~B}$, both genes were reported to be similarly expressed in a number of tissues (Peyrard et al., 1998; Takatsu et al., 1998). No data were available concerning the expression of $\sigma 1 \mathrm{C}$, which was identified during the second year of this study by genome sequencing projects. To examine if the three genes are ubiquitously expressed, we detected the respective RNA by PCR amplification of cDNA as well as by northern blot hybridisation.

Total RNA was isolated from various tissues (2.2.1.5) and converted to cDNA by reverse transcription with an oligo-dT-primer (see 2.2.1.6). Transcripts for $\sigma 1$ adaptins were amplified by use of specific oligonucleotide primers selected from the untranslated region of the mRNA. To verify the integrity of the cDNA preparation, hypoxanthine-phosphoribosyltransferase (hprt) was amplified as a control. $20 \mu \mathrm{l}$ of each PCR sample were loaded on a $2 \%$ agarose gel (fig. 3.3). 


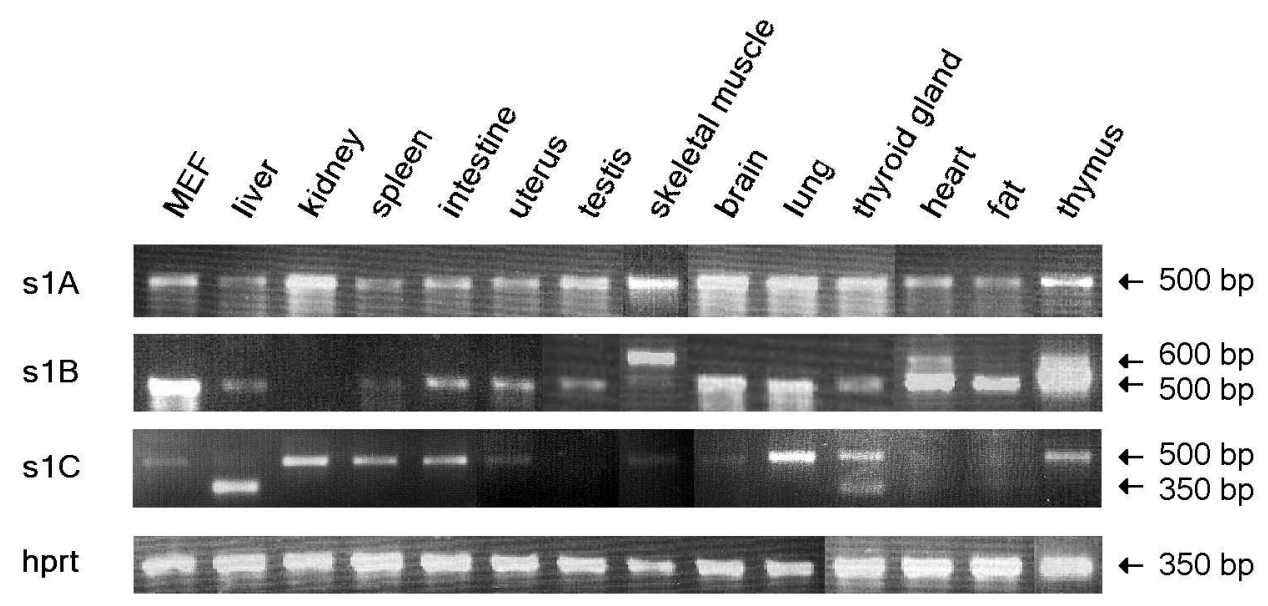

Figure 3.3: Detection of $\sigma$-adaptins by PCR. $\sigma 1 \mathrm{~A}, \sigma 1 \mathrm{~B}$ and $\sigma 1 \mathrm{C}$ cDNA were amplified from total cDNA of different tissues and loaded on an agarose gel. Amplification of the housekeeping gene hprt served as a control for cDNA quality (last row). The approximate size of the PCR products is indicated. For primer sequences see 2.1.8.

The PCR for $\sigma 1 \mathrm{~A}$ produced a $500 \mathrm{bp}$ band from all cDNA preparations which were tested (fig. 3.3, first row). In contrast, the $\sigma 1 \mathrm{~B}$ PCR was positive from cDNA of most tissues, but no band or only a very faint band was visible in kidney and spleen samples. Apart from the expected band at $500 \mathrm{bp}$, an additional product was seen at about $600 \mathrm{bp}$ in the samples of skeletal muscle, heart and thymus. This may correspond to another $\sigma 1 \mathrm{~B}$ mRNA form generated by alternative splicing.

Similar results as for $\sigma 1 \mathrm{~B}$ were obtained for $\sigma 1 \mathrm{C}$. Whereas the expected band of about $500 \mathrm{bp}$ could be amplified from the majority of cDNA preparations, the level of $\sigma 1 \mathrm{C}$ cDNA seemed too low for amplification from testis, skeletal muscle, heart and fat tissue. An additional band at about $350 \mathrm{bp}$ was produced from cDNA of liver and thyroid gland.

These data indicate that $\sigma 1 \mathrm{~A}$ mRNA is expressed in all the tissues examined at a detectable level, while $\sigma 1 \mathrm{~B}$ and $\sigma 1 \mathrm{C}$ transcripts are abundant only in certain tissues.

Since the amplification by PCR does not reflect the absolute levels of RNA, and its efficiency can be influenced by e.g., chemical contaminants of the RNA preparation, it was necessary to confirm the results by northern blot.

For preparation of northern blots, $10 \mu \mathrm{g}$ RNA were separated by agarose gel electrophoresis and transferred to a nylon membrane (2.2.1.8). The northern blots were hybridised with radioactively labelled DNA fragments comprising exons 2-4 of $\sigma 1 \mathrm{~A}$, -B and exons 3-5 of $\sigma 1 \mathrm{C}$, respectively (fig. 3.4). Despite the homologous organisation of the three genes, the corresponding RNA species differ considerably in their 


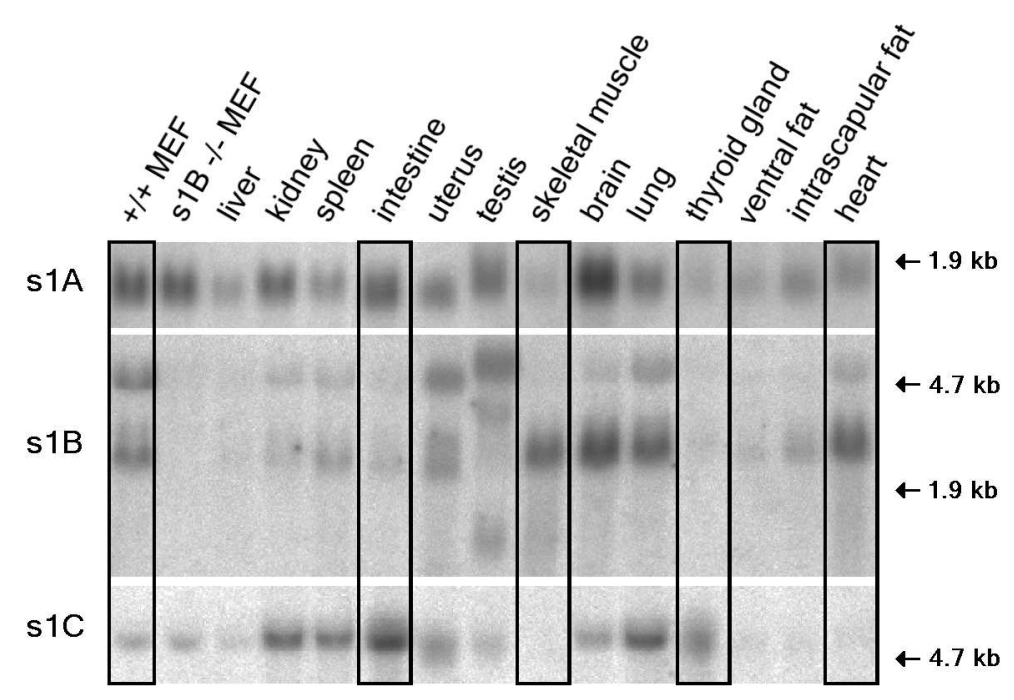

Figure 3.4: Northern blot hybridisation with probes for $\sigma \mathbf{1 A},-\mathbf{B}$ and $\mathbf{C}$. $10 \mu \mathrm{g}$ RNA were loaded except for ventral $(4 \mu \mathrm{g})$ and intrascapular fat $(8 \mu \mathrm{g})$. The position of $18 \mathrm{~S}(1.9 \mathrm{~kb})$ and $28 \mathrm{~S}$ rRNA $(4.7 \mathrm{~kb})$ is indicated.

apparent size. The $\sigma 1 \mathrm{~A}$ probe detected an RNA transcript smaller than $1.9 \mathrm{~kb}$. In one out of four experiments, there was also a signal for a larger RNA species of $\sigma 1 \mathrm{~A}$. Hybridisation with the $\sigma 1 \mathrm{C}$ probe labelled an RNA species larger than $4.7 \mathrm{~kb}$. In contrast, $\sigma 1 \mathrm{~B}$ was always seen as two bands from fibroblasts, one above $4.7 \mathrm{~kb}$ and one between 1.9 and $4.7 \mathrm{~kb}$. Several $\sigma 1 \mathrm{~B}$ RNA species of different size were detected in testis, while the size of $\sigma 1 \mathrm{~A}$ and $\sigma 1 \mathrm{C}$ RNA appeared similar to the other tissues.

All the northern blots were hybridised with hprt cDNA as a control probe to compare hybridisation signals between tissues and on different membranes. Accordingly, each signal was standardised to the hprt signal (fig. 3.5).

As confirmed by their hybridisation pattern, $\sigma 1$-adaptin genes are expressed in a tissue-specific manner. Whereas all the three genes were detected at a comparable level in e.g., mouse embryonic fibroblast or lung RNA, testis and brain apparently contained mainly $\sigma 1 \mathrm{~A}$ and $-\mathrm{B}$ transcripts. $\sigma 1 \mathrm{~A}$ and $\sigma 1 \mathrm{C}$ mRNA were dominant over $\sigma 1 \mathrm{~B}$ in intestine and $\sigma 1 \mathrm{C}$ was the most abundant isoform in thyroid gland. In contrast, the signal for $\sigma 1 \mathrm{~B}$ was stronger than the others in skeletal muscle and heart. RNA from intrascapular fat was chosen due to the high fraction of brown adipose tissue, whereas ventral fat consists of white adipose tissue only. Both were labelled with very low intensity by all the probes and did not show any clear preference among the isoforms.

Since it is unclear whether $\sigma 1 \mathrm{~A}$, -B and -C preferentially associate with either $\gamma 1$ or $\gamma 2$ or with both, we were interested to know if the expression of $\gamma$-adaptin genes 


\section{Results}

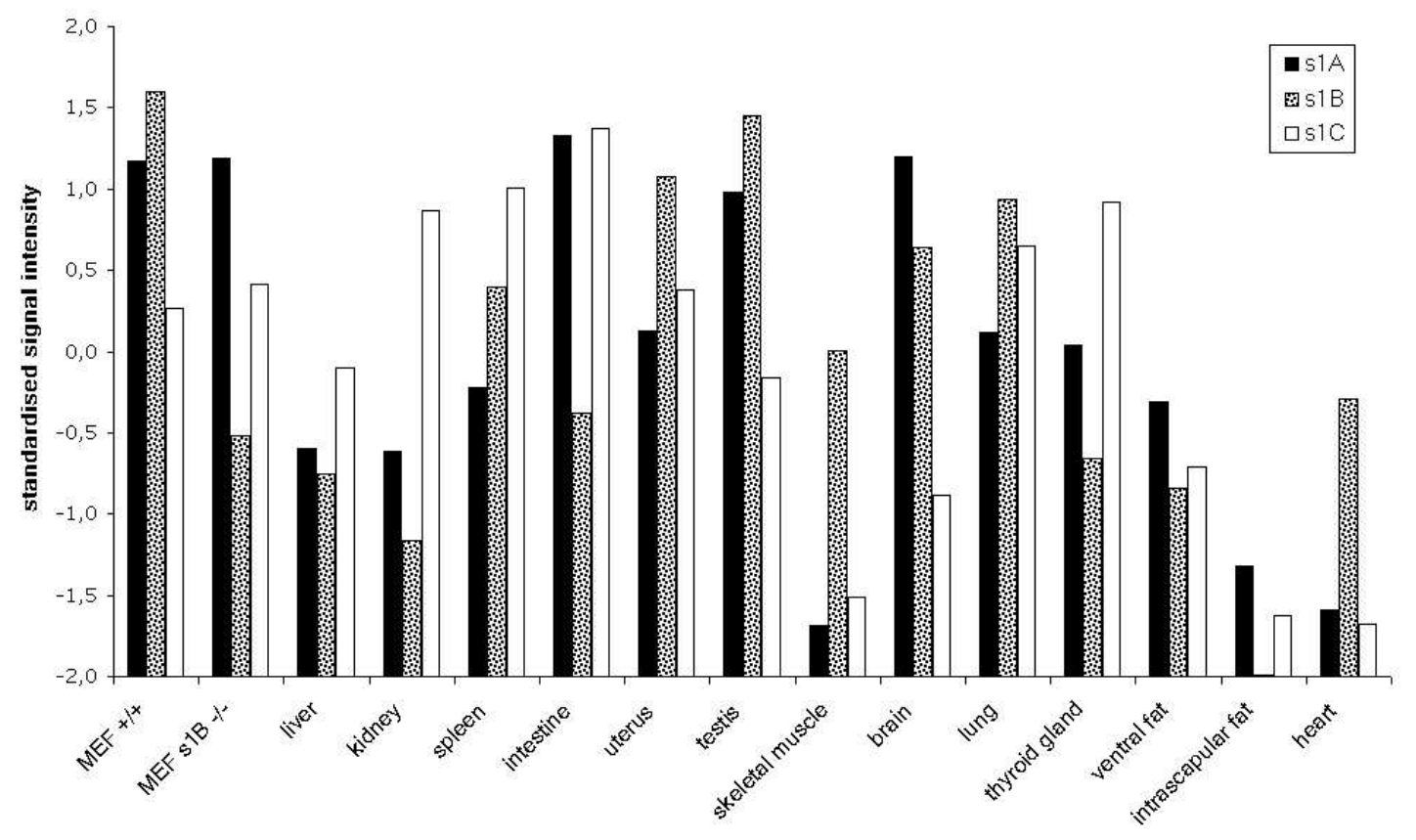

Figure 3.5: Expression profile of $\sigma \mathbf{1 A}$, -B and -C mRNA. Northern blot signals were quantified and normalised to the signal intensity of hprt.

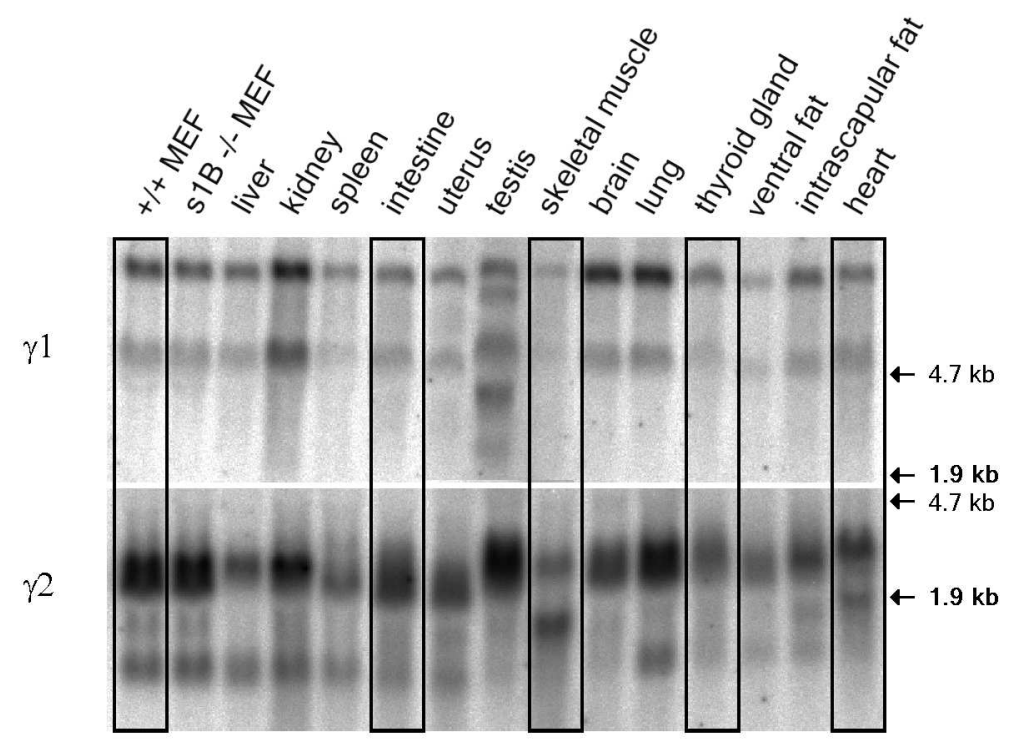

Figure 3.6: Northern blot of $\gamma \mathbf{1}$ - and $\gamma \mathbf{2}$-adaptin. The position of $18 \mathrm{~S}(1.9 \mathrm{~kb})$ and $28 \mathrm{~S}$ rRNA $(4.7 \mathrm{~kb})$ is indicated. 
would show a tissue-specific pattern. For this purpose, the tissue northern blots were decorated with cDNA probes comprising hinge and ear region of $\gamma 1$ or $\gamma 2$ (fig.3.6).

For both genes, mRNA species of two different sizes were detected in most tissues, both longer than $4.7 \mathrm{~kb}$ for $\gamma 1$ and one longer, one shorter than $1.9 \mathrm{~kb}$ for $\gamma 2$. Both $\gamma 1$ and $\gamma 2$ were expressed in all tissues examined, in contrast to $\sigma 1$ isoforms. The total level of $\gamma$-adaptin RNA appeared comparable between the different tissues. But interestingly, the signal for $\gamma 2$ was much stronger than that for $\gamma 1$ in skeletal muscle RNA, which may indicate a closer relationship of $\sigma 1 \mathrm{~B}$ and $\gamma 2$ in this tissue. 


\section{Results}

\subsubsection{Alternative splicing of $\sigma 1 \mathrm{~B}$}

Intriguingly, entries of $\sigma 1 \mathrm{~B}$ in the protein database as well as the cDNA cloned from rat in our lab showed some ambiguity at the C-terminus. Our rat cDNA and some of the database sequences contained an insertion of three amino acids ("DAK") at position 143, which was missing in other sequences. In addition, two different cDNA fragments of $500 \mathrm{bp}$ and $600 \mathrm{bp}$ were amplified by $\sigma 1 \mathrm{~B}-\mathrm{PCR}$ (see fig. 3.3).

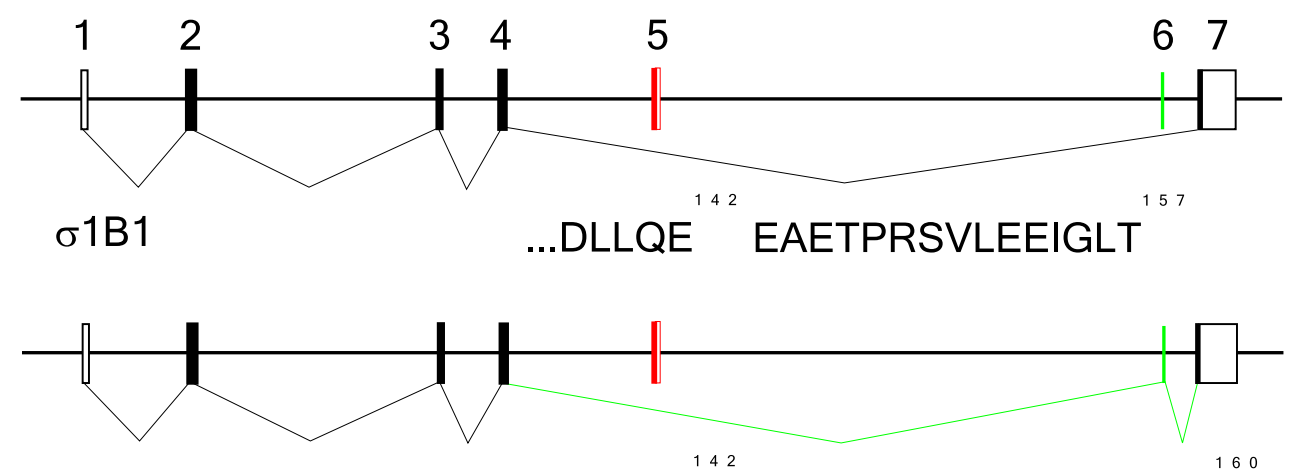

б1B2 ...DLLQE DAKEAETPRSVLEEIGLT

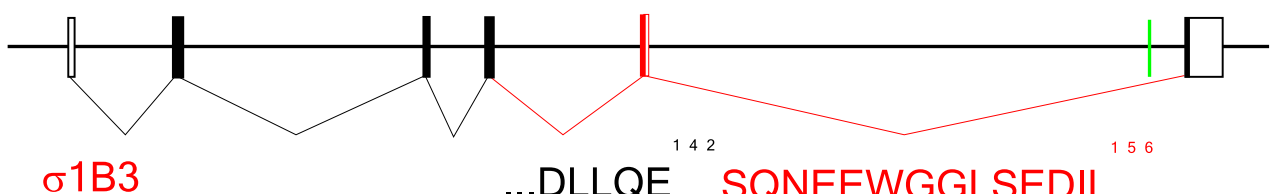

$\underline{1 \mathrm{~kb}}$

Figure 3.7: Alternative splicing at the $\sigma 1 \mathrm{~B}$ gene locus. Empty and filled boxes indicate non-coding and coding exons, respectively. The C-terminal amino acid sequence of each variant is shown below the exon structure. All the three $\sigma 1 \mathrm{~B}$ splice forms are identical up to the end of exon 4, corresponding to the amino acid sequence "DLLQE". To generate $\sigma 1 \mathrm{~B} 1$, exon 4 is directly spliced to exon 7 , which contains the C-terminal 15 residues. The alternative exon 6 (green) is included for $\sigma 1 \mathrm{~B} 2$, corresponding to a 3 aa-insertion, whereas alternative splicing of exon 4 to exon 5 (red) replaces the entire C-terminus in $\sigma 1 \mathrm{~B} 3$.

By sequencing of the $500 \mathrm{bp}-\mathrm{PCR}$ fragment, we found that it contained two forms of $\sigma 1 \mathrm{~B}$. One of them was identical to the commonly approved sequence consisting of exons 1-4 and 7 (fig. 3.7). This form was the major $500 \mathrm{bp}$-amplificate from e.g., fibroblasts, liver, spleen, muscle and fat, and we refer to it as $\sigma 1 \mathrm{~B} 1$. The second form of $\sigma 1 \mathrm{~B}$ was the dominant 500 bp-product from brain cDNA and contains an additional exon after exon 4, which encodes for the "DAK"-insertion at amino acid position 143. In our scheme (fig. 3.7), this splice variant is depicted as $\sigma 1 \mathrm{~B} 2$, 
comprising exons 1-4, 6 and 7 .

Similarly, the inclusion of another alternative exon, exon 5, in the mRNA gives rise to the 600 bp-product, equivalent to the exon sequence 1-4, 5, 7 (fig. 3.7). Because exon 5 contains an in-frame stop codon, the C-terminus of the resulting protein, named $\sigma 1 \mathrm{~B} 3$, is completely different from $\sigma 1 \mathrm{~B} 1$ and -2 .

We conclude from these data that three different mRNA variants are generated from the $\sigma 1 \mathrm{~B}$ gene by alternative splicing and refer to the resulting proteins as $\sigma 1 \mathrm{~B} 1,-2$ and -3 .

In order to detect the expression of the splice variants, we tried to amplify each one using a universal $\sigma 1 \mathrm{~B}$ forward primer and a specific reverse primer. The primer for specific annealing with the $\sigma 1 \mathrm{~B} 1$ form was chosen spanning the transition of exon 4 to 7 with both exons contributing one half each. For $\sigma 1 \mathrm{~B} 2$, the primer comprised 7 nucleotides from exon 7 , the complete 9 bp-exon 6 as well as 6 nucleotides from exon 4. A stretch of nucleotides from the $5^{\prime}$ end of exon 5 was selected to amplify $\sigma 1 \mathrm{~B} 3$.

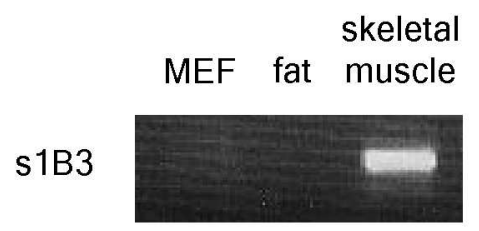

Figure 3.8: Detection of the splice variant $\sigma 1 \mathrm{~B} 3$ by PCR.

Only the reverse primer for $\sigma 1 \mathrm{~B} 3$ in combination with a forward primer from exon 2 amplified a specific PCR product directly from cDNA template. Among the tissues examined, this product was obtained from skeletal muscle (fig. 3.8), testis and heart. We then sought to detect the splice variants of $\sigma 1 \mathrm{~B}$ directly on northern blot. Hybridisations using the specific oligonucleotides as probes for each variant did not result in a detectable signal. In contrast, a PstI-BsaAI restriction fragment comprising the 95 bp of exon 5 and 20 bp from exon 7 (fig. 3.7) revealed to be suitable as a probe for $\sigma 1 \mathrm{~B} 3$ (fig. 3.9).

$\sigma 1 \mathrm{~B} 3$ was detected mainly in skeletal muscle, and at a lower level in brain, lung, adipose tissue and heart. Since the expression of $\sigma 1 \mathrm{~B}$ and $\sigma 1 \mathrm{~B} 3$ does not show the same profile - for example, the signal for $\sigma 1 \mathrm{~B}$ is strongest in brain and lung, whereas $\sigma 1 \mathrm{~B} 3$ signal peaks in skeletal muscle -, alternative splicing is clearly regulated in a tissue-specific way. 


\section{Results}
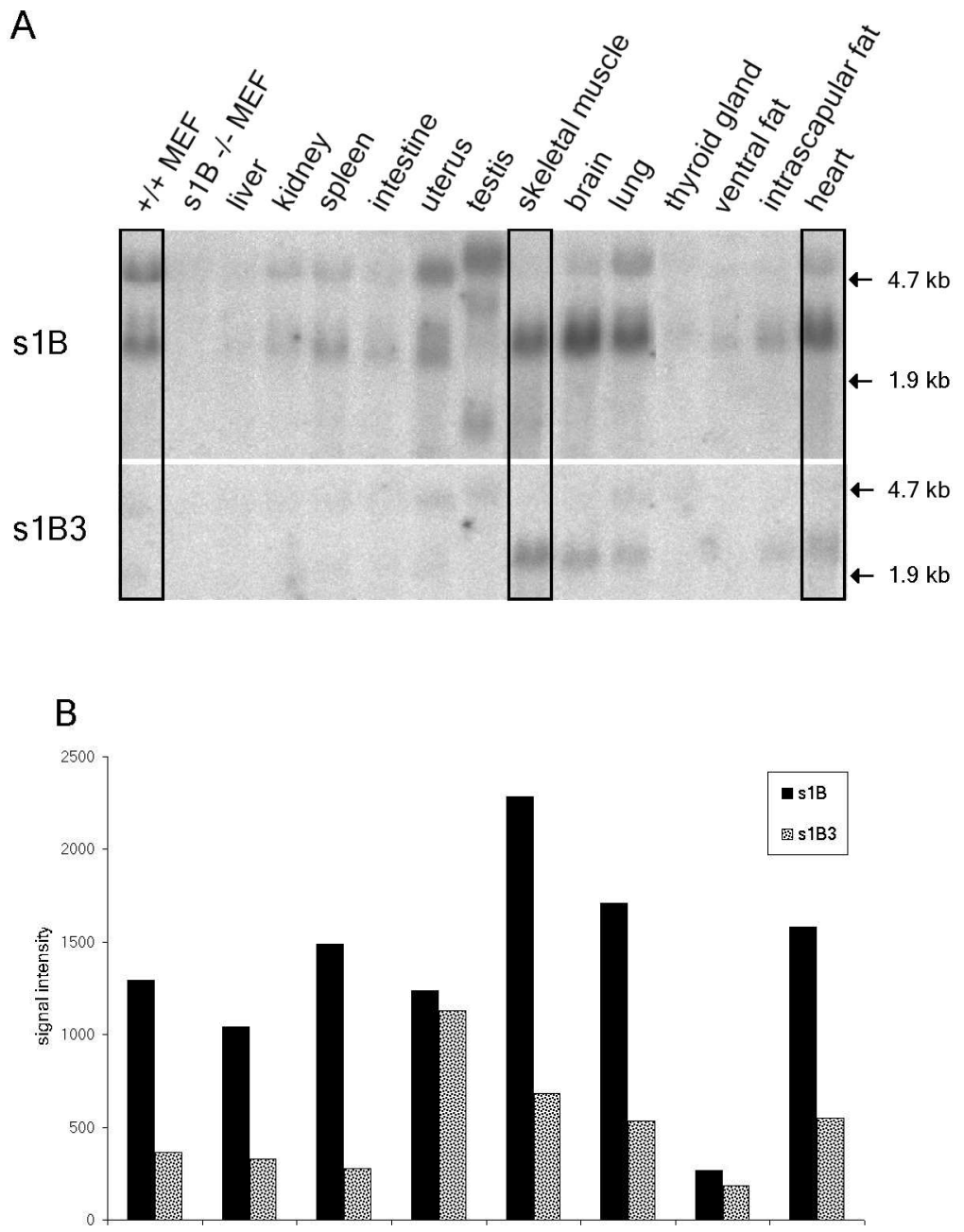

C

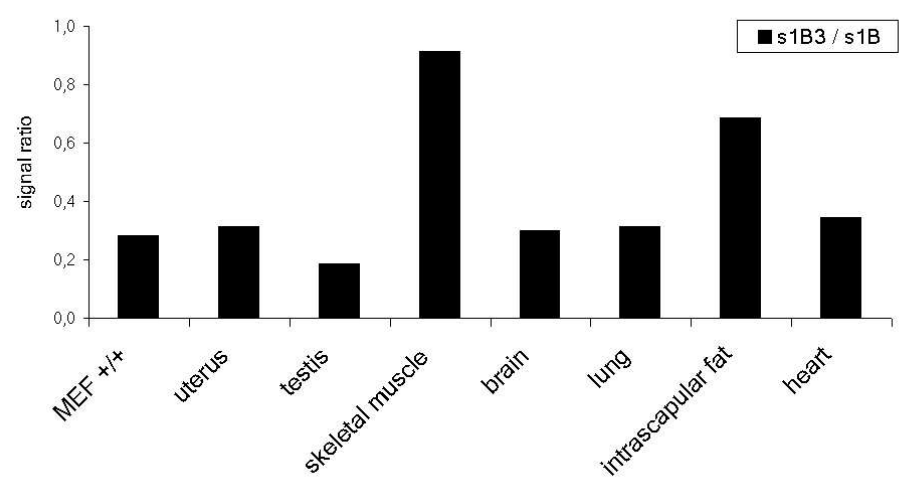

Figure 3.9: Northern blot hybridisation with the $\sigma 1 \mathrm{~B} 3$-specific exon compared to the universal $\sigma 1 \mathrm{~B}$ probe. (A) $10 \mu \mathrm{g}$ of RNA were loaded except for fat as indicated in fig. 3.6. (B) Signal intensities for $\sigma 1 \mathrm{~B}$ or $\sigma 1 \mathrm{~B} 3$ after background substraction. (C) Ratio of $\sigma 1 \mathrm{~B} 3: \sigma 1 \mathrm{~B}$ intensities. Column labels for both diagrams (B and $\mathrm{C}$ ) are shown in $\mathrm{C}$. 


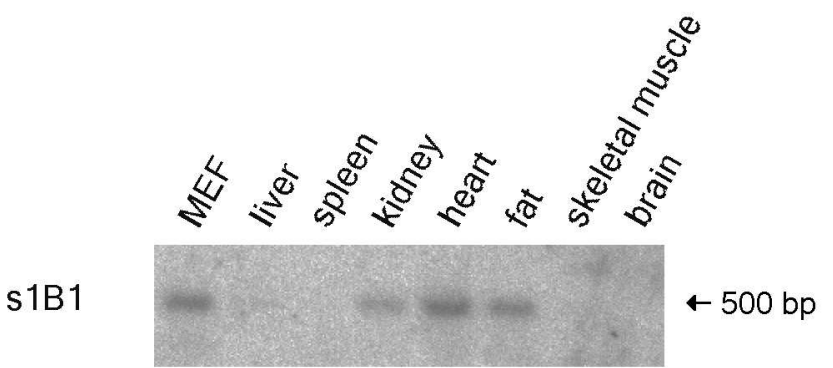

Figure 3.10: Hybridisation of $\sigma 1 \mathrm{~B}$ PCR products with a specific oligonucleotide for $\sigma \mathbf{1 B 1}$. Each lane contained $20 \mu \mathrm{l}$ of PCR sample.

Since $\sigma 1 \mathrm{~B} 1$ and $\sigma 1 \mathrm{~B} 2$ could not be specifically amplified even by nested PCR, we decided to amplify all forms of $\sigma 1 \mathrm{~B}$ by universal PCR (fig. 3.3), to blot the PCR samples onto a nylon membrane and to hybridise it with the specific oligonucleotide primers.

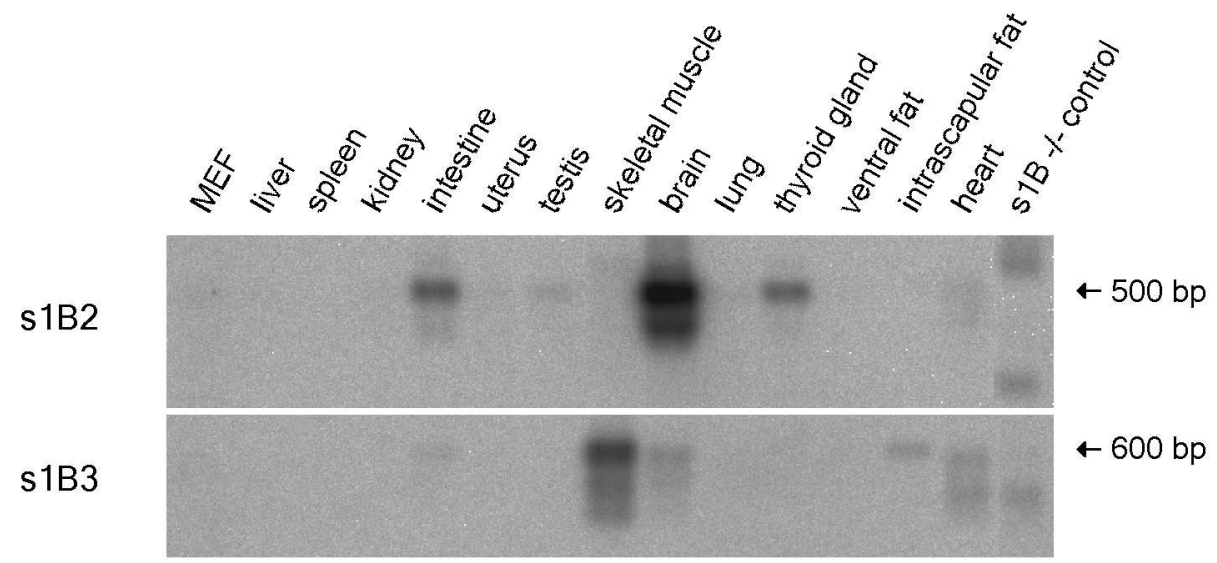

Figure 3.11: Hybridisation of $\sigma 1 \mathrm{~B}$ PCR products with specific oligonucleotides for $\sigma \mathbf{1 B 2}$ and -3. $20 \mu \mathrm{l}$ of PCR samples were loaded on each lane. The $\sigma 1 \mathrm{~B}-/$ - control was chosen from brain for $\sigma 1 \mathrm{~B} 2$ (upper panel, last lane) or from skeletal muscle for $\sigma 1 \mathrm{~B} 3$ (lower panel, last lane).

By this approach, $\sigma 1 \mathrm{~B} 1$ was detected in fibroblasts, in kidney, heart and fat (fig. 3.10). The $\sigma 1 \mathrm{~B} 1$-specific oligonucleotide produced a high background labelling on $\sigma 1 \mathrm{~B}$-deficient samples (not shown) and the blot had to be repeatedly washed at increasing temperature to obtain a specific staining. Some samples from which $\sigma 1 \mathrm{~B} 1$ had been directly sequenced, such as liver and spleen, were not significantly labelled, indicating limited sensitivity of the detection.

In contrast to the $\sigma 1 \mathrm{~B} 1$-oligonucleotide, the primers for detection of $\sigma 1 \mathrm{~B} 2$ and $\sigma 1 \mathrm{~B} 3$ showed almost no unspecific staining (fig. 3.11). The $\sigma 1 \mathrm{~B} 2$-oligonucleotide labelled 


\section{Results}

the PCR samples from intestine, brain and thyroid gland only, whereas skeletal muscle, brain, intrascapular fat and heart seemed to contain $\sigma 1 \mathrm{~B} 3$.

In contrast to $\sigma 1 \mathrm{~A},-\mathrm{B}$ and $-\mathrm{C}$, which seem to be co-expressed in most tissues, the alternative splice events that generate $\sigma 1 \mathrm{~B} 2$ or $\sigma 1 \mathrm{~B} 3$ only take place in specific tissues. 


\subsection{Generation of antisera against $\sigma 1$-adaptins and $\gamma$ 2-adaptin}

As there were no antibodies available which could detect specifically $\sigma 1 \mathrm{~A}$ or $\sigma 1 \mathrm{~B}$, we wanted to generate antisera against these two proteins. In addition to the high amino acid identity between them, both possess only moderate antigen qualities, because their surface contains many hydrophobic areas which are normally buried in the AP-1 complex. Nevertheless, we used the full-length $\sigma 1 \mathrm{~A}$ and $\sigma 1 \mathrm{~B}$ fused to glutathione-S-transferase (GST) as antigens in the first immunisation approach.

We further aimed to generate an antiserum against $\gamma 2$-adaptin to include this isoform in our analyses. The hinge and ear domains of this protein, which extend as soluble domains from the core fold and which show high antigenicity, were fused to GST as an antigen for immunisation.

To induce a specific immune response against epitopes that differ between $\sigma 1 \mathrm{~A}$ and $\sigma 1 \mathrm{~B}$, rabbits were injected with peptides from the N-terminal region of $\sigma 1 \mathrm{~A}$ and $\sigma 1 \mathrm{~B}$ in the second approach. The C-terminal peptide of $\sigma 1 \mathrm{~B} 3$ was chosen as an additional antigen in order to study the unique properties of this $\sigma 1 \mathrm{~B}$ splice variant.

\subsubsection{GST-fusion proteins as antigen}

$\sigma 1 \mathrm{~A}$ and $\sigma 1 \mathrm{~B} \mathrm{cDNAs}$ were amplified from mouse or rat cDNA preparations. The BamHI restriction sites introduced by PCR were used for cloning of both cDNAs into the vector pGEX-2T to express the proteins with their N-termini attached to glutathione-S-transferase (GST) via a linker of 10-16 aa. The GST-tag served for purification of the fusion proteins from E.coli extracts by binding to glutathione (GSH)-coupled sepharose. An overview of the purification procedure is shown in fig. 3.12 .

From the molecular weight of $\sigma 1 \mathrm{~A}$ and $\sigma 1 \mathrm{~B}$, which is $18 \mathrm{kDa}$, a fusion protein to the $26 \mathrm{kDa}$ GST-domain plus linker sequence will measure about $45 \mathrm{kDa}$, seen as prominent band on the Coomassie gel. Most of recombinant $\sigma 1$ was not solubilised in the presence of $1 \%$ Triton X-100 (lane 2 and 8 of fig. 3.12) indicating the formation of inclusion bodies. These are large protein aggregates often produced by artificial overexpression, in particular, if the protein is normally part of a complex and contains hydrophobic surface areas, as in the case of adaptins. Induction of the bacterial expression at restrictive growth conditions did not decrease the insoluble 


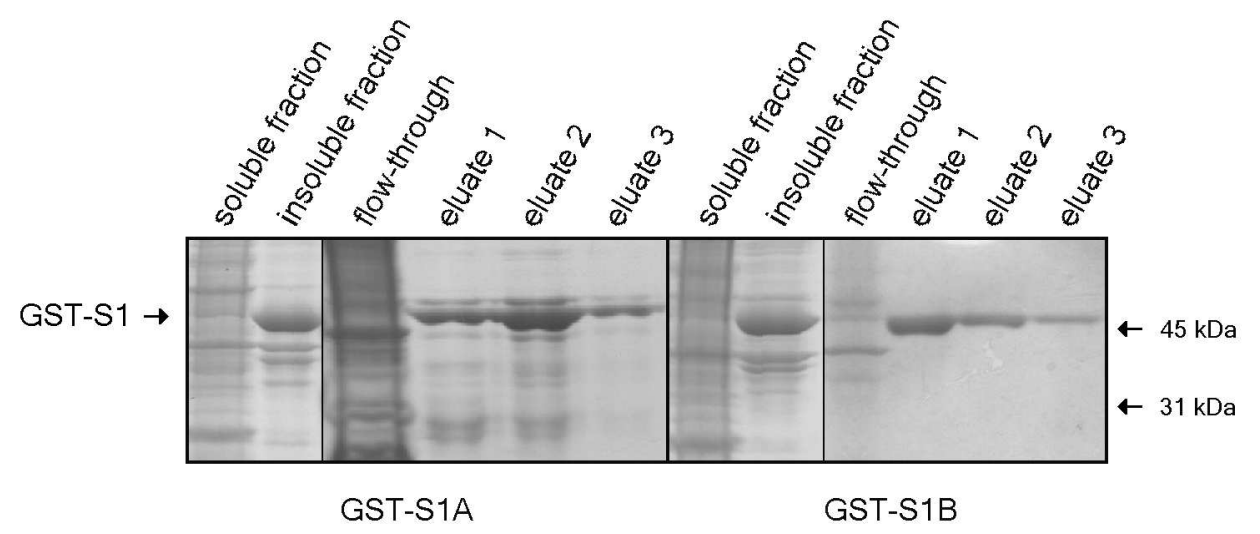

Figure 3.12: Overview of GST- $\sigma$ 1A and GST- $\sigma$ 1B purification. $20 \mu$ l aliquots of each fraction were loaded on a $10 \%$ SDS-PAGE and stained with Coomassie.

fraction of $\sigma 1$. GST- $\sigma 1 \mathrm{~A}$ and $-\sigma 1 \mathrm{~B}$ from the soluble fraction were bound to GSHsepharose and eluted with excess GSH. The content of full-length fusion protein was $70-80 \%$ in the eluates shown and generally in the range of $50-80 \%$ in all the eluates used for immunisation (2.2.3.8).

The rabbit sera were regularly tested against GST, GST-fusion proteins and fibroblast cell extracts (2.2.3.3) by western blot. After the 5. boost, both sera at a 1:250 dilution showed some reactivity with a protein at about $18 \mathrm{kDa}$ in cell extracts (fig. 3.13). The rabbits were sacrificed to collect their blood after the 6 . booster injection.

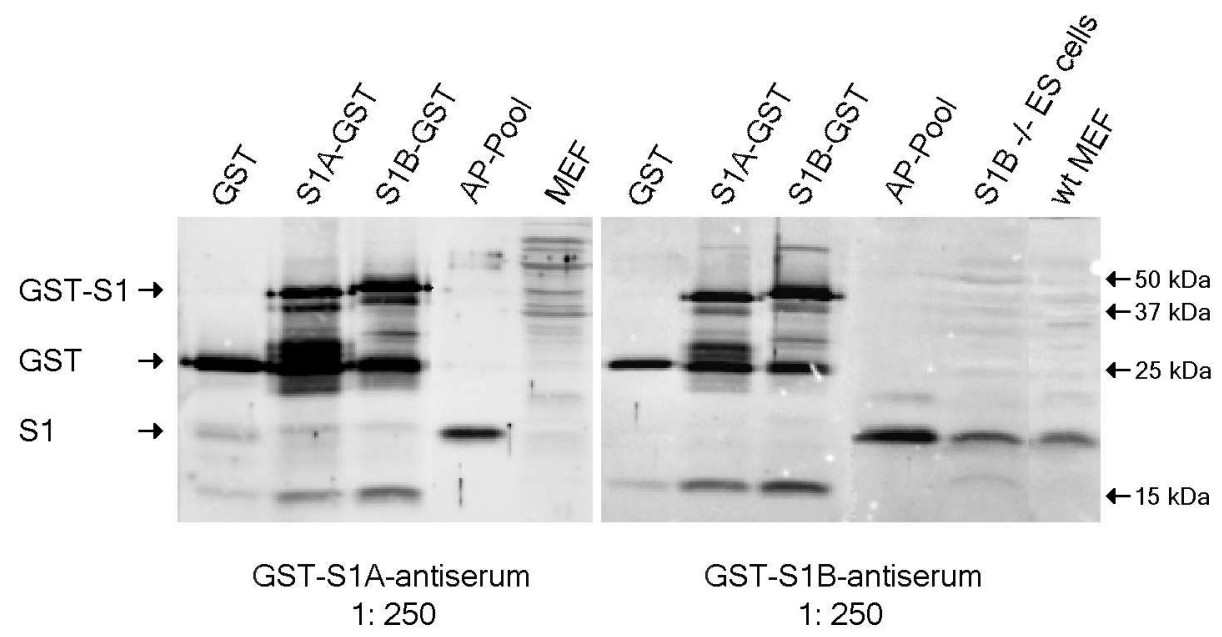

Figure 3.13: Test of GST-antisera in western blot. $25 \mathrm{ng}$ of GST-proteins, $2 \mu \mathrm{g}$ of purified AP-Pool and $100 \mu \mathrm{g}$ of cell extracts were loaded onto a $15 \%$ SDS-PAGE.

Both GST- $\sigma 1 \mathrm{~A}$ and GST- $\sigma 1 \mathrm{~B}$ antisera recognised GST as well as the GST-fusion proteins. In a gelfiltration fraction enriched for adaptor complexes (2.2.3.4), the 
antisera reacted with a distinct band at about $18 \mathrm{kDa}$. Only the serum against GST- $\sigma 1 \mathrm{~B}$ was able to recognise this band in a wt total cell extract as well as in an extract from $\sigma 1 \mathrm{~B}-/-$ ES cells. Hence, the serum crossreacts with endogenous $\sigma 1 \mathrm{~A}$. Since a third $\sigma 1$-adaptin was identified during the course of this study, we wanted to know whether the GST- $\sigma 1 \mathrm{~B}$ antiserum would interact with this protein as well.

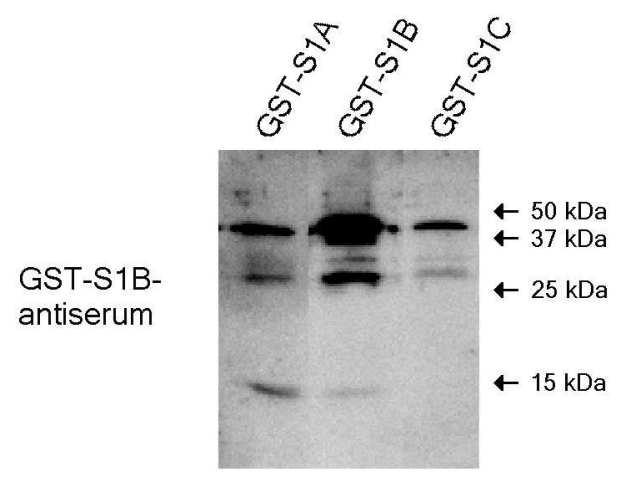

Figure 3.14: Crossreaction of GST- $\sigma 1 \mathrm{~B}$ antiserum with GST- $\sigma$ 1A and GST$\sigma 1 \mathrm{C}$.

GST- $\sigma 1 \mathrm{C}$ is indeed recognised by the GST- $\sigma 1 \mathrm{~B}$ antiserum on western blot (fig. 3.14). However, the crossreaction could either be due to the high homology between the $\sigma 1$ proteins or due to the GST-tag present in the preparations.

Whereas the GST- $\sigma 1 \mathrm{~B}$ antiserum was suitable for western blot, it could not be used for immunofluorescence labelling of fibroblast cells. This could either indicate that the epitopes recognised are not accessible in the AP-1 complex, or that the epitopes have to be unfolded for binding. Because the application for both immunofluorescence and immunoprecipitation depends on recognition of native epitopes, the GST- $\sigma 1 \mathrm{~B}$ antiserum was not tested for immunoprecipitation.

Since we wanted to study the relation of $\sigma 1$-adaptins to the large subunits $\gamma 1$ and $\gamma 2$, but antibodies were only available for $\gamma 1$, we also generated a GST-fusion for $\gamma 2$. A cDNA fragment encoding residues 577-791 of $\gamma 2$, comprising the hinge and ear domains (g2HE), was amplified from mouse cDNA. After cloning into pCR2.1 vector, the insert was cleaved at the adjacent EcoRI sites and ligated into pGEX-2T. Overexpression of the resulting GST-fusion protein GST-g2HE in E. coli revealed that it is mainly found in the soluble fraction. Eluates from GST-purification were of considerably higher purity than those obtained for GST- $\sigma 1$ (not shown).

The antiserum obtained after the 3 . boost showed no affinity to GST alone (fig. 3.15 ), but recognised purified GST-g2HE and a prominent band of about $88 \mathrm{kDa}$ 


\section{Results}

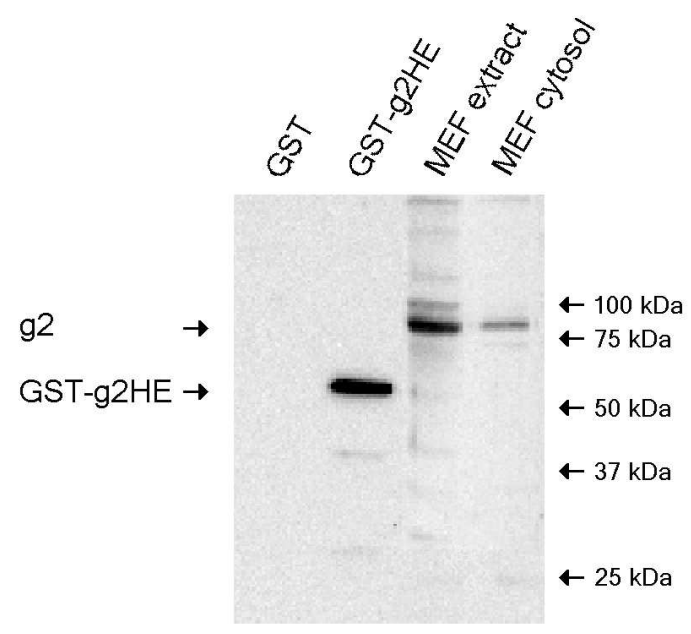

Figure 3.15: Test of $\gamma \mathbf{2}$-antiserum in western blot. (25 ng of GST or GST$\mathrm{g} 2 \mathrm{HE}, 100 \mu \mathrm{g}$ of MEF extract, $18 \mu \mathrm{g}$ of MEF cytosol).

in cell extracts, which is the size of full-length $\gamma 2$. In addition, a fainter signal developed at about $100 \mathrm{kDa}$, which probably corresponds to $\gamma 1$-adaptin.

The $\gamma 2$-antiserum was purified by ion exchange spin columns to enrich antibodies with respect to other serum constituents and the Ig-enriched fraction was subsequently used for western blot and immunofluorescence (see fig. 3.26 and 3.29). It was further tested if the antiserum could immunoprecipitate $\gamma 2$ from cell extracts, but this was not the case.

\subsubsection{Peptides as antigen}

Since the antisera against GST-fusion proteins detected $\sigma 1$ only in enriched fractions or in a non-discriminating manner, peptides from the most variable region between $\sigma 1 \mathrm{~A}$ and $\sigma 1 \mathrm{~B}$ (S1A21-38 and S1B20-37, see fig. 3.1) and from the C-terminus of $\sigma 1 \mathrm{~B} 3$ were used as antigens in a second attempt.

Peptides were synthesised including a terminal cysteine residue for crosslinking to the carrier protein hemocyanin after purification by C18 cartridge and mass spectrometry analysis (2.2.3.6). It was chosen to attach the S1A/B-specific peptides via the C-terminus, because this end is orientated towards the center of AP-1, whereas the $\sigma 1 \mathrm{~B} 3$-peptide was fixed via an N-terminal cysteine, as it corresponds to the $\mathrm{C}$ terminus of the protein. After coupling to hemocyanin (2.2.3.7), $300 \mu \mathrm{g}$ and $150 \mu \mathrm{g}$ peptide aliquots were injected into rabbits for primary immunisation and booster injections, respectively. 


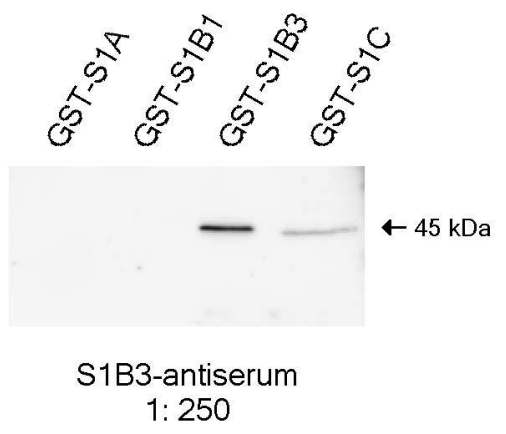

Figure 3.16: Recognition of GST- $\sigma$ 1B fusion proteins by $\sigma 1 \mathrm{~B} 3$ peptideantiserum. $125 \mathrm{ng}$ of each GST-protein were loaded.

The sera were collected about 14 days after immunisation and were tested by western blot against postnuclear supernatants and GST-proteins. All the antisera showed numerous crossreactions in fibroblast extracts and did not detect a distinct band at the expected size of about $18 \mathrm{kDa}$. The antisera against S1A21-38 and S1B20-37 did not even recognise the corresponding GST-proteins (data not shown). In contrast, the serum against the $\sigma 1 \mathrm{~B} 3 \mathrm{C}$-terminal peptide reacted with GST- $\sigma 1 \mathrm{C}$ in addition to GST- $\sigma 1 \mathrm{~B} 3$, whereas it did not recognise $\sigma 1 \mathrm{~A}$ or $\sigma 1 \mathrm{~B} 1$ (fig. 3.16). This crossreaction is probably due to a short stretch of amino acid residues which are similar between the $\sigma 1 \mathrm{~B} 3-$ and the $\sigma 1 \mathrm{C}$-C-terminus (fig. 3.17).

\section{б1B3 . . QESQNEEWGGLSEDIL. $\sigma 1 C \quad \ldots$. QETM-EEYMNKPTF.}

Figure 3.17: C-terminal amino acid sequence of $\sigma 1 \mathrm{~B} 3$ and $\sigma 1 \mathrm{C}$.

Since the peptide antisera were obtained only recently and gave poor results in western blot experiments, they were not used for further studies. 


\section{$3.3 \sigma 1 \mathrm{~B}$ knock-out mouse model}

Chromosomal DNA can be specifically modified by homologous recombination with exogenous DNA (Thomas \& Capecchi, 1987). At least 1-1.5 kb of genomic sequence are required at either side of the mutant region to enable correct targeting in addition to random integration of the construct into the genome. To disrupt the open reading frame for $\sigma 1 \mathrm{~B}$ (gene locus Ap1s2) on mouse chromosome X, a replacement vector was constructed by insertion of a neomycin resistance cassette into exon 3 .

\subsubsection{Cloning of the targeting construct and ES cell culture}

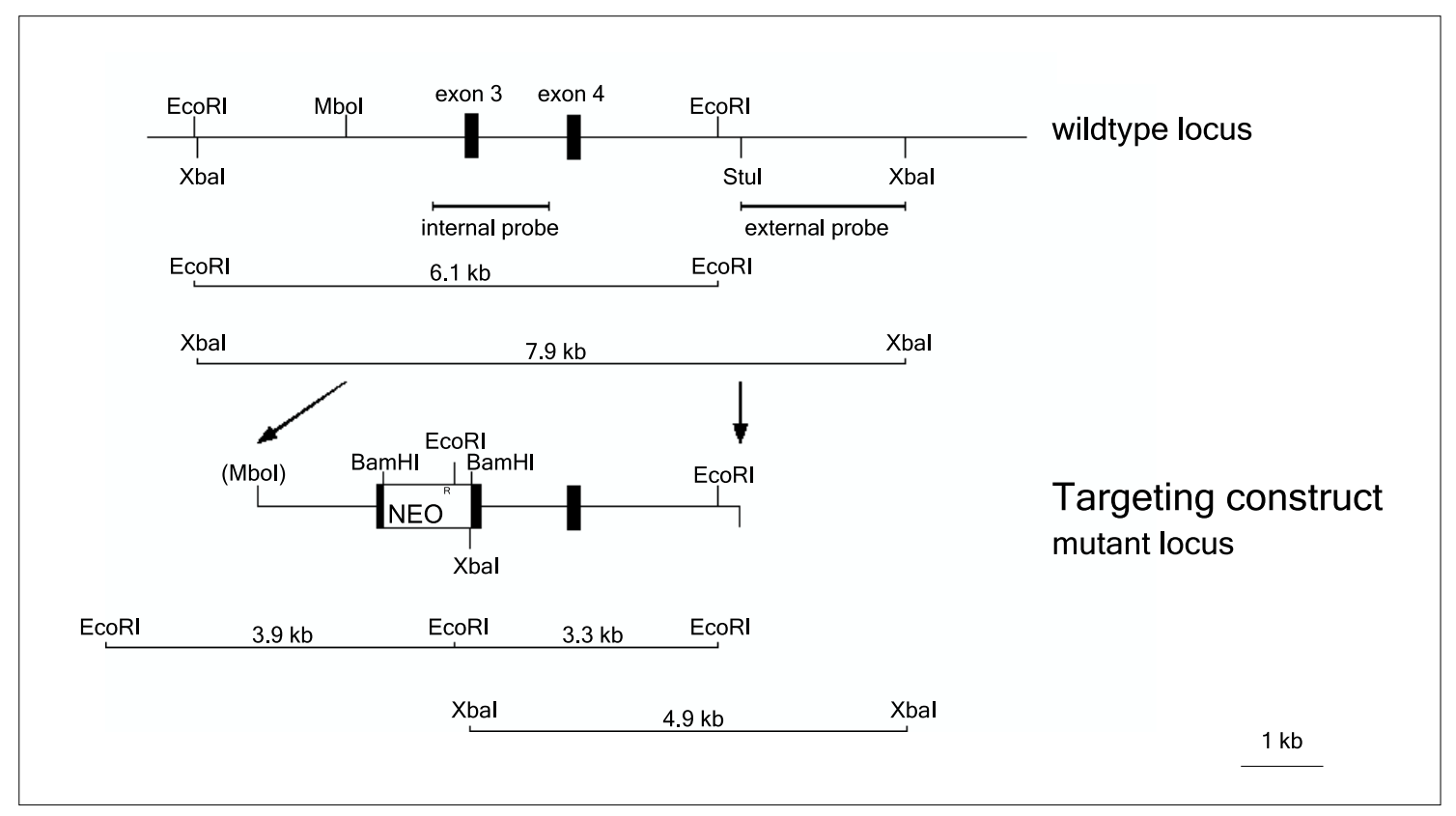

Figure 3.18: Knock-out strategy for $\sigma \mathbf{1 B}$. A genomic DNA fragment containing exon 3 and 4 of the $\sigma 1 \mathrm{~B}$ locus was modified by insertion of a neomycin resistance cassette into exon 3 . If the mutant locus, which replaced the targeting construct against the wt sequence, was digested with EcoRI or XbaI, the resulting fragments differed in size from the wt fragments. This change could be detected by southern blot hybridisation with the internal and external probes 3.20.

To clone genomic DNA fragments from the $\sigma 1 \mathrm{~B}$ locus (Ap1s2), a phage cosmid library of the mouse genome had been screened with $\sigma 1 \mathrm{~B}$ cDNA. A cosmid clone containing exons 3 and 4 on a $7.2 \mathrm{~kb}$ MboI-fragment had been identified, obtained from the RZPD center and cloned into the vector pBKS. By PCR mutagenesis, a BamHI restriction site had been introduced into exon 3 . About $2.7 \mathrm{~kb}$ of the fragment were removed from the 3 '-end by restriction digestion with StuI (genomic site) 
and ClaI (vector site). The entire genomic fragment cloned was mapped by restriction digestion with various enzymes (not shown) and the $5^{\prime}$-region was sequenced to confirm correct mutagenesis. The cDNA providing neomycin resistance was prepared by BamHI digestion of pBSK(Neo2xKpnI) and inserted into the BamHI site of the construct in opposite orientation to the $\sigma 1 \mathrm{~B}$-reading frame. Finally, the targeting construct for homologous recombination with the mouse genomic DNA measured about $5.5 \mathrm{~kb}$, with about $1.5 \mathrm{~kb}$ genomic sequence upstream and about $2.7 \mathrm{~kb}$ downstream of the neomycin resistance cassette (fig. 3.18).

The targeting vector was linearised at the SacII restriction site of the vector adjacent to the $5^{\prime}$-end of the construct and introduced into E14-1 ES cells by electroporation. E14-1 are derived from the inbred mouse strain 129/Ola (Hooper et al. 1987), the same source strain as had been used to generate the cosmid DNA library. 111 clones were selected for resistance to neomycin. Frozen aliquots were stored in liquid nitrogen and the cells were cultured in the absence of feeder fibroblasts to isolate genomic DNA. The clones were analysed by genomic PCR and southern blot hybridisation to verify whether the gene locus was rearranged in the desired way. Since the ES cells were established from a male blastocyst, they only contain one copy of the Ap1s2 gene.

If the construct integrated at the correct site, the PCR with a forward primer upstream of the MboI site and a reverse primer in the neomycin cassette (fig. 3.18) generates a product of about $1.5 \mathrm{~kb}$, which was indeed seen with 12 out of 111 clones. Alternatively, the wt gene locus was detected by PCR with the same forward primer and a reverse primer downstream of exon 3 (fig. 3.19).

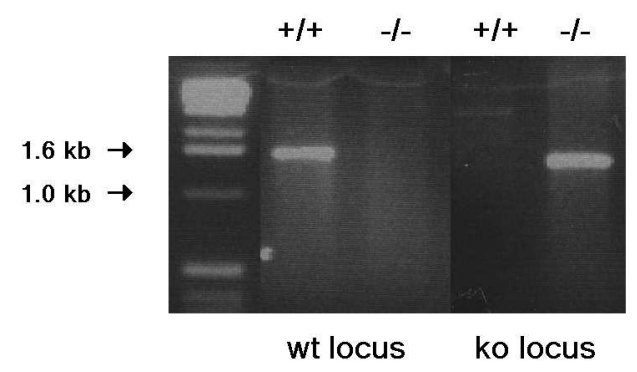

Figure 3.19: Genomic PCR of the Ap1s2 locus. PCR amplification of genomic DNA using a forward primer upstream of the targeting construct sequence together with a reverse primer downstream of exon 3 produced a $1.6 \mathrm{~kb}$ fragment from the wt locus in contrast to the ko locus. Combination with a reverse primer from the neomycin cassette amplified a $1.5 \mathrm{~kb}$ fragment from the ko locus only. 


\section{Results}

The positive clones were further tested by southern blot hybridisation as indicated in fig. 3.18. A $1.4 \mathrm{~kb}$ BglII-fragment from the targeting construct served as an internal probe to detect the wildtype locus as well as exogenous DNA integrated at any location in the genomic DNA. To confirm the rearrangement of the Ap1s2 locus, a $1.5 \mathrm{~kb} \mathrm{NcoI/PstI-fragment} \mathrm{from} \mathrm{the} \mathrm{genomic} \mathrm{region} \mathrm{downstream} \mathrm{of} \mathrm{the} \mathrm{construct}$ was used as external probe (fig. 3.20).

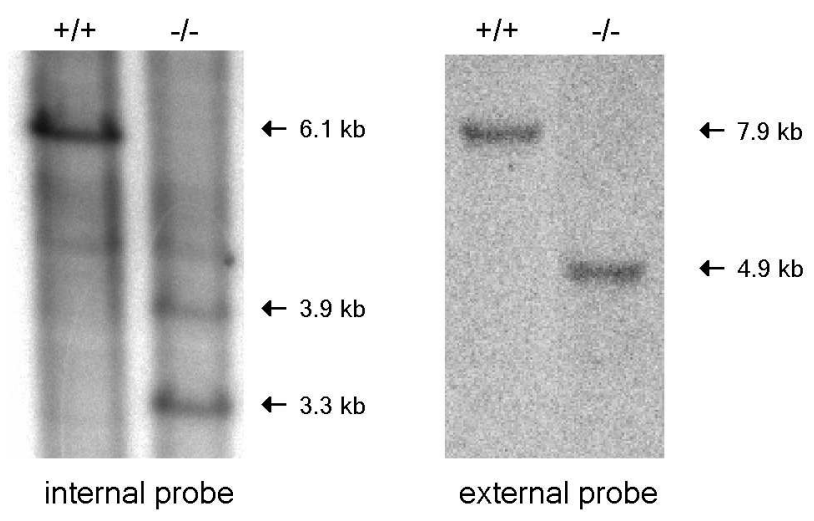

Figure 3.20: Genotyping of ES cell clones. Genomic DNA containing the mutant $\sigma 1 \mathrm{~B}$ locus showed a different hybridisation pattern than wt DNA by Southern blot. The internal probe was applied to EcoRI-digested DNA (left) and the external probe to XbaI-digested DNA (right).

After digestion of genomic DNA with EcoRI, the internal probe detected the wildtype locus as $6.1 \mathrm{~kb}$ fragment, whereas the mutant locus appeared as two fragments of $3.9 \mathrm{~kb}$ and $3.3 \mathrm{~kb}$, because an additional EcoRI site had been introduced with the neomycin resistence cassette. Similarly, the $7.9 \mathrm{~kb}$ XbaI-fragment seen with the external probe from digestion of wt DNA, which contains the entire targeting region, is shortened to a $4.9 \mathrm{~kb}$ fragment from the mutant DNA due to an additional XbaI-site in the neomycin cassette.

As the genomic fragment cloned from the library cosmid did not contain any XbaI site by restriction mapping, the size of the XbaI-fragment detected from the mutant locus by the external probe was initially estimated to 5.5-6 kb (the size of the cloned genomic region downstream of exon 3, see fig. 3.18). Surprisingly, the mutant fragment was shorter, but the targeting seemed to be correct, as the wt fragment had disappeared. At the same time, a preliminary sequence assembly of the mouse genome was published which included an XbaI restriction site at less than $5 \mathrm{~kb}$ downstream of exon 3. To explain this conflict, the genomic fragment from the cosmid was sequenced completely. The cloned fragment was found to align perfectly to the database sequence for about $4.9 \mathrm{~kb}$ downstream of exon 3 , but the stretch 
around the XbaI-site in question was replaced by a sequence identified as E. coli transposon Tn1000 by BLAST search (gi X60200).

The ES cell clone 111 was selected for injection into blastocysts.

\subsubsection{Generation of $\sigma$ 1B-deficient mice}

Recombinant mouse ES cells can integrate into an embryo and develop into all types of cells due to their totipotent state. The ES cells were established from the 129/Ola mouse strain which carries the dominant wt allele for agouti coat colour, whereas the blastocysts derived from the mouse strain C57 BL/6J with a recessive mutant allele at the agouti locus resulting in black coat colour. Therefore, the chimeric animals can be distinguished by their patchy, two-coloured coat. If the transgenic ES cells contributed to the germ cells of a chimeric mouse, agouti-coloured mice carrying the genetic modification in all cells will be born in the next generation. Usually, germline transmission of the male ES cells is only seen in male chimera.

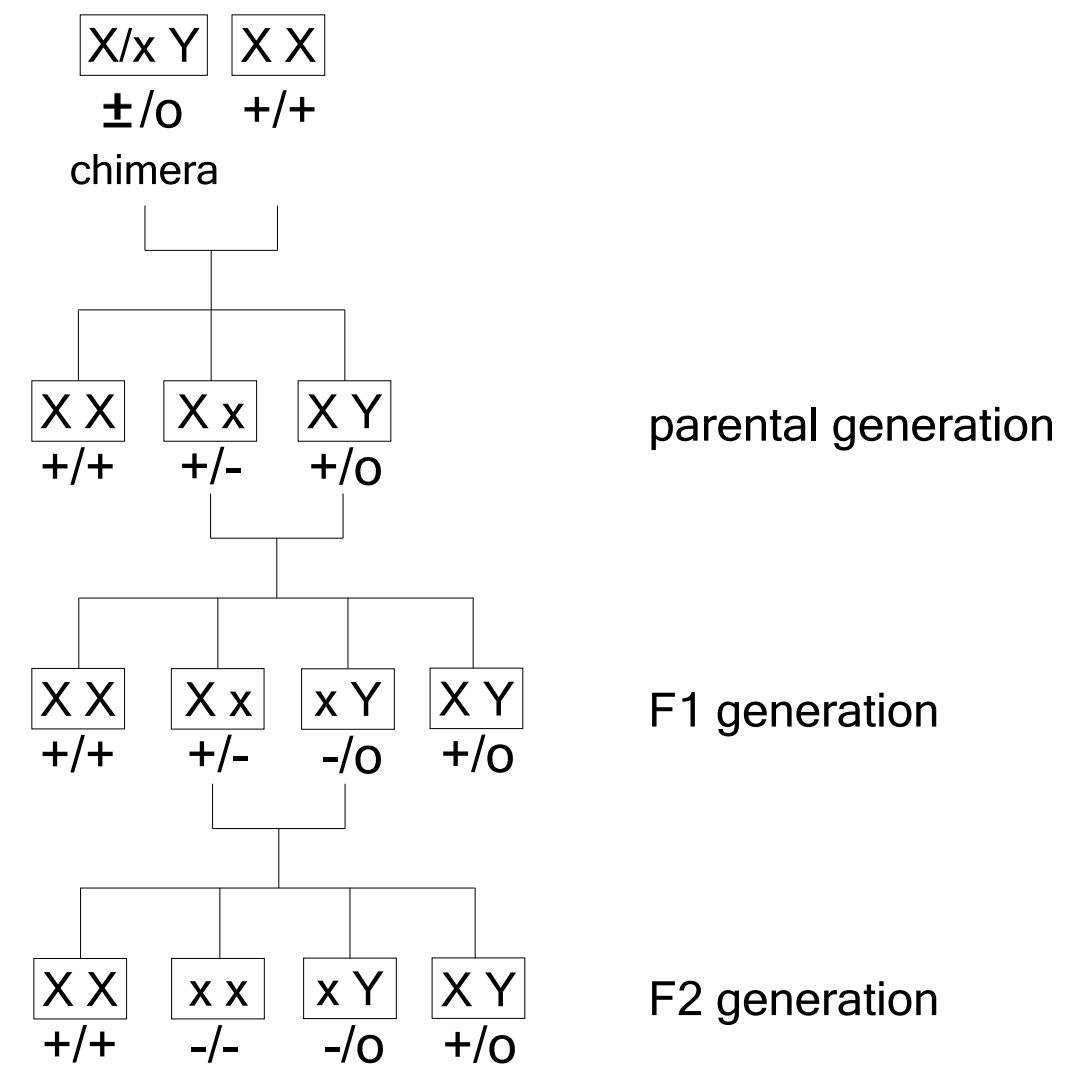

Figure 3.21: Breeding of the S1B111 mouse strain carrying X-chromosomal deficiency of $\sigma \mathbf{1 B}$. The capital $\mathrm{X}$ or $\mathrm{Y}$ letters signify the wildtype sex chromosomes, whereas the small $\mathrm{X}$ stands for the mutant $\mathrm{X}$-chromosome. 


\section{Results}

Manipulation of blastocysts was performed by the microinjection facility at the MPI of experimental medicine, Göttingen. Blastocysts were isolated from 8-16 week old female mice at day 3.5 of pregnancy, injected with ES cells from a single cell suspension of clone S1B111 and transplanted into foster mothers. 15 mice were born by the foster mothers, out of which four were chimeric mice, three males and one female. One of the male chimera contained about $50 \%$ of transgenic cells (as estimated from the coat colour), while their contribution to the other chimera was less. After mating to C57 BL/6J females, half of the offspring mice of the $50 \%$ chimeric male were agouti, $i$. e. transgenic, whereas only black animals were born from the other mating pairs. All the agouti females carried the mutant $\sigma 1 \mathrm{~B}$ allele as evident from the inheritance scheme shown in fig. 3.21.

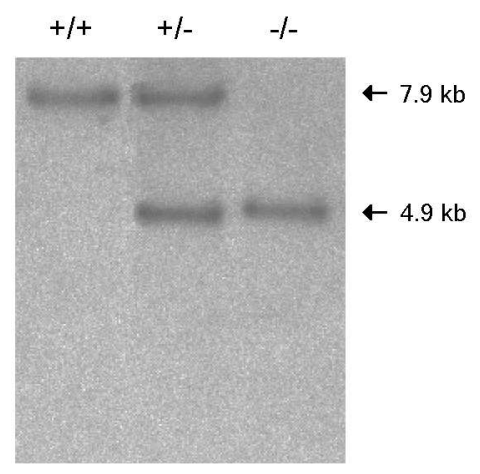

Figure 3.22: Southern blot hybridisation of genomic DNA from S1B11 mice. Genomic DNA was digested with XbaI, separated on an agarose gel and transferred to nylon membrane. The blot was hybridised with the external probe of the Ap1s2 locus (see fig. 3.18).

The heterozygous females were further mated to their wt male littermates and gave birth to $\sigma 1 \mathrm{~B}$-/- male mice in the F1 generation of breeding (fig. 3.21). As the deficient males were viable and fertile, they could be mated to their heterozygous female littermates in order to obtain $\sigma 1 \mathrm{~B}$-/- female mice in the F2 generation. Mice were routinely genotyped at the age of 3-7 weeks by cutting a $0.5-0.7 \mathrm{~cm}$ piece of their tail for isolation of genomic DNA and subsequent PCR (2.2.1.3). A southern blot displaying the hybridisation pattern of wildtype, heterozygous and deficient DNA with the external probe, after digestion with XbaI, is shown in fig. 3.22. The disruption of the $\sigma 1 \mathrm{~B}$ locus was confirmed by the absence of the corresponding RNA transcript (fig. 3.4, 3.34). 
The female $\sigma 1 \mathrm{~B}$-/- mice were viable and fertile as well as the males. Litters with deficient mice were carefully watched and weighed right after birth until adulthood. No apparent phenotype was observed that distinguished the $\sigma 1 \mathrm{~B}-/-$ animals from wt animals.

In addition to the genetic background mixed of 129/Ola : C57 BL/6J = 1:3, the male chimera was mated to a $129 / \mathrm{Sv}$ female to generate an inbred strain carrying the mutant allele on a background composed of 129/Ola : 129/Sv =1:3. As random mutations in a particular genetic background can eventually have a strong influence on the phenotype, different genetic backgrounds are used to ensure that observations and conclusions on transgenic mice are background-independent. As for $\sigma 1 \mathrm{~B}-/$ mice on a 129/(Ola/Sv) background, they also did not apparently differ from their wt littermates.

\begin{tabular}{|c|c|c|c|c|c|c|c|c|}
\hline mating & $\begin{array}{c}\text { litter } \\
\text { number }\end{array}$ & $\begin{array}{c}\text { average } \\
\text { litter size }\end{array}$ & $+/ o$ & $-/ 0$ & $+/+$ & $+/-$ & $-/-$ & $\begin{array}{c}\text { total } \\
\text { animal } \\
\text { number }\end{array}$ \\
\hline \multicolumn{9}{|c|}{$75 \%$ C57 BL/6J } \\
\hline \multirow[t]{2}{*}{$+/-\otimes+/ o$} & 5 & 7.2 & 12 & 13 & 4 & 7 & - & 36 \\
\hline & & & $33 \%$ & $36 \%$ & $11 \%$ & $19 \%$ & & \\
\hline \multirow{2}{*}{$+/-\otimes-/ o$} & 3 & 7 & 7 & 4 & - & 6 & 4 & 21 \\
\hline & & & $33 \%$ & $19 \%$ & & $29 \%$ & $19 \%$ & \\
\hline \multicolumn{9}{|c|}{$75 \% 129 / \mathrm{Sv}$} \\
\hline \multirow[t]{2}{*}{$+/-\otimes+/ o$} & 5 & 6.2 & 4 & 8 & 6 & 13 & - & 31 \\
\hline & & & $13 \%$ & $26 \%$ & $19 \%$ & $42 \%$ & & \\
\hline \multirow[t]{2}{*}{$+/-\otimes-/ o$} & 4 & 5 & 3 & 6 & - & 2 & 9 & 20 \\
\hline & & & $15 \%$ & $30 \%$ & & $10 \%$ & $45 \%$ & \\
\hline summary & & & $24 \%$ & $29 \%$ & $9 \%$ & $26 \%$ & $12 \%$ & 108 \\
\hline
\end{tabular}

Table 3.1: Genotype distribution of S1B111 litters.

Upon mating of a heterozygous female mouse to a wildtype or deficient male, animals of four different genotypes could be born as indicated (fig. 3.21 and table 3.1), which would be predicted to occur at equal numbers. When considering one type of mating in one genetic background, the distribution of genotypes in litters of S1B111 did not exactly conform to mendelian laws. But in the summary of all heterozygous matings, which produced 108 animals in total, the genotypes are almost evenly distributed: $24 \%$ of male mice were wildtype compared to $29 \%$ of $\sigma 1 \mathrm{~B}$ deficient males. Among the female offspring, heterozygous mice accounted for $26 \%$, whereas the fourth genotype, which could be either wildtype female or $\sigma 1 \mathrm{~B}-/$ female depending on the father, contributed $21 \%$. Thus, it can be excluded that 


\section{Results}

deficiency of $\sigma 1 \mathrm{~B}$ has a disadvantageous effect prior to birth. Moreover, the average litter size was in the typical range.

In the first litter of the S1B111 C57 BL/6J F1 generation, an apparent abnormality was observed, which was initially suspected to accompany $\sigma 1 \mathrm{~B}$ deficiency. All the five $\sigma 1 \mathrm{~B}$-/- males became distinguishable from the three wildtype littermates at an age of about six months. Their motoric abilities were severely compromised and they acquired a large hunchback, as shown by X-ray analysis (fig. 3.23). On one hand, the spine of the deficient mice was more strongly bent. On the other hand, the tissue between spine and skin above the scapula, which consists of muscle and intrascapular fat, seemed to be reduced. Control mice developed a hunchback as well, but later and less pronounced, as it is generally observed among ageing animals.

Since this phenotype was not confirmed by subsequent litters, there is no direct connection to the genotype. At most, it could be a synthetic effect of $\sigma 1 \mathrm{~B}$-deficiency together with random mutations.

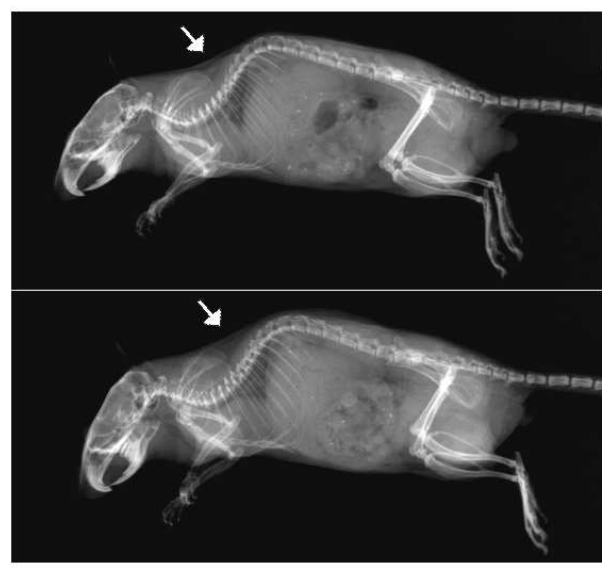

wildtype

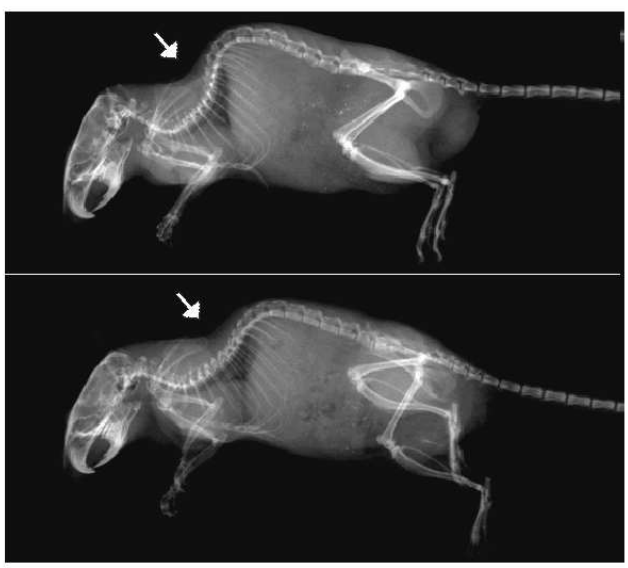

$\sigma 1 \mathrm{~B}-/-$

Figure 3.23: Hunchback phenotype of $\sigma 1 \mathrm{~B}-/-$ mice from one litter. Arrows point out the area of electrontranslucent tissue which differed between wt and $\sigma 1 \mathrm{~B}-/-$ mice.

Only mice from the $75 \%$ C57 BL/6J strain were used for the experiments described in the following sections. 


\subsubsection{Anatomy and histology of $\sigma 1 \mathrm{~B}-/-$ mice}

The dissection of $\sigma 1 \mathrm{~B}-/$ - mice to examine their anatomical integrity did not reveal any abnormalities compared to wt mice. Four mice were subjected to perfusion fixation with $2 \%$ PFA and $2 \%$ glutaraldehyde and sent to the lab of Prof. Renate Lüllmann-Rauch (Department of Anatomy, University of Kiel) for further analysis by light and electron microscopy. Sections were prepared in particular from heart and skeletal muscle, lymphatic tissues, liver, brain and intrascapular fat. No apparent differences were found between $\sigma 1 \mathrm{~B}$-deficient tissues and control tissues. Light microscopical pictures of selected $\sigma 1 \mathrm{~B}$-/- tissues are shown in fig. 3.24.

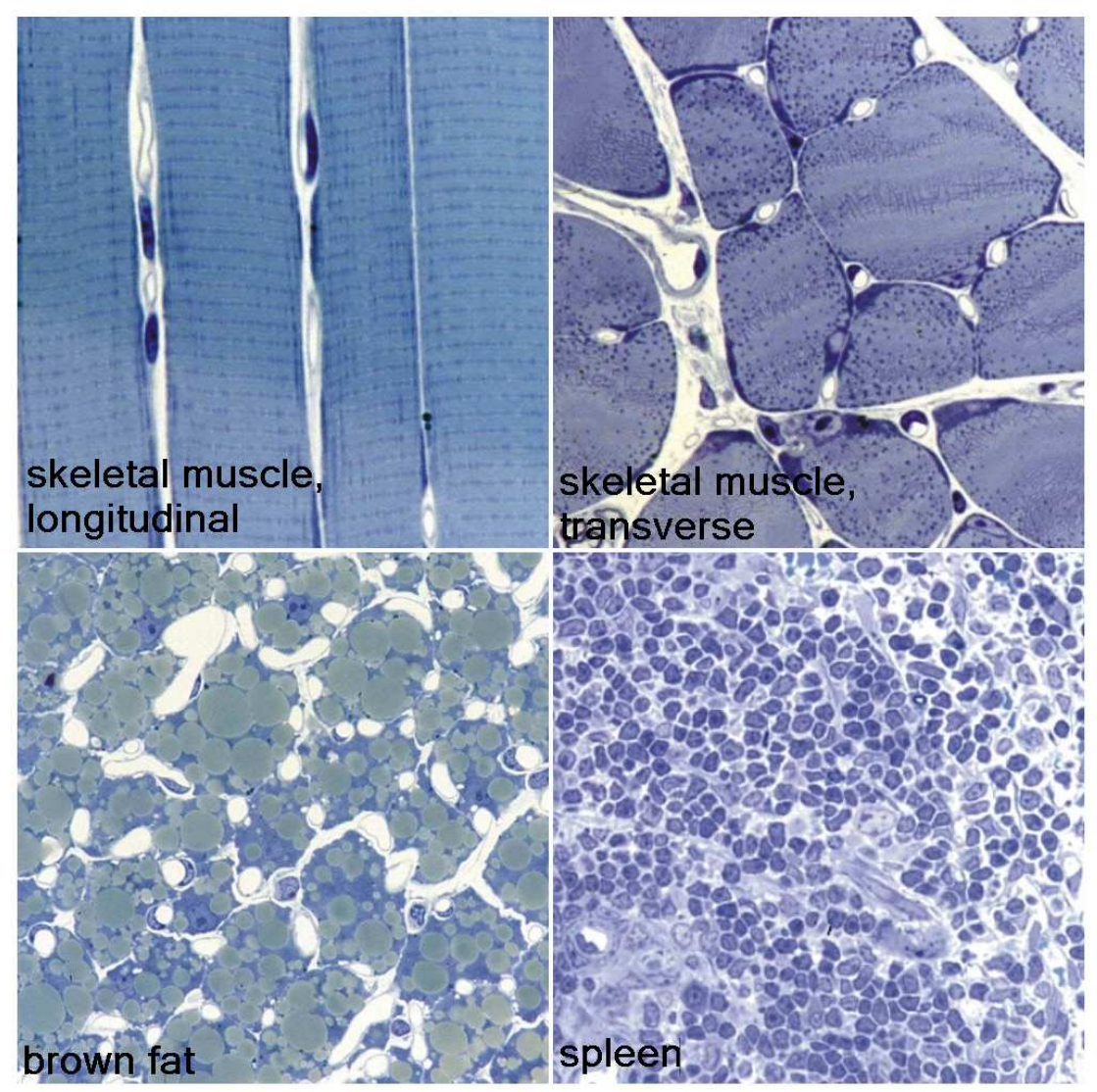

Figure 3.24: Light microscopy of $\sigma 1 \mathrm{~B}$-/- tissues after hematoxylin-eosinstaining. 


\subsubsection{Analysis of AP-1 in $\sigma 1 \mathrm{~B}-/$ - fibroblasts}

In order to analyse AP-1 on a cellular level, mouse embryonic fibroblast cell lines were established from wt and $\sigma 1 \mathrm{~B}$-/- embryos at day 13.5 of pregnancy (2.2.2.2). The primary fibroblasts obtained are spontaneously able to transform into permanent cell lines. Genotyping of DNA was done as described (see fig. 3.19, 3.22).

\subsubsection{Composition of AP-1}

The AP-1 complex is stabilised by multiple high affinity subunit interactions. $\gamma$ - and $\sigma 1$ - as well as $\mu 1$ - and $\beta 1$-adaptins form hemicomplexes which bind to each other by high affinity $\gamma$ - $\beta$-interactions. Formation of hemicomplexes is required for solubility of the adaptins. Thus, deficiency in one subunit leads to destabilisation of partial complexes and adaptins. This has been demonstrated in case of $\mu 1 \mathrm{~A}$-deficiency, which causes a decrease in $\gamma 1$ and $\sigma 1$ levels in fibroblasts (Meyer et al., 2000). As for the $\sigma 1 \mathrm{~B}-/$ - fibroblasts, the lack of $\sigma 1 \mathrm{~B}$ could be compensated by upregulation of $\sigma 1 \mathrm{~A}$ or $\sigma 1 \mathrm{C}$ expression.

Postnuclear supernatants, which contain all cellular components except nuclei, were prepared from control and $\sigma 1 \mathrm{~B}$-/- fibroblasts (2.2.3.3). $100 \mu \mathrm{g}$ protein per lane were loaded onto SDS-PAGE, transferred to nitrocellulose by western blot and decorated with antibodies against different adaptins (fig. 3.25).

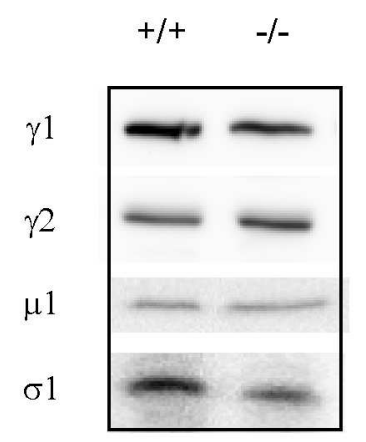

Figure 3.25: Detection of AP-1 subunits by western blot. The adaptin level in cell extracts from wt and $\sigma 1 \mathrm{~B}-/$ - fibroblasts was examined for $\gamma 1$, $\gamma 2, \mu 1$ and $\sigma 1$.

$\gamma 1, \gamma 2$ and $\mu 1$ and $\sigma 1$ were detected at similar levels in $\sigma 1 \mathrm{~B}-/$ - and control cell extracts. After stripping the membranes, they were subsequently decorated with control antibodies to normalise the adaptin signals to the protein load. None of the AP-1 subunits showed a significant change in protein level. Remarkably, the total 
signal for $\sigma 1$-adaptin as detected by the GST- $\sigma 1 \mathrm{~B}$-antiserum (fig. 3.13) was not apparently altered, suggesting, that the amount of $\sigma 1 \mathrm{~A}$ and $\sigma 1 \mathrm{C}$ proteins increased in $\sigma 1 \mathrm{~B}$-deficient cells.

To know whether complex assembly of AP-1 is affected by the lack of $\sigma 1 \mathrm{~B}$, the cytosolic fraction of MEF cells was analysed by gelfiltration, which separates the proteins depending on their molecular weight and their Stokes radius.

Cytosol was prepared from fibroblast cells by 100,000xg centrifugation of cell lysates according to 2.2.3.4. $250 \mu \mathrm{g}$ protein were loaded onto a Sephadex 200 column at a flow rate of $40 \mu \mathrm{l} / \mathrm{min}$. $40 \mu \mathrm{l}$-fractions were collected $10 \mathrm{~min}$ after start of the filtration. $\gamma 1, \gamma 2$ and $\mu 1 \mathrm{~A}$ were detected in the fractions by western blot.

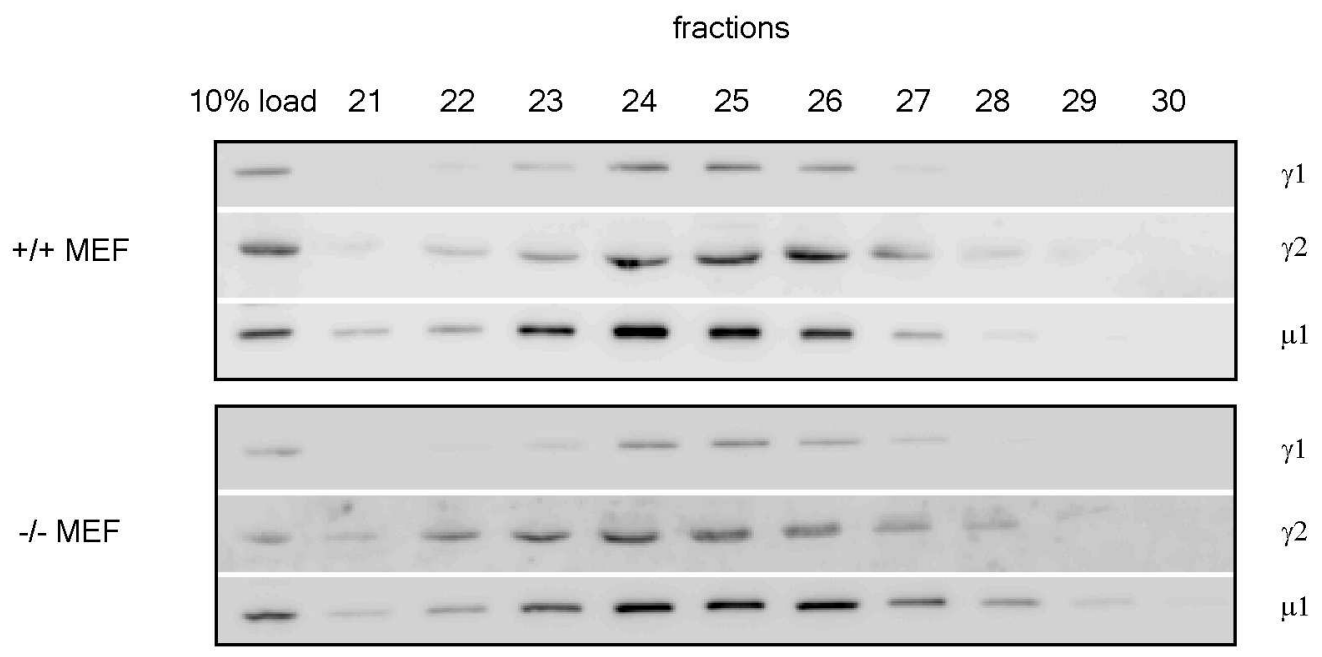

Figure 3.26: Gelfiltration of cytosol. $25 \mu \mathrm{g}$ cytosol were loaded as reference in lane 1. Fractions 21-30 of the gelfiltration are shown which contain the eluate peak of AP-1, detected by antibodies against $\gamma 1, \gamma 2$ and $\mu 1$.

The AP-1 complex has a molecular weight of about $280 \mathrm{kDa}$. Its peak is detected in fractions $24-26$ of both control and $\sigma 1 \mathrm{~B}$-/- cytosol (fig. 3.26). The fractionation pattern does not apparently change in the absence of $\sigma 1 \mathrm{~B}$. In fact, a size difference of about $20 \mathrm{kDa}$ cannot be resolved by this gelfiltration, which means that trimeric AP1 complexes lacking only $\sigma 1$ are not separated from the tetramers and would elute in the same fractions. But no adaptins were detected in later fractions. Therefore, we can conclude that $\sigma 1 \mathrm{~B}$-deficiency does not prevent the complex assembly of the remaining AP-1 subunits, and that these complexes are present at wildtype levels.

It is not known, if $\gamma 2$-adaptin forms a complex with other AP-1 subunits in vivo. In yeast-2-hybrid experiments, an affinity to $\sigma 1 \mathrm{~A}$ and $\sigma 1 \mathrm{~B}$ was detected, but no 


\section{Results}

interaction with $\beta 1$-adaptin (Takatsu et al., 1998). In addition, no colocalisation with clathrin could be observed in vivo, whose binding requires the presence of $\beta$ adaptin. Surprisingly, $\gamma 2$ cofractionated with AP-1 in our gelfiltration, indicating that its complex is similar to AP-1 in size. Similar to $\gamma 1$, the fractionation pattern of $\gamma 2$ was not affected by $\sigma 1 \mathrm{~B}$ deficiency.

Unfortunately, our antisera did not immunoprecipitate adaptins and therefore complex composition could not be studied in more detail. 


\subsubsection{Subcellular distribution of AP-1 adaptins}

\section{Membrane localisation of AP-1}

The cellular localisation of the AP-1 complex can be visualised by indirect immunofluorescence against the $\gamma 1$-adaptin subunit, shown on confocal images in fig. 3.27. Fibroblasts were grown overnight on glass coverslips and treated with para-formaldehyde for fixation. Labelling was performed with the monoclonal $\gamma 1$ antibody (1:100) and $\alpha$-mouse IgG-antibody coupled to Texas Red as secondary antibody (2.2.3.9).

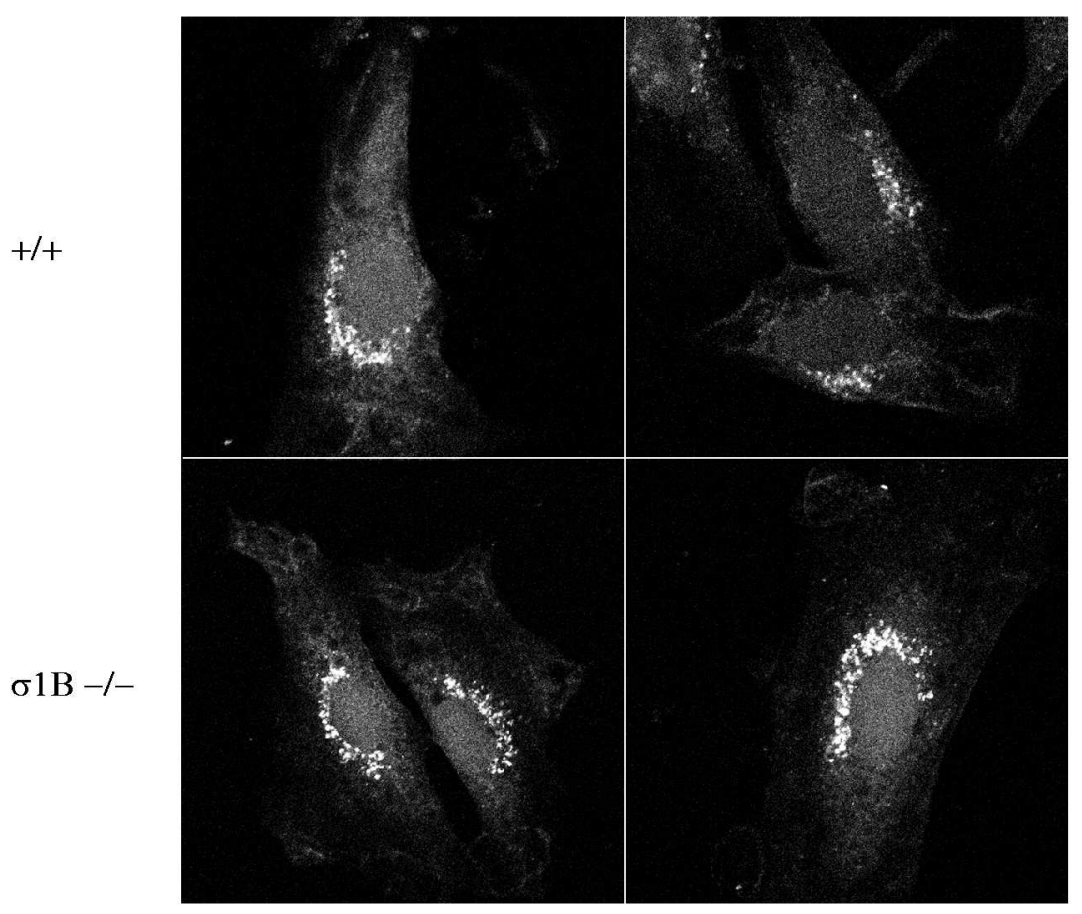

Figure 3.27: Intracellular localisation of $\gamma \mathbf{1}$-adaptin. Confocal images show $\gamma 1$-staining of wt (upper row) and $\sigma 1 \mathrm{~B}-/$ - fibroblasts (lower row).

$\gamma 1$-adaptin stained a perinuclear area in both wt and $\sigma 1 \mathrm{~B}-/$ - fibroblasts, which is typical for localisation to the TGN. Thus, the membrane binding of $\gamma 1$-containing complexes remains largely unaffected by the deficiency of $\sigma 1 \mathrm{~B}$. This also suggests that the AP-1 pools incorporating $\sigma 1 \mathrm{~A}$ or $\sigma 1 \mathrm{~B}$ either associate with similar parts of the TGN covering the whole TGN area, or otherwise, that the localisation of the AP-1 pool containing $\sigma 1 \mathrm{~B}$ does not contribute remarkably to the immunofluorescent pattern of $\gamma 1$-adaptin. 


\section{Results}

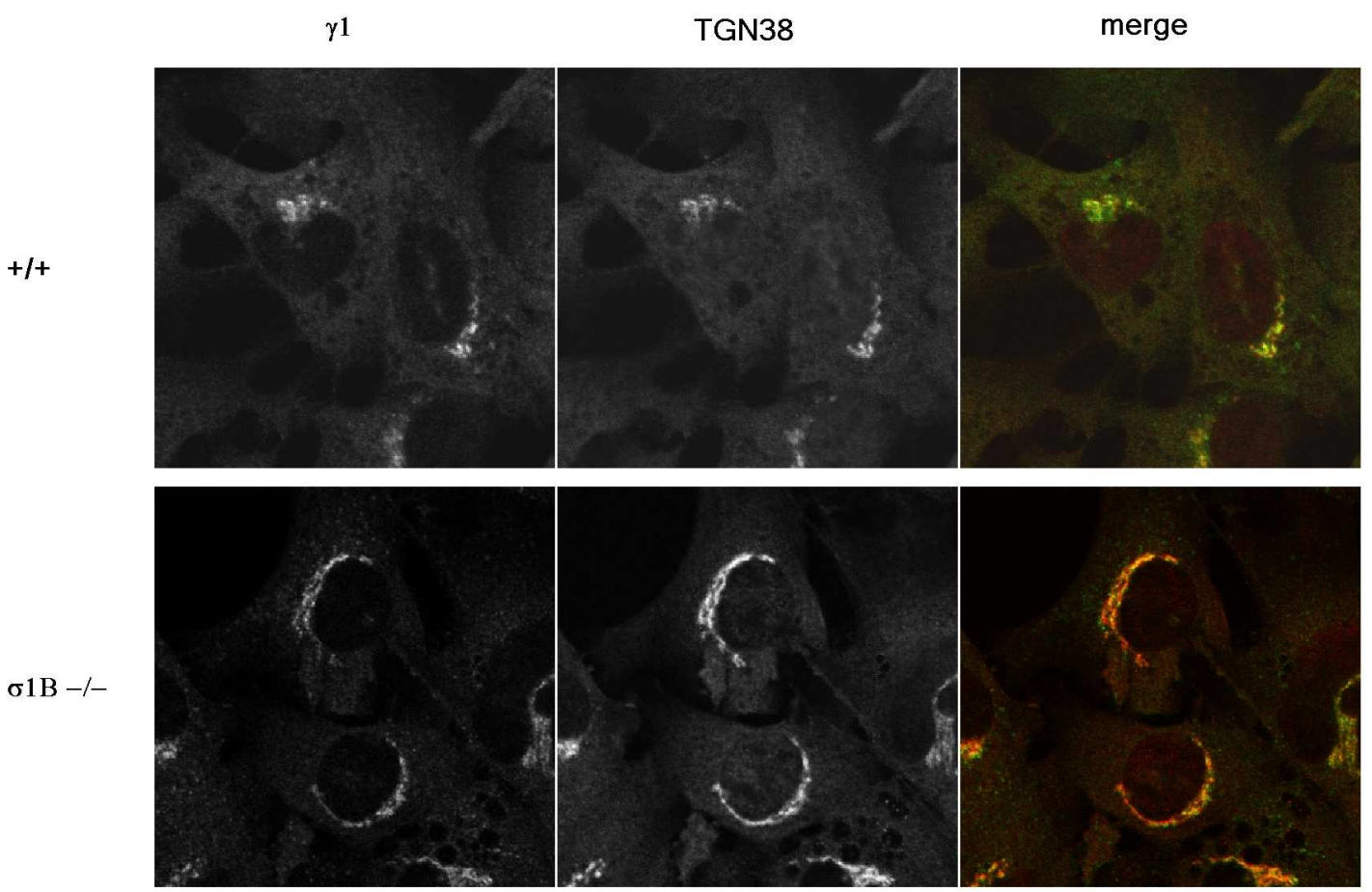

Figure 3.28: Colocalisation of $\gamma \mathbf{1}$-adaptin with TGN38. Panels show wt fibroblasts (upper row) and $\sigma 1 \mathrm{~B}$-/- fibroblasts (lower row) which were stained for $\gamma 1$-adaptin (left) and TGN38 (middle). Both stainings are merged in the right column ( $\gamma 1$-adaptin: green, TGN38: red).

To determine the positioning of $\gamma 1$ with respect to the Golgi apparatus, cells were simultaneously labelled for $\gamma 1$ and the TGN marker protein TGN38. Immunofluorescence was done according to the PFA-fixation protocol (2.2.3.9). $\alpha$-mouse IgG-FITC and $\alpha$-rabbit IgG-Texas Red were used as secondary antibodies for $\gamma 1$ and TGN38, respectively.

$\gamma 1$-adaptin was mainly associated with the TGN, as it overlapped extensively with TGN38 (fig. 3.28). The selected fibroblast cells shown differ slightly in their Golgi morphology. One of them appears more compact, triangular and was located on one side of the nucleus, whereas the other extends at least around half of the nucleus. Both staining patterns were commonly observed in fibroblasts of both genotypes.

\section{Subcellular localisation of $\gamma 2$-adaptin}

The polyclonal $\gamma$-antiserum (see 3.2.1) was tested for immunofluorescence microscopy. It was raised against hinge and ear domains of $\gamma 2$, but crossreacts with $\gamma 1$ to some extent on western blot (see fig. 3.15). Fibroblasts were grown on coverslips overnight, treated with acetone-methanol for fixation and labelled with the 
mouse monoclonal antibody against $\gamma 1$, diluted 1:100, and an Ig-enriched fraction from our polyclonal antiserum against $\gamma 2$, diluted 1:50. $\alpha$-mouse IgG-antibody coupled to FITC and $\alpha$-rabbit IgG-antibody coupled to Cy3 were used as secondary antibodies.

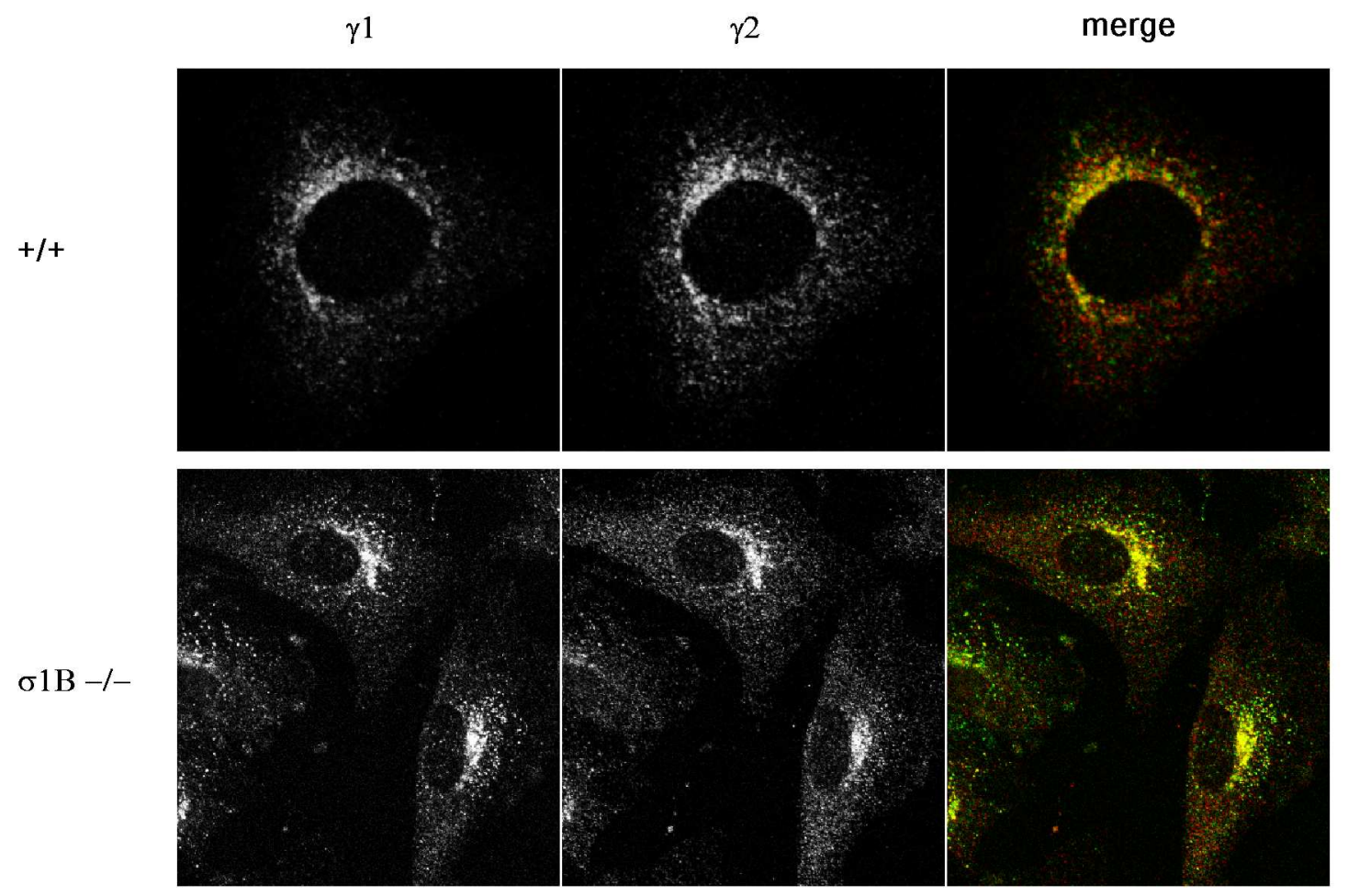

Figure 3.29: Immunostaining of $\gamma$-adaptins. Confocal images show the single stainings for $\gamma 1$ (left) and $\gamma 2$ (middle) as well as the merge of both patterns (right; $\gamma 1$ : green, $\gamma 2$ : red).

The $\gamma$ 2-antiserum mainly stained a perinuclear compartment similar to the pattern observed with the monoclonal $\gamma 1$-antibody, and there was a significant, although not complete, overlap between the two labellings (fig. 3.29).

In contrast to the $\gamma 1$-staining, the staining efficiency of the $\gamma 2$-antiserum varied considerably in the range of $20-80 \%$ between cell lines and experiments, for which we do not have an explanation yet. 


\section{Results}

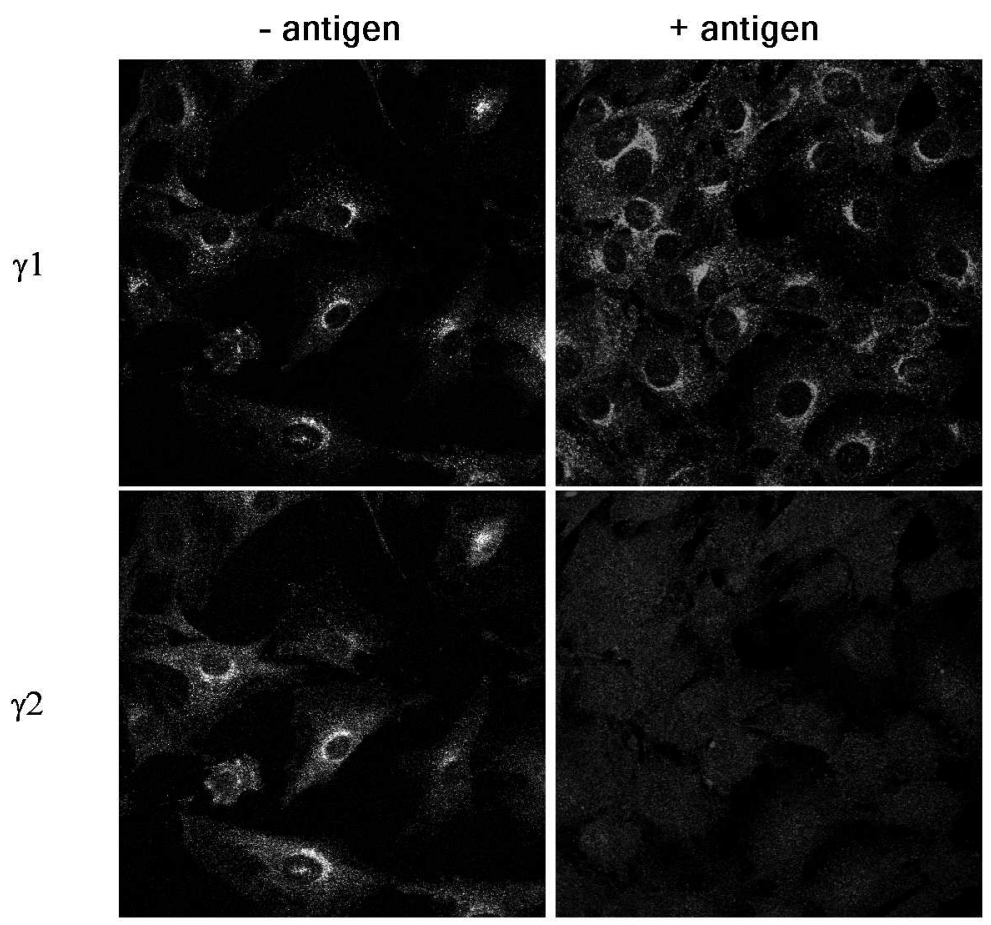

Figure 3.30: Immunolabelling with $\gamma$-antiserum is blocked by addition of the antigen GST-g2HE. The panels show an overview of cells stained for $\gamma 1$ (upper row) and $\gamma 2$ (lower row) without supplement (left) and in the presence of GST-g2HE antigen (right).

To examine the specificity of the polyclonal $\gamma 2$-antiserum, the labelling solution was supplemented with the original antigen, GST-g2HE in about 4fold molar excess. As shown in fig. 3.30, $\gamma 2$-antibodies did not bind to the cells under these conditions, whereas the monoclonal antibodies against $\gamma 1$ were not affected. This demonstrated that the polyclonal antiserum reacts only with epitopes present on the GST-g2HE antigen, some of which may be shared with $\gamma 1$-adaptin. 


\section{Subcellular distribution of mannose 6-phosphate receptors}

MPRs are sorted into transport vesicles at the TGN by AP-1. Therefore, a defect in AP-1 function would alter the steady-state localisation of the receptors, as observed in $\mu 1 \mathrm{~A}$-/- fibroblasts (Meyer et al., 2000). In control cells, MPR46 and MPR300 are mainly found at the TGN.
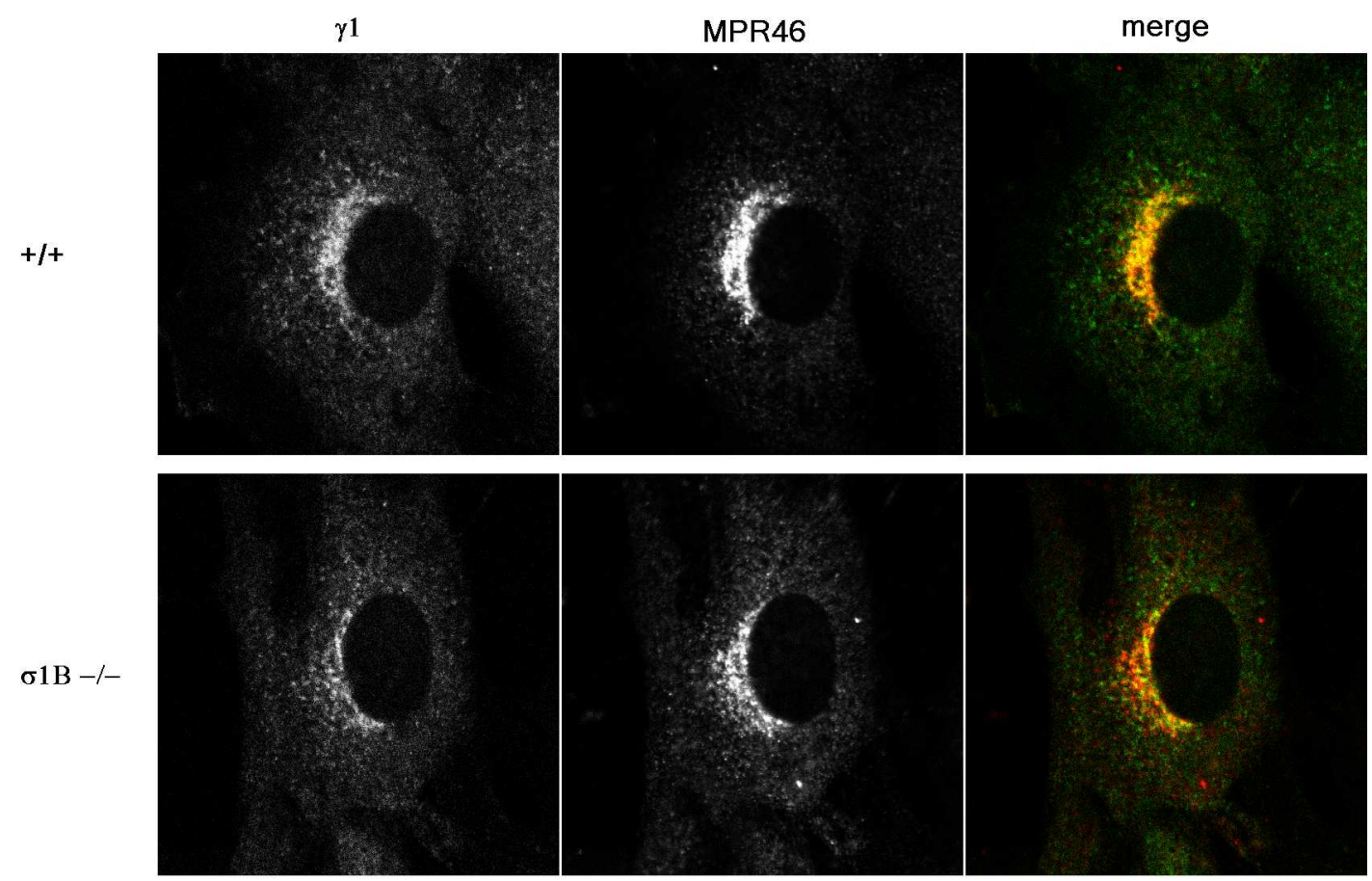

Figure 3.31: Colocalisation of $\gamma \mathbf{1 - a d a p t i n}$ and MPR46. Single staining for $\gamma 1$ adaptin (left column) and MPR46 (middle column); merge (right column; $\gamma 1$ : green; MPR46:red).

Fibroblast cells were grown overnight, fixed according to the acetone-methanolprotocol (2.2.3.9) and stained with antibodies against $\gamma 1$-adaptin and MPR46 (fig. 3.31) or MPR300 (fig. 3.32). The secondary antibodies used were $\alpha$-mouse IgGFITC for $\gamma 1$ and $\alpha$-rabbit IgG-Texas Red for MPRs.

MPR46 was found to colocalise with $\gamma 1$-adaptin at the TGN in both control and $\sigma 1 \mathrm{~B}$-/- fibroblasts (fig. 3.31).

Similarly, the distribution of MPR300 overlapped with $\gamma 1$-adaptin, mostly in the TGN region. One of the selected control cells (fig. 3.32, upper row, to the right of the picture) shows an array of vesicular structures between the TGN and the plasma membrane which stained for $\gamma 1$ and MPR300 as well and probably corresponds to endosomes. 


\section{Results}

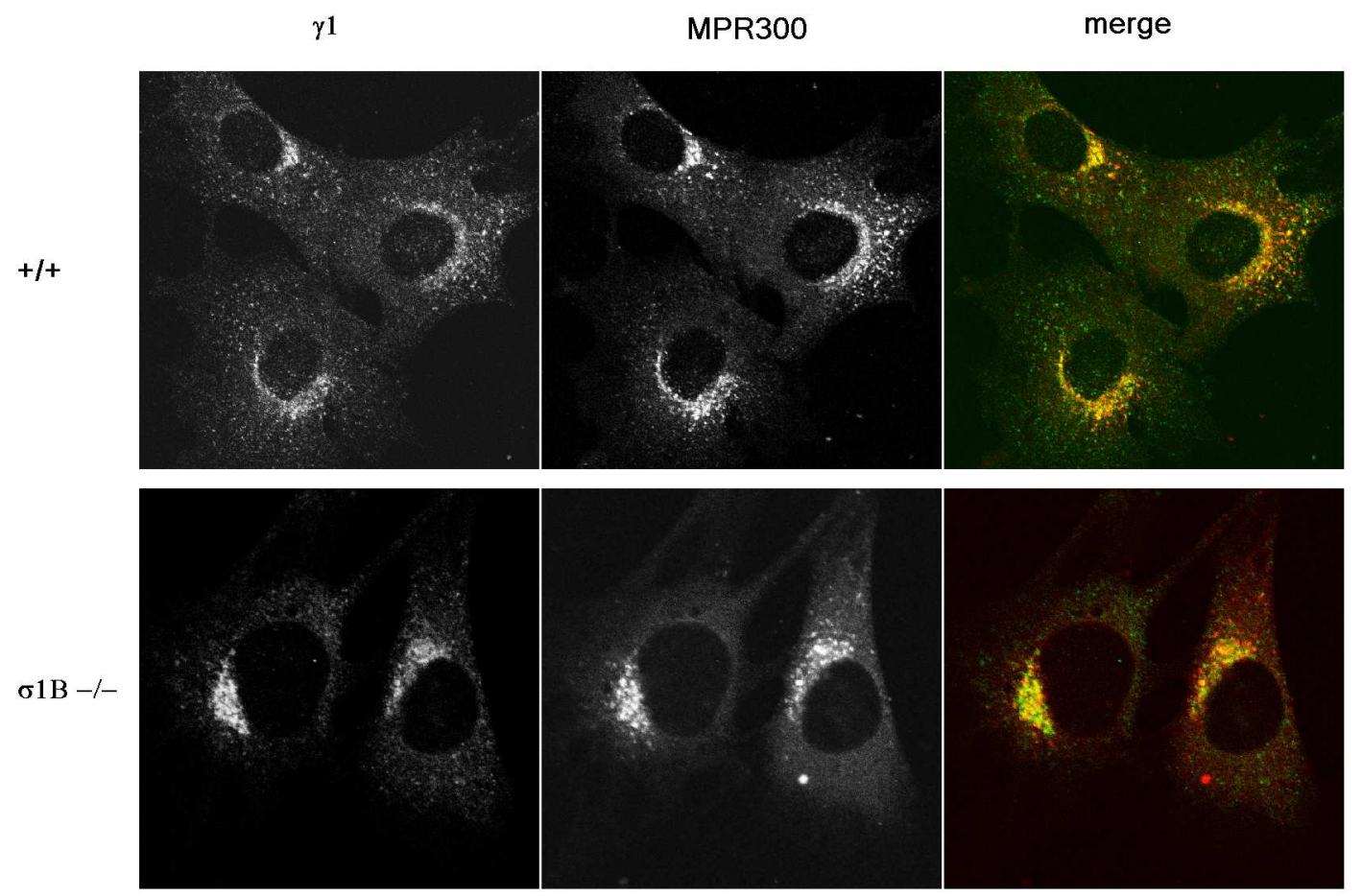

Figure 3.32: Colocalisation of $\gamma \mathbf{1}$-adaptin and MPR300. Single staining for $\gamma 1$-adaptin (left column) and MPR300 (middle column); merge (right column; $\gamma 1$ : green; MPR300:red). 


\subsubsection{Analysis of $\sigma 1 \mathrm{~B}-/-$ skeletal muscle}

\subsubsection{Expression of AP-1 subunits in skeletal muscle}

Since the expression profile of $\sigma 1$-adaptin genes suggested a major role for $\sigma 1 \mathrm{~B}$ in skeletal muscle, we wanted to know whether the levels of AP-1 subunits in this tissue are affected by $\sigma 1 \mathrm{~B}$-deficiency. We therefore analysed $\gamma 1$ and $\gamma 2$-adaptin in skeletal muscle extracts by western blot.

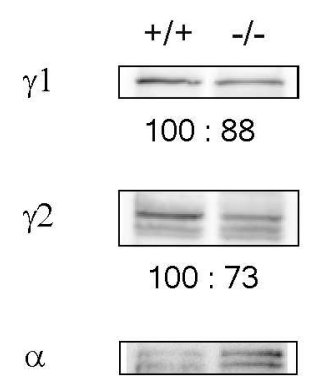

Figure 3.33: Western blot of $\gamma \mathbf{1}$ - and $\gamma \mathbf{2}$-adaptin in skeletal muscle extracts. Signal intensities were normalised to the intensity of $\alpha$-adaptin and expressed as percent of wt level.

The preliminary data shown in fig. 3.33 indicate that the protein level of $\gamma 1$ and $\gamma 2$ may be decreased in skeletal muscle. The signals for $\gamma 1$ and $\gamma 2$-adaptin were quantified and normalised to the intensity of $\alpha$-adaptin in the same lanes. Since only one extract per genotype was tested, the significance of this result has to be verified.

Even though the amount of protein loaded was increased to $200 \mu \mathrm{g}$ per lane, we could not detect a distinct band for $\sigma 1$-adaptin by western blot. The levels of $\sigma 1$ were therefore examined by northern blot.

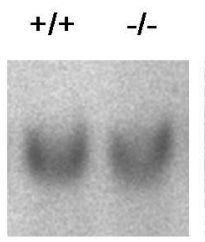

$\sigma 1 \mathrm{~A}$

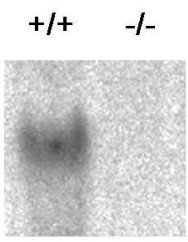

$\sigma 1 \mathrm{~B}$

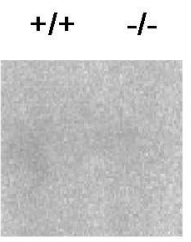

$\sigma 1 \mathrm{C}$

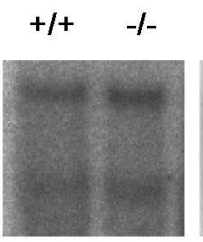

$\gamma 1$

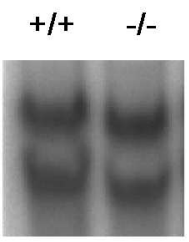

$\gamma 2$

Figure 3.34: RNA level of adaptins in skeletal muscle. Hybridisation patterns of RNA from control and $\sigma 1 \mathrm{~B}-/-$ muscle are shown for $\sigma 1 \mathrm{~A}$, -B and -C and for $\gamma 1$ and $\gamma 2$ (from left to right). 


\section{Results}

Total RNA was prepared from ventral or hindlimb muscle of wt and $\sigma 1 \mathrm{~B}$-deficient mice. $10 \mu \mathrm{g}$ per lane were loaded on an agarose gel, transferred to nylon membrane and hybridised with specific cDNA fragments for $\sigma 1$-adaptin and $\gamma$-adaptin mRNA (fig. 3.34).

Whereas $\sigma 1 \mathrm{~B}$ mRNA was absent from $\sigma 1 \mathrm{~B}$-/- muscle RNA preparations, the mRNA for the other $\sigma 1$ subunits and for $\gamma$-adaptins was not affected. $\sigma 1 \mathrm{~A}, \gamma 1$ and $\gamma 2 \mathrm{mRNA}$ were detected at a similar level as in wt muscle RNA and $\sigma 1 \mathrm{C}$ mRNA could not be detected in any of the muscle RNA samples.

\subsubsection{Localisation of AP-1}

Heart and skeletal muscle were excised from wt and $\sigma 1 \mathrm{~B}-/-$ mice after perfusion fixation with $4 \%$ PFA (2.2.4.2). Cryosections of $7 \mu \mathrm{m}$ thickness were prepared by Susanne Lausmann (MPI of biophysical chemistry, Göttingen). Sections of one animal per genotype were stained with the monoclonal $\gamma 1$-antibody and a Cy2coupled secondary antibody in two experiments. Confocal images are shown in fig. 3.35 .

In skeletal muscle, the Golgi apparatus is present as compact Golgi stacks including cis-, medial- and trans-Golgi cisternae which are either associated with the nuclei at the surface of the fiber or dispersed within the myofibrillar core (Ralston et al., 1999; Kaisto, 2003). Consistently, $\gamma 1$-adaptin was detected as perinuclear dots (arrowheads) as well as dispersed internal dots coincident with the I-bands along the striated pattern (arrow, fig. 3.35 A and B). A similar labelling pattern was obtained for cardiac muscle (fig. 3.35 C-F). These structures were observed in wt and in $\sigma 1 \mathrm{~B}$ deficient muscle, although they seemed to be less abundant in the deficient samples on the average (fig. $3.35 \mathrm{~B}, \mathrm{D}$ and F), suggesting that the AP-1 complex is indeed affected by $\sigma 1 \mathrm{~B}$-deficiency in muscle tissues. The preliminary results need to be confirmed by additional labelling series including a reference staining. 


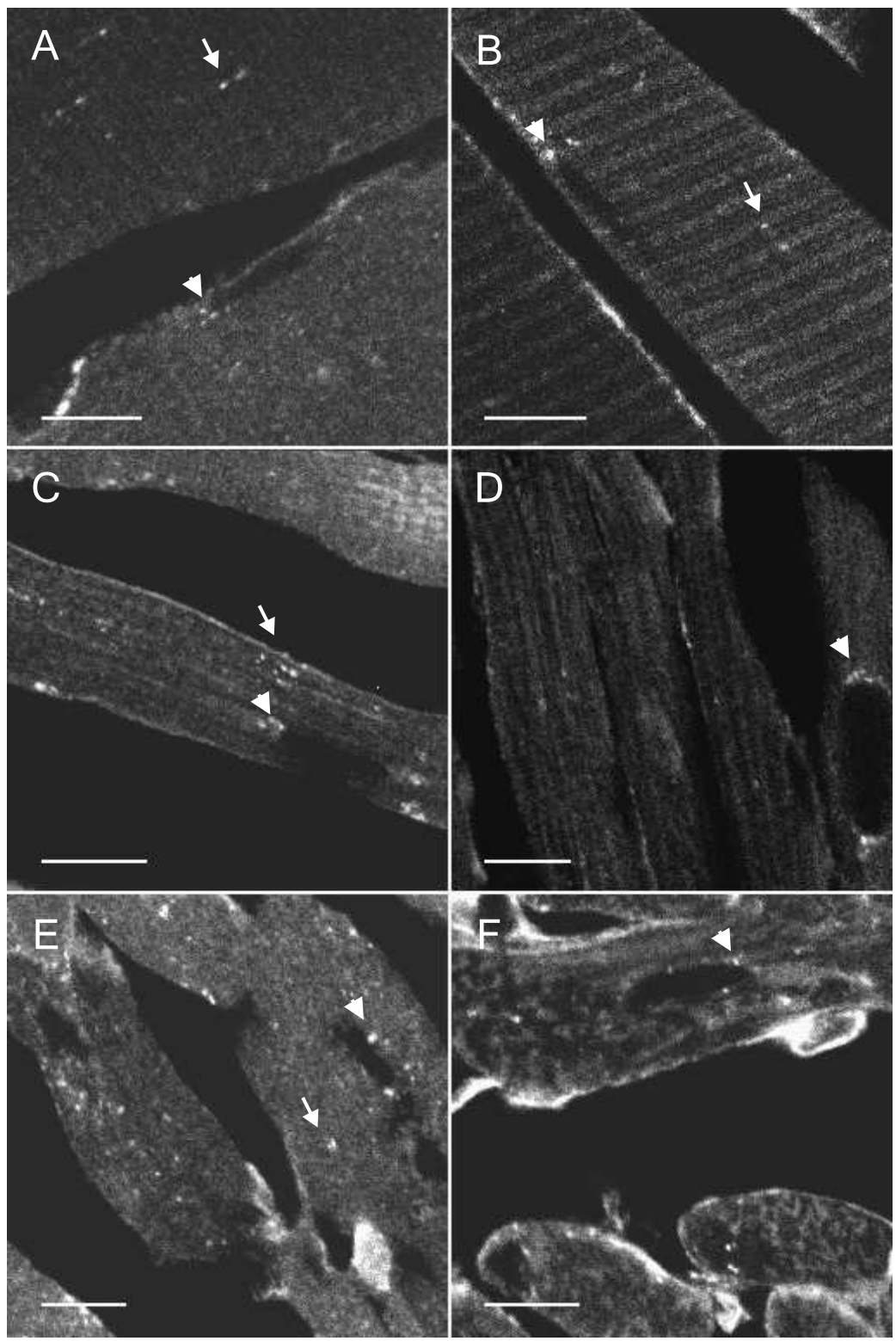

Figure 3.35: Immunolabelling of $\gamma \mathbf{1}$-adaptin in sections of muscle tissue. Representative images of wt (A, C and E) and $\sigma 1 \mathrm{~B}$-deficient sections (B, $\mathrm{D}$ and $\mathrm{F}$ ) are shown from skeletal muscle (A and $\mathrm{B})$ and cardiac muscle (longitudinal: $\mathrm{C}$ and $\mathrm{D}$, transverse: $\mathrm{E}$ and $\mathrm{F}$ ). Arrowheads point to perinuclear labelling, whereas arrows indicate staining spread throughout the cell. Bars: $10 \mu \mathrm{m}$. 


\section{Results}

\subsubsection{Microarray analysis}

$\sigma 1 \mathrm{~B}$ seems to be the prominent $\sigma 1$-adaptin in muscle, but its deficiency did not result in any apparent muscle-related phenotype. Thus, there could be a compensatory mechanism to overcome the lack of $\sigma 1 \mathrm{~B}$. Since the expression profile of a cell is supposed to reflect its actual condition and to respond actively to disturbances from outside and inside, a microarray experiment was performed to identify genes whose expression is modulated upon deficiency of $\sigma 1 \mathrm{~B}$.

Microarray slides were produced by the laboratory of Dr. Jobst Landgrebe (Microarray facility, Medical faculty). They contained 22,000 non-redundant clones from a mouse cDNA library (2.2.1.9). Each slide was hybridised with a mixture of cDNA preparations from skeletal muscle and liver, which were labelled by incorporation of fluorescent $\mathrm{Cy} 3-$ and $\mathrm{Cy} 5-\mathrm{dCTP}$, respectively. The liver cDNA served as reference for normalisation of the signals from different array slides. To reduce the influence of technical variability, each skeletal muscle sample was hybridised to two microarrays. Total RNA was prepared from the ventral muscles of two $\sigma 1 \mathrm{~B}-/-$ males and two wt littermates. As the yield was less than the $200 \mu \mathrm{g}$ needed, some of the RNA was transcribed into cDNA and used for linear amplification by PCR. Both RNA and cDNA were fluorescently labelled, which includes reverse transcription of the RNA, and mixed for the hybridisation. The contribution of amplified cDNA was about $33 \%$ of the total probe.

All the Cy3-signals were standardised to the Cy5-reference signal. By comparison of the signal ratios from $\sigma 1 \mathrm{~B}-/$ - and wt skeletal muscle, 59 genes were identified, that appeared to be differentially expressed with an unadjusted error probability $\mathrm{P}$ $<0.05$ (see table 3.2). The estimate is an expression for the change in mRNA level:

$$
\frac{\text { mRNA }_{\text {ko }}}{\text { mRNA }_{w t}} \approx 2^{\text {estimate }}
$$

Therefore, genes with a negative estimate are downregulated, while genes with a positive estimate are upregulated in $\sigma 1 \mathrm{~B}$-/- skeletal muscle. The reported level of expression differences ranged between 5fold downregulation and 5fold upregulation. Examination of the raw data revealed that six of the identified genes were obviously false positives not discovered by the statistics. Staining artefacts are generally masked as signal values 0 or 1 . If a specific spot showed an artefact on 3-4 arrays of one genotype, the gene appeared as differentially expressed. These genes are not included in the table.

26 genes encode for unknown proteins. 
Table 3.2: Genes that are differentially expressed in $\sigma 1 \mathrm{~B}$-/- skeletal muscle. Gene symbols are taken from the Locus Link database (NCBI). A negative estimate value indicates a decreased amount of mRNA, whereas a positive value stands for an increase in mRNA levels.

\begin{tabular}{|c|c|c|c|}
\hline gene symbol & & estimate & probability \\
\hline Gjb5 & $\begin{array}{l}\text { gap junction membrane channel } \\
\text { protein beta } 5\end{array}$ & -2.424 & 0.049 \\
\hline 1810013L24Rik & & -2.249 & 0.046 \\
\hline Tagln2 & transgelin, actin-binding protein & -1.805 & 0.038 \\
\hline Aup1 & $\begin{array}{l}\text { ancient ubiquitous protein } 1 \text {, un- } \\
\text { known function }\end{array}$ & -1.535 & 0.041 \\
\hline Mm. 229324 & putative $\mathrm{K}^{+}$-channel & -1.476 & 0.049 \\
\hline Uble1a & ubiquitin-like activating enzyme & -1.270 & 0.029 \\
\hline 2310033A20Rik & & -1.251 & 0.038 \\
\hline 4932425I24Rik & & -1.185 & 0.039 \\
\hline Cdca3 & $\begin{array}{l}\text { cell division cycle associated protein } \\
3\end{array}$ & -1.003 & 0.009 \\
\hline Angptl6 & angiopoietin-related growth factor & -0.946 & 0.027 \\
\hline Mrpl35 & $\begin{array}{l}\text { mitochondrial ribosomal protein } \\
\text { L35 }\end{array}$ & -0.912 & 0.036 \\
\hline Tesk2 & testis-specific kinase 2 & -0.887 & 0.048 \\
\hline BC004701 & & -0.865 & 0.039 \\
\hline 9530048O09Rik & & -0.856 & 0.048 \\
\hline 4930573C15Rik & & -0.841 & 0.049 \\
\hline 1700092M07Rik & & -0.818 & 0.033 \\
\hline Mm. 235118 & $\begin{array}{l}\text { oligophrenin } 1 \text {, associated with } \mathrm{X} \text { - } \\
\text { linked mental retardation }\end{array}$ & -0.782 & 0.017 \\
\hline Syne2 & $\begin{array}{l}\text { synaptic nuclear envelope protein } \\
\text { with muscle-specific forms }\end{array}$ & -0.728 & 0.043 \\
\hline Zfx & zinc-finger protein, X-linked & -0.707 & 0.010 \\
\hline AI314180 & & -0.704 & 0.035 \\
\hline A230098E07Rik & & -0.691 & 0.049 \\
\hline D830007B15 & & -0.675 & 0.047 \\
\hline Mm. 138483 & & -0.640 & 0.030 \\
\hline AA 871546 & & -0.612 & 0.037 \\
\hline
\end{tabular}




\section{Results}

\begin{tabular}{|c|c|c|c|}
\hline gene symbol & & estimate & probability \\
\hline Vps26 & $\begin{array}{l}\text { vacuolar protein sorting protein } 26 \\
\text { (yeast) }\end{array}$ & -0.607 & 0.048 \\
\hline 2610307O08Rik & & -0.599 & 0.041 \\
\hline Sh3bgr & $\begin{array}{l}\text { SH3-binding domain glutamic acid- } \\
\text { rich protein }\end{array}$ & -0.592 & 0.047 \\
\hline Cks2 & CDC28 regulatory subunit & -0.582 & 0.034 \\
\hline 5830411G16Rik & & -0.560 & 0.046 \\
\hline 2200008D09Rik & & -0.532 & 0.040 \\
\hline 2610318G18Rik & & -0.519 & 0.044 \\
\hline 1110036H21Rik & & -0.486 & 0.035 \\
\hline Ptgfr & prostaglandin $\mathrm{F}$ receptor & -0.389 & 0.028 \\
\hline 1200008A14Rik & & 0.677 & 0.039 \\
\hline Pcbp2 & poly $(\mathrm{rC})$ binding protein 2 & 0.912 & 0.039 \\
\hline Epb4.115 & erythrocyte protein band 4.1 -like 5 & 0.966 & 0.021 \\
\hline Mm. 193061 & & 0.976 & 0.028 \\
\hline Chuk & I kappa B kinase alpha & 0.983 & 0.046 \\
\hline Mm. 25750 & & 1.129 & 0.027 \\
\hline 5330432J06Rik & & 1.195 & 0.036 \\
\hline Raly & hnRNP & 1.207 & 0.037 \\
\hline B230217J03Rik & & 1.235 & 0.019 \\
\hline \multirow[t]{2}{*}{ Zfp185 } & zinc-finger protein & 1.243 & 0.050 \\
\hline & KIAA0286 & 1.250 & 0.032 \\
\hline $\mathrm{Hal}$ & $\begin{array}{l}\text { histidine-ammonia-lyase (sarcoplas- } \\
\text { matic reticulum) }\end{array}$ & 1.419 & 0.038 \\
\hline 4832416J22 & & 1.430 & 0.048 \\
\hline 0610006K04Rik & & 1.433 & 0.049 \\
\hline Ech1 & enoyl-CoA hydratase (peroxisomal) & 1.450 & 0.041 \\
\hline Srr & serine racemase & 1.723 & 0.038 \\
\hline \multirow[t]{2}{*}{ LOC218811 } & contains COPII Sec24 domain & 1.945 & 0.044 \\
\hline & & 2.298 & 0.048 \\
\hline Ap4s1 & $\begin{array}{l}\text { adaptor-related protein complex } \\
\text { AP-4, sigma } 1\end{array}$ & 2.485 & 0.050 \\
\hline Cap2 & adenylate cyclase-associated protein & 2.649 & 0.021 \\
\hline
\end{tabular}




\subsubsection{Verification of microarray results by northern blot}

cDNA clones of microarray candidate genes were obtained and confirmed by sequencing. The constructs were digested with NotI or NotI and EcoRI to release the cDNA inserts from the vector. Northern blots containing total RNA from wt and $\sigma 1 \mathrm{~B}$-/- skeletal muscle were prepared as described in 3.3.5.1 and hybridised with radioactively labelled cDNA probes (fig. 3.36).

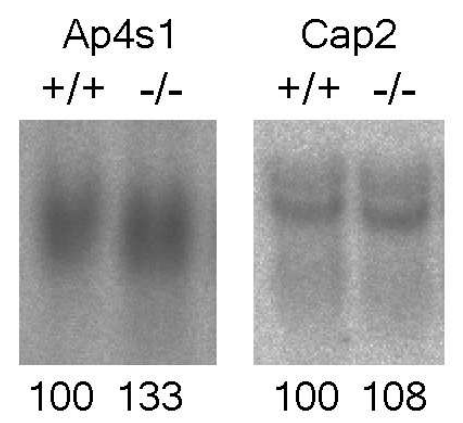

Figure 3.36: Northern blot hybridisation for Ap4s1 and Cap2. Signal intensities were quantified and normalised to the signal of hprt in the same lane.

The estimate values from the microarray screen had indicated a range of about 35fold increase of the Ap4s1, Cap2 or Srr mRNA level in $\sigma 1 \mathrm{~B}$-/- RNA preparations, whereas expression of Tesk2 and Uble1a seemed to be downregulated about $50 \%$ (see table 3.2). By northern blot, only one of the five candidates, Ap4s1, showed a change in expression level (fig. 3.36), whereas the other transcripts appeared at equal levels in $\sigma 1 \mathrm{~B}$-/- and wt skeletal muscle (shown only for Cap2). Ap4s1 expression was examined in three RNA preparations per genotype, which showed similar results, suggesting that the amount of Ap4s1 transcripts is about 30\% increased in $\sigma 1 \mathrm{~B}-/-$ skeletal muscle.

\subsubsection{FACS-analysis of $\sigma 1 \mathrm{~B}-/-$ T-lymphocytes}

T-lymphocyte populations in the thymus had been shown to be affected in $\gamma 1$ adaptin +/- mice, namely, the fraction of $\mathrm{CD} 4{ }^{+}$-lymphocytes was about $20 \%$ reduced (Zizioli et al., 1999). Therefore, we wanted to investigate if $\mathrm{T}$ cells are influenced by $\sigma 1 \mathrm{~B}$-deficiency as well.

Thymic maturation of $\mathrm{T}$ cells from bone marrow precursors, the thymocytes, occurs by positive and negative selection of cells dependent on the avidity of their $\mathrm{T}$ cell 


\section{Results}

receptor complexes (TCRs) to self-antigens presented by major-histocompatibility complexes I or II (MHCI and MHCII). The interaction of TCR with MHC complexes triggers an intracellular signaling cascade which promotes cell death or survival. CD4 and CD8 are co-receptors for TCR and responsible for recognition of MHCII and MHCI, respectively. Upon arrival of bone marrow precursor lymphocytes in the thymus, expression of CD4 and CD8 is activated and both proteins are exposed on the surface of T-lymphocyte precursors during selection. During maturation, either CD4 or CD8 expression is downregulated producing CD4 single-positive T-helper cells and CD8 single-positive cytotoxic T cells. These leave the thymus to enter the blood circulation and to reach secondary lymphatic organs.

In contrast, the cell surface marker CD5 is generally found on thymocytes, $\mathrm{T}$ cells and a specific subset of B cells. CD5 is assumed to influence thymocyte selection by modulating the TCR signaling response (Azzam et al., 1998, 2001).

T cells were isolated from thymus and spleen of 12 mice from four different litters at the age of 6-9 weeks (see table 3.4). Aliquots of $10^{6}$ cells were either stained for CD4 and CD8 or for CD5 with fluorescently labelled antibodies as indicated in column 3 (2.2.4.3). The percentage of cells which were positive only for CD4 or for CD8 or for both, as well as the fraction stained for CD5, is given in column 4 for thymus samples and in column 6 for spleen samples. In addition, the ratio of CD4/CD8 single-positive cells was calculated as a measure for the equilibrium between the two populations (columns 5 and 7 ).

Table 3.4: FACS analysis of T-lymphocytes. The values indicate the amount of viable cells in $\%$ that stained positive for the particular antigen.

\begin{tabular}{|l|c|c|c|c|c|c|}
\hline animal & sex/genotype & CD & thymus (\%) & CD4/CD8 & spleen (\%) & CD4/CD8 \\
\hline 1 & male & 4 & 8.40 & 2.80 & 28.90 & 1.72 \\
& $+/ \mathrm{o}$ & 8 & 2.99 & & 16.80 & \\
& 9 weeks & $4+8$ & 85.80 & & 1.04 & \\
& & 5 & 84.84 & & 45.25 & \\
\hline 2 & female & 4 & 8.25 & 3.03 & 25.58 & 1.75 \\
& $+/+$ & 8 & 2.72 & & 14.64 & \\
& 9 weeks & $4+8$ & 86.31 & & 1.11 & \\
& & 5 & 94.81 & & 39.51 & \\
\hline 3 & female & 4 & 9.02 & 3.13 & 31.13 & 2.14 \\
& $+/+$ & 8 & 2.88 & & 14.57 & \\
& 9 weeks & $4+8$ & 85.53 & & 1.32 & \\
& & 5 & 94.25 & & 48.51 & \\
& & & &
\end{tabular}




\begin{tabular}{|c|c|c|c|c|c|c|}
\hline animal & sex/genotype & $\mathrm{CD}$ & thymus (\%) & CD4/CD8 & spleen $(\%)$ & CD4/CD8 \\
\hline 4 & $\begin{array}{c}\text { male } \\
-/ \mathrm{o} \\
8.5 \text { weeks }\end{array}$ & $\begin{array}{c}4 \\
8 \\
4+8 \\
5\end{array}$ & $\begin{array}{c}8.62 \\
3.95 \\
84.60 \\
96.68\end{array}$ & 2.18 & $\begin{array}{c}27.67 \\
18.17 \\
0.90 \\
44.17\end{array}$ & 1.52 \\
\hline 5 & $\begin{array}{c}\text { female } \\
-/- \\
8.5 \text { weeks }\end{array}$ & $\begin{array}{c}4 \\
8 \\
4+8 \\
5\end{array}$ & $\begin{array}{c}9.78 \\
3.46 \\
82.77 \\
95.24\end{array}$ & 2.83 & $\begin{array}{c}27.68 \\
17.37 \\
0.99 \\
42.60\end{array}$ & 1.59 \\
\hline 6 & $\begin{array}{c}\text { female } \\
-/- \\
8.5 \text { weeks }\end{array}$ & $\begin{array}{c}4 \\
8 \\
4+8 \\
5 \\
\end{array}$ & $\begin{array}{c}10.15 \\
4.66 \\
81.70 \\
96.84 \\
\end{array}$ & 2.18 & $\begin{array}{c}22.83 \\
15.64 \\
1.52 \\
39.53 \\
\end{array}$ & 1.46 \\
\hline 7 & $\begin{array}{c}\text { male } \\
-/ \mathrm{o} \\
7.5 \text { weeks }\end{array}$ & $\begin{array}{c}4 \\
8 \\
4+8 \\
5 \\
\end{array}$ & $\begin{array}{c}8.94 \\
4.30 \\
84.17 \\
97.44 \\
\end{array}$ & 2.08 & $\begin{array}{c}30.80 \\
16.19 \\
1.23 \\
48.68 \\
\end{array}$ & 1.90 \\
\hline 8 & $\begin{array}{c}\text { male } \\
-/ \mathrm{o} \\
7.5 \text { weeks }\end{array}$ & $\begin{array}{c}4 \\
8 \\
4+8 \\
5\end{array}$ & $\begin{array}{c}8.64 \\
4.05 \\
84.49 \\
96.07\end{array}$ & 2.13 & $\begin{array}{c}31.01 \\
16.15 \\
1.52 \\
50.70\end{array}$ & 1.92 \\
\hline 9 & $\begin{array}{c}\text { female } \\
-/- \\
7.5 \text { weeks }\end{array}$ & $\begin{array}{c}4 \\
8 \\
4+8 \\
5\end{array}$ & $\begin{array}{c}8.14 \\
5.00 \\
83.74 \\
95.35\end{array}$ & 1.63 & $\begin{array}{c}28.85 \\
19.74 \\
0.99 \\
49.54\end{array}$ & 1.46 \\
\hline 10 & $\begin{array}{c}\text { male } \\
+/ \mathrm{o} \\
6.5 \text { weeks }\end{array}$ & $\begin{array}{c}4 \\
8 \\
4+8 \\
5\end{array}$ & $\begin{array}{c}9.09 \\
4.15 \\
83.70 \\
91.24\end{array}$ & 2.19 & $\begin{array}{c}30.99 \\
19.18 \\
1.32 \\
48.52\end{array}$ & 1.62 \\
\hline 11 & $\begin{array}{c}\text { male } \\
+/ \mathrm{o} \\
6.5 \text { weeks }\end{array}$ & $\begin{array}{c}4 \\
8 \\
4+8 \\
5\end{array}$ & $\begin{array}{c}33.92 \\
2.51 \\
58.62 \\
67.39\end{array}$ & 13.51 & $\begin{array}{c}28.42 \\
16.45 \\
1.49 \\
44.49\end{array}$ & 1.73 \\
\hline 12 & $\begin{array}{c}\text { female } \\
+/+ \\
6.5 \text { weeks }\end{array}$ & $\begin{array}{c}4 \\
8 \\
4+8 \\
5\end{array}$ & $\begin{array}{c}8.97 \\
2.60 \\
85.45 \\
84.40\end{array}$ & 3.45 & $\begin{array}{c}27.31 \\
13.90 \\
1.11 \\
39.46\end{array}$ & 1.97 \\
\hline
\end{tabular}




\section{Results}

Whereas the cell suspensions isolated from thymus contained mainly T cells (the CD5 fraction or the sum of CD4-CD8 fractions), less than half of the cells in the spleen samples were stained with the antibodies used. This may be due to contamination with blood cells. The results are summarised in table 3.6, expressed as mean values including the standard deviation. Cell density in the preparation from thymus of mouse 11 was significantly higher than in the other samples, which may have caused the incomplete staining. Therefore, these values were not considered in the summary (see table 3.6).

\begin{tabular}{|l|c|c|c|c|}
\hline & \multicolumn{2}{|c|}{ thymus } & \multicolumn{2}{c|}{ spleen } \\
\hline & $+/+$ & $-/-$ & $+/+$ & $-/-$ \\
\hline $\mathrm{CD}^{+}{ }^{+} \mathrm{CD}^{-}$ & $8.75 \pm 0.39$ & $\begin{array}{c}9.05 \pm 0.77 \\
(103 \%, \\
\mathrm{P} \approx 0.43)\end{array}$ & 28.72 & 28.14 \\
& & $\begin{array}{c}4.24 \pm 0.55 \\
(138 \%, \\
\mathrm{CD}^{-} \mathrm{CD} 8\end{array}$ & 15.92 & 17.21 \\
& $3.07 \pm 0.62$ & $\mathrm{P} \approx 0.01)$ & & \\
\hline $\mathrm{CD}^{+}{ }^{+} \mathrm{CD}^{+}$ & & $83.58 \pm 1.13$ & & \\
\hline $\mathrm{CD}{ }^{+} \mathrm{CD}^{-} / \mathrm{CD}^{-} \mathrm{CD} 8^{+}$ & $2.92 \pm 0.74$ & $2.17 \pm 0.39$ & 1.82 & 1.64 \\
\hline $\mathrm{CD} 5$ & 89.91 & 96.27 & 44.29 & 45.87 \\
\hline
\end{tabular}

Table 3.6: Summary of FACS results. Mean values and standard deviation were calculated from the data given in table $3.4(\mathrm{n}=5$ for wt thymus or $\mathrm{n}=6$ otherwise). The thymic CD8-positive T cell population showed a $40 \%$ increase in $\sigma 1 \mathrm{~B}$-/- thymus compared to wt thymus, with a probability of $\mathrm{P} \approx 0.01$ according to t-test statistics.

The reported composition of wt $\mathrm{T}$ cells conformed well to the present knowledge of $\mathrm{T}$ cell development. In thymus, the main fraction of about $85 \%$ expressed CD4 and CD8, which is characteristic for thymocytes during maturation. About 9\% displayed CD4 only, while about $3 \%$ were CD 8 single-positive cells. Since only mature $\mathrm{T}$ cells are supposed to enter the circulation, it was reasonable that double-positive $\mathrm{T}$ cells accounted only for about $2 \%$ of the $\mathrm{T}$ cells present in spleen. About $57 \%$ were CD4-positive, about $32 \%$ were CD8-positive T cells.

The data from $\sigma 1 \mathrm{~B}-/$ - samples revealed a significant increase of the $\mathrm{CD} 4^{-} \mathrm{CD} 8^{+}$fraction from thymus compared to wt samples, whereas the other values did not change beyond the range of standard deviation. 


\section{Discussion}

\subsection{The $\sigma 1$-adaptin family}

Three genes for $\sigma$-adaptin developed at the level of vertebrates.

$\sigma 1 \mathrm{~A}$ and $\sigma 1 \mathrm{~B}$ were known as isoforms of $\sigma 1$-adaptin at the beginning of this study. During the progress of genomic sequencing projects, a third gene was identified in mouse and human, named $\sigma 1 \mathrm{C}$. Since only one $\sigma 1$-adaptin had been reported from yeast and other model organisms, we were interested to record and classify the known $\sigma 1$-adaptin proteins among eukaryotes and to estimate the occurrence of gene diversification. This analyis would refine the phylogenetic overview of the whole adaptin family given by Boehm \& Bonifacino (2001) with respect to the $\sigma 1$ branch.

The public database of EST entries (NCBI) was searched for sequences matching $\sigma 1$. Search results were grouped and assembled into complete cDNA sequences, and a selection of these sequences was used for the generation of an alignment and a phylogenetic tree of $\sigma 1$-adaptin.

$\sigma 1 \mathrm{~A},-\mathrm{B}$ and $-\mathrm{C}$ were found in all vertebrate organisms examined including pig, chicken, frog and fish, but database entries from organisms such as fruitfly, worm and yeast reported only one sequence for $\sigma 1$. As the genomic sequence of these organisms is known completely and they are subjected to extensive genetic investigations, it can be concluded that they really contain only one form of $\sigma 1$-adaptin. In the cress A. thaliana as a representative of plants, two $\sigma 1$-genes have been identified, encoding for proteins which are to $97.5 \%$ identical. Hence, these genes probably developed by a gene duplication that occurred within the plant kingdom only.

Among the three proteins known in vertebrates, $\sigma 1 \mathrm{C}$ shows the highest variability between different organisms. It appears also to be the most related to the nonvertebrate $\sigma 1$-adaptins. However, the functional relevance of these relations is not clear. 


\section{$\sigma 1 \mathrm{~A},-\mathrm{B}$ and -C RNA transcripts show a tissue-specific distribution.}

Upon cloning of $\sigma 1 \mathrm{~A}$ and $\sigma 1 \mathrm{~B}$, their RNA transcript had been detected in various tissues by northern blot, leading to their characterisation as ubiquitous proteins (Peyrard et al., 1998; Takatsu et al., 1998). We wanted to extend this analysis to a larger number of tissues and examine the expression pattern of $\sigma 1 \mathrm{C}$ as well.

First, we specifically amplified the cDNA of $\sigma 1 \mathrm{~A}$, -B and -C from different tissues by PCR. The $\sigma 1 \mathrm{~A}$ cDNA was detected in all tissues examined. In contrast, the products for $\sigma 1 \mathrm{~B}$ and $\sigma 1 \mathrm{C}$ showed a tissue-specific pattern. Thus, $\sigma 1 \mathrm{~B}$ was present at significant levels in all tissues examined except kidney, whereas $\sigma 1 \mathrm{C}$ was not detected in testis, heart and fat.

In addition to the $\sigma 1 \mathrm{~B}$ and $\sigma 1 \mathrm{C}$ PCR products of the expected size, an additional PCR product was observed for $\sigma 1 \mathrm{~B}$ in skeletal muscle, heart and thymus and for $\sigma 1 \mathrm{C}$ in liver and thyroid gland. This indicates that two different mRNA variants are formed in the respective tissues by alternative splicing. We pursued this possibility in the case of $\sigma 1 \mathrm{~B}$ (see 3.1.2 and below).

The PCR results were confirmed by hybridisation of tissue northern blots, revealing that the three genes are expressed in a tissue-specific manner (fig. 3.4 and fig. 3.5). Whereas $\sigma 1 \mathrm{~A}$ RNA could again be detected in most tissues, significant levels of $\sigma 1 \mathrm{~B}$ or $\sigma 1 \mathrm{C}$ RNA were present only in part of the tissues examined. Standardisation of the signals to the expression level of the house-keeping gene hprt clearly demonstrated that $\sigma 1 \mathrm{~A}$, -B or -C RNA levels depend on the specific tissue. Several tissues apparently contained equal amounts of the three transcripts, e.g., liver, lung or adipose tissue. $\sigma 1 \mathrm{~A}$ and $\sigma 1 \mathrm{~B}$ were detected at similar levels in testis and brain, while $\sigma 1 \mathrm{~A}$ and $\sigma 1 \mathrm{C}$ appeared to be equally expressed in intestine. $\sigma 1 \mathrm{C}$ expression was dominant in kidney and thyroid gland. $\sigma 1 \mathrm{~B}$ was obviously the most prominent $\sigma 1$ RNA in skeletal and heart muscle, which had already been indicated by the northern blot analyis of $\sigma 1 \mathrm{~A}$ and $\sigma 1 \mathrm{~B}$ published in Takatsu et al. (1998). In fact, the hybridisation pattern we observed corresponds well to their results for heart, brain and skeletal muscle, whereas their experiment would suggest different conclusions concerning other tissues. But a definite comparison of the results is not possible, since they did not refer to a control hybridisation.

In contrast to the $\sigma 1$-adaptin genes, $\gamma 1$ and $\gamma 2$ seemed to be ubiquitously expressed at comparable levels. 


\section{The $\sigma 1 \mathrm{~B}$ gene encodes for three different proteins that are generated by tissue-specific alternative splicing.}

Splice variants of $\sigma 1 \mathrm{~B}$ were discovered in this study due to persistent conflicts among the sequences known, which prompted us to sequence products of $\sigma 1 \mathrm{~B}$ PCR from several tissues. Two variants were found in addition to the original $\sigma 1 \mathrm{~B} 1$ : Inclusion of an alternative 9 bp-exon (exon 6 in fig. 3.7) into the mRNA after exon 4 leads to the synthesis of $\sigma 1 \mathrm{~B} 2$, which contains three additional amino acids at position 142 compared to $\sigma 1 \mathrm{~B} 1$. Another alternative exon (exon 5 in fig. 3.7) can be inserted at the same position of the mRNA, giving rise to $\sigma 1 \mathrm{~B} 3$ with a completely different C-terminus after amino acid position 142.

The original $\sigma 1 \mathrm{~B}$ form, $\sigma 1 \mathrm{~B} 1$, was detected from several tissues, e.g., liver, kidney, heart and skeletal muscle, either by direct sequencing of universal $\sigma 1 \mathrm{~B}-\mathrm{PCR}$ products or by specific hybridisation of the PCR samples. In contrast, the splice variant $\sigma 1 \mathrm{~B} 2$ appeared to be present only in brain, intestine and thyroid gland.

The third variant, $\sigma 1 \mathrm{~B} 3$ could be detected by different techniques. All of them showed positive results for skeletal muscle and heart muscle. Other tissues produced weak signals with only one method, which need further confirmation. For example, testis seemed to contain $\sigma 1 \mathrm{~B} 3$ according to specific PCR, but the corresponding $\sigma 1 \mathrm{~B}-\mathrm{PCR}$ sample was not labeled by $\sigma 1 \mathrm{~B} 3$-primer hybridisation.

\subsection{Generation of antibodies}

To facilitate the analysis of endogenous $\sigma 1 \mathrm{~A}$ and $\sigma 1 \mathrm{~B}$, we intended to generate specific antibodies against the two proteins. Both were purified as GST-fusion proteins and used for immunisation of rabbits. One of the resulting sera, directed against GST- $\sigma 1 \mathrm{~B}$, detected a distinct band at the expected size of $18 \mathrm{kDa}$ in fibroblast cell extracts and was subsequently used for western blot experiments. However, there was still a clear signal in $\sigma 1 \mathrm{~B}$-/- samples, indicating that the GST- $\sigma 1 \mathrm{~B}$-antiserum crossreacted with $\sigma 1 \mathrm{~A}$ and $\sigma 1 \mathrm{C}$ (fig. 3.13). The antiserum against GST- $\sigma 1 \mathrm{~A}$ also recognised an appropriate band in purified adaptor-fractions, but was not suitable for analysis of raw cell extracts.

Both antisera were used for affinity purification to enrich antibodies from the polyclonal pool which would be specific for $\sigma 1 \mathrm{~A}$ or $\sigma 1 \mathrm{~B}$. The GST- $\sigma 1 \mathrm{~A}$ antiserum was first absorbed against the GST- $\sigma 1 \mathrm{~B}$ protein to remove crossreacting antibodies and vice versa. The pretreated sera were further incubated with the specific GST-antigen coupled to sepharose beads. After washing of the beads, specifically bound material 


\section{Discussion}

was eluted at $\mathrm{pH}$ 2.3. No immunoreactivity against $\sigma 1$ could be found in the eluates, suggesting that the fraction of isoform-specific antibodies was very low in the original antisera.

In order to offer mainly specific epitopes as antigens for immunisation, we selected peptides from the variable region of $\sigma 1 \mathrm{~A}$ and $\sigma 1 \mathrm{~B}$ near the $\mathrm{N}$-terminus (amino acid residues 21-38 and 20-37, respectively) and coupled them via a terminal cysteine residue to the carrier protein KLH. The antisera obtained showed various crossreactions but did not even detect the purified GST- $\sigma 1$ proteins.

Thus, no $\sigma 1 \mathrm{~A}$ - or $\sigma 1 \mathrm{~B}$-specific antisera could be generated, maybe due to the $87 \%$ identity of the two proteins at the amino acid level and the poor antigenicity of their variable stretches.

After identification of the $\sigma 1 \mathrm{~B}$ splice variant $\sigma 1 \mathrm{~B} 3$, which contains an entirely different C-terminus compared to $\sigma 1 \mathrm{~A}$ and $\sigma 1 \mathrm{~B} 1$, this C-terminal peptide was used for immunisation of a rabbit in the same way as described for $\sigma 1 \mathrm{~A}$ and -B peptides. Whereas the antiserum specifically recognised $\sigma 1 \mathrm{~B} 3$ and $\sigma 1 \mathrm{C}$, which contains a sequence related to the $\sigma 1 \mathrm{~B} 3$-peptide, it did not detect $\sigma 1 \mathrm{~B} 1$ and $\sigma 1 \mathrm{~A}$ (fig. 3.16). However, no specific signal was observed using cell extracts from mouse embryonic fibroblasts. Since $\sigma 1 \mathrm{~B} 3$ is not present in fibroblasts, as shown by PCR (fig. 3.8), only $\sigma 1 \mathrm{C}$ could have been detected in this case. Considering that $\sigma 1 \mathrm{~B} 3$ and $\sigma 1 \mathrm{C}$ show variable expression levels depending on the specific tissue, further experiments should test the reactivity of this antiserum against extracts from different sources.

One aspect of studying $\sigma 1$-adaptins concerned their relationship to the isoform $\gamma 2$. As no antiserum was available, we raised an antiserum against a GST-fusion protein comprising the hinge and ear domains of $\gamma 2$, whose homologous regions in $\gamma 1$ had been successfully used for immunisation. A serum was obtained which recognised a clear band at the appropriate size of $88 \mathrm{kDa}$ in fibroblast extracts, but showed weak crossreactivity to a $100 \mathrm{kDa}$ protein, probably corresponding to $\gamma 1$-adaptin. It could be used for western blot analysis and immunofluorescence labelling, but was not suitable for immunoprecipitation.

\subsection{Generation and analysis of $\sigma 1 \mathrm{~B}$ deficient mice}

To inactivate the mouse $\sigma 1 \mathrm{~B}$ gene on chromosome $\mathrm{X}$, a replacement vector for homologous recombination in ES cells was constructed starting from a cloned fragment of genomic DNA that contained exons 3 and 4. By insertion of a neomycin resistance cassette into exon 3 in reverse orientation, the open reading frame of $\sigma 1 \mathrm{~B}$ was disrupted at amino acid position 72. After transfection of ES cells and selection of 
neomycin-resistant clones, $10 \%$ of the isolated clones had exchanged the mutated genomic fragment for the wt counterpart. This recombination frequency is in the upper range of examples reported in the literature (Snouwaert et al., 1992; Hasty et al., 1994). On one hand, the use of isogenic DNA and the length of our targeting construct may have favoured homologous recombination. On the other hand, the efficiency can be influenced by intrinsic properties of the gene locus itself, such as the chromosomal environment (Mansour et al., 1988).

The recombinant ES cell clone S1B111 was injected into blastocysts and integrated successfully into 3 chimeric males, out of which one showed germline transmission of the $\sigma 1 \mathrm{~B}$-deficient cells. Hence, the ES cells had preserved their totipotent state during 12 passages in culture, which is an important criterium for the generation of transgenic mice.

The offspring of the chimera contained heterozygous female mice, which were mated to wt males to generate $\sigma 1 \mathrm{~B}$-deficient male mice in the $\mathrm{F} 1$ generation. These were subsequently crossed with their heterozygous female littermates and produced $\sigma 1 \mathrm{~B}$ deficient females in the F2 generation (see fig. 3.21). Both male and female $\sigma 1 \mathrm{~B}-/-$ mice were viable and fertile. Genotypes in offspring of heterozygous females mated to wt or $\sigma 1 \mathrm{~B}-/$ - males were evenly distributed, in agreement with mendelian laws (see fig. 3.1). It can therefore be excluded that $\sigma 1 \mathrm{~B}$-deficiency has any impact on prenatal development of mice. No $\sigma 1 \mathrm{~B}$ RNA transcript was detected in RNA from $\sigma 1 \mathrm{~B}$-/- sources (see fig. 3.4, 3.34), indicating that the gene locus was indeed disrupted by insertion of the neomycin resistance cassette, and moreover, that the mutant locus was not transcribed. The absence of $\sigma 1 \mathrm{~B}$ could not be demonstrated on the level of protein, since our GST- $\sigma 1 \mathrm{~B}$ antiserum was not specific for $\sigma 1 \mathrm{~B}$.

$\sigma 1 \mathrm{~B}$-deficient mice did not show any apparent phenotype compared to their wildtype littermates. Their development was not obviously disturbed and no abnormalities were observed up to the age of 1 year. Further analysis of selected tissues by light and electron microscopy did not report any abnormal changes in $\sigma 1 \mathrm{~B}-/$ - animals compared to wt animals.

The genetic background can significantly influence the expression of a mutant phenotype. Therefore, a second S1B111 strain was established on a genetic background mixed of 129/Sv and 129/Ola (3:1) in contrast to the genetic background of the first one, which was composed of C57 BL/6J and 129/Ola mouse strains (3:1).

Since two genes were known for mouse $\sigma 1$-adaptin at the beginning of this study, it was clear that the disruption of only one of them could be compensated by the remaining gene. Consequently, disruption of the mouse $\sigma 1 \mathrm{~A}$ gene locus was conceived as a parallel approach to this study to allow for the generation of $\sigma 1 \mathrm{~A} / \mathrm{B}$ double- 


\section{Discussion}

deficient mice. However, no homologous recombination event could be detected among 96 clones selected after electroporation of the targeting construct. Further attempts of electroporation failed due to problems with ES cell culture. Thus, the project was not completed.

Even though $\sigma 1 \mathrm{~A}$ and, as we know now, $\sigma 1 \mathrm{C}$ could take over the function of $\sigma 1 \mathrm{~B}$, it was surprising that $\sigma 1 \mathrm{~B}-/-$ mice were not affected at all, because the three $\sigma 1$-genes show a tissue-specific expression profile, as revealed in this study. If we assume a specific function of $\sigma 1 \mathrm{~B}$ based on its expression, the lack of $\sigma 1 \mathrm{~B}$ would have to be compensated concerning this function by a mechanism which does not involve $\sigma 1 \mathrm{~A}$ or $\sigma 1 \mathrm{C}$.

\section{$4.4 \sigma 1 \mathrm{~B}$-deficient fibroblasts}

\section{The protein level of the remaining AP-1 subunits and their assembly into a complex are not affected by $\sigma 1 \mathrm{~B}$-deficiency.}

Fibroblast cell lines were established from mouse embryos to study the composition and localisation of AP-1 in $\sigma 1 \mathrm{~B}$-deficient cells.

In fibroblasts, the AP- 1 complex consists of $\gamma 1, \beta 1, \mu 1 \mathrm{~A}$ and $\sigma 1 \mathrm{~A}$. Upon identification of $\gamma 2$ and $\sigma 1 \mathrm{~B}$ it was speculated that they may form a variant AP-1 complex in addition to the established AP-1 containing $\gamma 1$ and $\sigma 1 \mathrm{~A}$. However, experimental evidence to support this idea is still missing. Due to its $87 \%$ homology to $\sigma 1 \mathrm{~A}, \sigma 1 \mathrm{~B}$ can most probably integrate into the AP-1 complex at the place of $\sigma 1 \mathrm{~A}$. Both $\sigma 1 \mathrm{~A}$ and $\sigma 1 \mathrm{~B}$ were also shown to interact with $\gamma 2$, the homolog of $\gamma 1$, in yeast 2-hybrid experiments, whereas no interaction was detected between $\gamma 2$ and $\beta 1$.

No specific functions have yet been described for $\sigma$-adaptins, in contrast to the other three types of adaptor subunits. It is commonly assumed that it may serve as a stabilising domain for the complex assembly.

Previous experiments demonstrated that the absence of $\mu 1 \mathrm{~A}$ destabilises other AP-1 subunits decreasing the amount of $\gamma 1$-adaptin by $30 \%$ and the amount of $\sigma 1$-adaptin by $70 \%$ (Meyer et al., 2000). Similarly, the level of all AP-1 subunits was reduced to $50 \%$ in cells which were heterozygous for $\gamma 1$-adaptin (Zizioli et al., 1999). Thus, if the depletion of one subunit reduces the protein level of another, this is an indication for an interaction of the two proteins.

$\sigma 1 \mathrm{~B}$-deficient fibroblasts contained as much $\sigma 1$-adaptin than wt, as detected by western blot with the GST- $\sigma 1 \mathrm{~B}$ antiserum. This could be due to a very low endogenous level of $\sigma 1 \mathrm{~B}$, whose depletion would not be apparent on western blot. Otherwise, 
$\sigma 1 \mathrm{~A}$ and/or $\sigma 1 \mathrm{C}$ proteins could be stabilised because they are incorporated into AP-1 instead of $\sigma 1 \mathrm{~B}$. Consistently, the protein levels of $\gamma 1, \gamma 2$ and $\mu 1$ were also not affected in $\sigma 1 \mathrm{~B}$-deficient fibroblasts.

Complex assembly of AP-1 in $\sigma 1 \mathrm{~B}$-/- cells was examined by gelfiltration of the cytosolic fraction, because available adaptin-antisera do not immunoprecipitate adaptor complexes from mouse. The fractionation pattern of the AP-1 subunits $\gamma 1$ and $\mu 1$ appeared identical to wt cytosol, indicating that the complex folds properly in the absence of $\sigma 1 \mathrm{~B}$.

$\gamma 2$ eluted in the same fractions as $\gamma 1$ and $\mu 1$, which demonstrates that it forms a complex of similar size to AP-1. As the fractionation profile remains the same in the absence of $\sigma 1 \mathrm{~B}$, formation of this complex does not depend on $\sigma 1 \mathrm{~B}$ as well.

\section{The intracellular distribution of $\gamma$-adaptins remains the same in $\sigma 1 \mathrm{~B}-/-$ as in wt fibroblasts.}

AP-1 localises to the TGN as well as dispersed endosomal elements in mouse embryonic fibroblasts. This was examined by immunofluorescence labelling of $\gamma 1$-adaptin alone and with respect to the marker protein TGN38. In $\sigma 1 \mathrm{~B}$-deficient as well as in wt fibroblasts, we observed $\gamma 1$-adaptin staining as a perinuclear array which is typical for the trans-Golgi network and which colocalised with TGN38. Thus, the AP-1 population containing $\sigma 1 \mathrm{~B}$ does not remarkably contribute to the staining pattern of $\gamma 1$ in these cells.

To test whether depletion of $\sigma 1 \mathrm{~B}$ affects the intracellular distribution of $\gamma 2$, we performed immunofluorescences with our polyclonal $\gamma 2$-antiserum, compromising on the crossreaction to $\gamma 1$-adaptin. The resulting pattern overlapped largely with the $\gamma 1$ staining, but not completely. In contrast to these observations, $\gamma 2$-adaptin had been reported previously to localise to the cis-Golgi/intermediate compartment by immunofluorescence and to show only limited overlap with $\gamma 1$ (Lewin et al., 1998; Takatsu et al., 1998). The apparent increase in colocalisation of $\gamma 1$ and $\gamma 2$ in our experiments could be partially due to crossreaction with $\gamma 1$. However, the $\gamma 2$-antiserum did not stain any part of the cis-Golgi, as detected by co-labelling for the marker protein GM130 (data not shown).

$\sigma 1 \mathrm{~B}$-deficiency did not apparently alter the immunofluorescence pattern obtained with the $\gamma 2$-antiserum, suggesting that $\sigma 1 \mathrm{~B}$ is not crucial for the distribution of $\gamma 2$ adaptin.

The mannose 6-phosphate receptors MPR46 and MPR300 are sorted into clathrincoated vesicles by AP-1. Deficiency of AP-1 results in a redistribution of the receptors from the TGN, their main localisation at steady state, to endosomal compart- 


\section{Discussion}

ments as observed in $\mu 1 \mathrm{~A}$-/- fibroblasts (Meyer et al., 2000). In contrast, depletion of $\sigma 1 \mathrm{~B}$ shows no effect on the localisation of MPRs.

\section{$4.5 \sigma 1 B-d e f i c i e n t$ muscle}

Because $\sigma 1 \mathrm{~B}$ appeared to be the dominant $\sigma 1$-RNA transcript in skeletal muscle and heart, we assumed that the consequences of $\sigma 1 \mathrm{~B}$-deficiency would be most pronounced in these tissues. However, no muscle-related phenotype was observed in mice and microscopical analysis of their ultrastructure did not reveal any morphological changes in $\sigma 1 \mathrm{~B}-/$ - mice (3.3.3).

The expression of AP-1 subunits was determined on RNA and protein levels. Northern blot hybridisation of skeletal muscle RNA confirmed the absence of $\sigma 1 \mathrm{~B}$ RNA, but did not reveal any changes in the level of $\sigma 1 \mathrm{~A}$, - $\mathrm{C}$ or $\gamma$ transcripts.

In contrast, both $\gamma 1$ and $\gamma 2$ proteins appeared to be slightly reduced in extracts of $\sigma 1 \mathrm{~B}$-deficient skeletal muscle compared to wt extracts, with $\gamma 2$ showing the more significant decrease of about 30\%. $\sigma 1$-adaptin could not be detected by the GST$\sigma 1 \mathrm{~B}$-antiserum in up to $200 \mu \mathrm{g}$ protein of any extract. This could be due to the high concentration of structural proteins in muscle, since the signal intensity for the $\gamma$-adaptin isoforms was also considerably lower in muscle extracts than in fibroblast extracts. Further experiments should use subcellular fractions of muscle tissue for detection of adaptins and apply buffer conditions that facilitate the clearance of structural proteins.

The localisation of $\gamma 1$-adaptin in mouse skeletal and cardiac muscle was examined by immunofluorescent labelling of cryosections. We observed a staining pattern that agrees essentially with the organisation of the Golgi apparatus in skeletal muscle as described in the literature (Kaisto, 2003; Towler et al., 2004b). $\gamma 1$-adaptin staining appeared as dots either around nuclei or in the myofibrillar core, reflecting the distribution of the Golgi stacks. Whereas the perinuclear Golgi was usually reported as a ring of several dots around the nucleus (Ralston et al., 1999), we found $\gamma 1$-adaptin dots only on one or two sides of the nuclei. Both wt and $\sigma 1 \mathrm{~B}-/-$ sections showed the same staining pattern. However, the structures seemed to be less abundant in the $\sigma 1 \mathrm{~B}$-deficient sections, suggesting a reduction in $\gamma 1$-membrane binding.

Since only one $\sigma 1 \mathrm{~B}-/$ - and one control mouse were analysed until now, the observations have to be verified in sections from another genotype-pair of mice. Further labelling experiments are required to examine the morphology of the Golgi as well as the localisation of $\gamma 2$-adaptin and of endocytic markers.

To screen for potential compensatory mechanisms which substitute for $\sigma 1 \mathrm{~B}$ function 
in skeletal muscle, we performed a microarray experiment with skeletal muscle RNA from wt and $\sigma 1 \mathrm{~B}-/$ - mice. Two microarrays were used per RNA sample as well as two animals per genotype to reduce the influence of technical and biological variability. We identified a total number of 53 candidate genes, whose expression appeared to be affected in $\sigma 1 \mathrm{~B}$-deficient muscle. Apart from 26 unknown genes, this group contained mainly genes that are not obviously related to vesicular transport, such as the gap junction protein Gjb5 or serine racemase Srr. Only two of the candidates participate in membrane trafficking, namely Ap4s1 or $\sigma 4$, the small subunit of the AP-4 complex, and mVps26, a component of the "retromer" complex (Seaman, 2004; Arighi et al., 2004).

Five of the candidate genes were tested for differential expression by northern blot analysis. Whereas four of them did not reveal changes on RNA level, the signal for the Ap4s1 transcript was found to be about $30 \%$ stronger in $\sigma 1 \mathrm{~B}-/$ - muscle RNA compared to wt RNA. The Ap4s1 probe was hybridised to two different blots containing RNA preparations from six mice, and both of the blots showed similar results upon normalisation of the signals to hprt hybridisation. However, the microarray experiment predicted a much stronger upregulation of $\sigma 4$ than the $30 \%$ increase confirmed.

Expression of Vps26 and other candidate genes still remains to be tested by northern blot. Since some cDNA probes only produced very low signals on total RNA, which could hardly be quantified, efficiency and resolution of northern blots could probably be improved by isolation of mRNA. Another possibility would be to perform quantitative PCR because of higher sensitivity.

In order to characterise the relationship of $\sigma 4$ or AP-4 and AP-1 in skeletal muscle, their expression should first of all be examined at the protein level. A mouse monoclonal antibody is available against $\epsilon$-adaptin, the AP-4 homologue to $\gamma 1$-adaptin, which could be used for western blot as well as for immunofluorescence studies. It is known that AP-4 localises to the TGN and probably binds to a coat protein different from clathrin (Hirst et al., 1999). In polarised cells, AP-4 participates in basolateral sorting (Simmen et al., 2002), probably sharing some of the cargo proteins with AP-1, such as furin and MPR46. However, there is no evident connection between AP-1 and AP-4 until now.

Thus, the absence of a phenotype in muscle tissues of $\sigma 1 \mathrm{~B}$-deficient mice is likely due to compensatory mechanisms. This could be upregulation of other transport units e.g., AP-4 or mVps26, or more indirect phenomena.

The organisation of vesicular transport differs remarkably between most mononucleated cells and skeletal muscle fibers (Towler et al., 2004b). Small assemblies of 


\section{Discussion}

Golgi stacks are associated with the nuclei or localise to the myofibrillar core of the muscle fiber. The precise arrangement depends on the type of fiber and is probably established by interaction with microtubuli (Ralston et al., 1999). Additional Golgi elements are found at the neuromuscular junction as a specialised site of secretion. Cardiac muscle is very similar to skeletal muscle, due to extensive connections between the mononucleated cells, but the morphology of its secretory compartments has not been determined in great detail.

Reflecting the specialised organisation of the secretory pathway in skeletal muscle, many components of the protein transport machinery were found as tissue-specific forms. One prominent example is $\mathrm{CHC} 22$, a muscle-specific isoform of clathrin heavy chain, which apparently differs from the ubiquitous form concerning localisation and interaction partners (Liu et al., 2001; Towler et al., 2004a). For most of these proteins, no specific functions have yet been described, but the interest in muscle-specific transport is continuously increasing.

\section{$4.6 \sigma 1 \mathrm{~B}-$ deficient T-lymphocytes}

The analyis of $\gamma 1$-adaptin $+/$ - mice had demonstrated that the development of T-lymphocytes was disturbed, resulting in an about $20 \%$ reduced population of $\mathrm{CD} 4{ }^{+} \mathrm{CD}^{-}$cells in the thymus. To determine if this process was affected in $\sigma 1 \mathrm{~B}-$ deficient mice as well, T-lymphocytes were isolated from thymus and spleen of 6 mice per genotype at the age of 7-9 weeks.

T-lymphocytes were labelled by fluorescent antibodies against CD4 and CD8 and quantitated by FACS analysis. In preparations from $\sigma 1 \mathrm{~B}-/-$ thymus, the fraction stained by CD8 only was increased about 1.4 fold to $4.2 \%$ compared to $3.1 \%$ of $\mathrm{T}$ cells in wt thymus, whereas the level of the other fractions remained unchanged. $\mathrm{T}$ cell preparations from spleen displayed only a slight increase of the CD8 single-positive population by 1.1 fold.

These results suggest, that the deficiency of $\sigma 1 \mathrm{~B}$ influenced the maturation of $\mathrm{T}$ lymphocytes, but did not affect the final level of CD4- or CD8-positive T cells in the periphery. The observed increase in the thymic CD8-positive population could be either due to a reduced exit rate from the thymus or due to alteration of the selection/proliferation equilibrium of thymocytes. Since the effect is contrary to the results from $\gamma 1+/$ - mice, the function of AP-1 cannot be clearly concluded. As for $\sigma 1$-adaptins, all the three genes are expressed in thymus. CD4- and CD8-positive Tlymphocytes could be selectively enriched by immunoisolation to determine whether they differ in expression of $\sigma 1$. Further work will intend to identify the molecular mechanisms underlying this phenotype. 


\subsection{Perspective}

Since there is no specific antiserum against one of the $\sigma 1$-adaptins, we cannot specifically detect the endogenous proteins. This problem could be overcome by expressing them as fusion constructs to short amino acid tags which can be labelled and immunoprecipitated by specific antibodies. Using this approach, it should be investigated if the AP-1 complexes containing different $\sigma 1$-subunits localise to specific intracellular compartments, and if they associate with $\gamma 1, \gamma 2$ or both $\gamma$-adaptins. These experiments are already in preparation.

To establish a specific immunofluorescence staining for $\gamma 2$, the domains of $\gamma 1$ which are homologous to the part of $\gamma 2$ used as an antigen, should be purified as GST-fusion protein and mixed with the polyclonal $\gamma 2$-antiserum to test whether the crossreaction with $\gamma 1$-adaptin can be blocked while $\gamma 2$-adaptin is still recognised.

Moreover, $\sigma 1 \mathrm{~B}$-/- skeletal muscle should be further examined by western blot and by immunostaining. The dominant expression of $\sigma 1 \mathrm{~B}$ in muscle tissues needs to be confirmed at the protein level. Muscle cryosections should be stained for $\gamma 1$ adaptin in combination with marker proteins for the Golgi and for the neuromuscular junction.

Verification of differential expression in $\sigma 1 \mathrm{~B}$-/- skeletal muscle should be pursued considering more sensitive detection methods such as quantitative PCR. 
4 Discussion 


\section{Summary}

The comparison of database sequences from representative organisms revealed that three genes for $\sigma 1$-adaptin exist in all the vertebrates. Expression of the three $\sigma 1$ genes $\sigma 1 \mathrm{~A}$, - $\mathrm{B}$ and $-\mathrm{C}$ in various tissues was examined using PCR and northern blot. Most tissues contained all three transcripts, but their expression levels varied depending on the tissue. $\sigma 1 \mathrm{~B}$ was the most abundant RNA isoform in skeletal muscle and heart. Alternative splicing of $\sigma 1 \mathrm{~B}$ RNA was shown to generate two different mRNA variants due to the incorporation of two alternative exons after exon 4 . The previously known form, $\sigma 1 \mathrm{~B} 1$, appears to be ubiquitously expressed, whereas the variant $\sigma 1 \mathrm{~B} 2$ was specifically detected in intestine, brain and thyroid gland. In contrast, $\sigma 1 \mathrm{~B} 3$ is formed in skeletal muscle and heart.

By immunisation of rabbits, polyclonal antisera were generated against $\sigma 1$-adaptin and $\gamma 2$-adaptin, which could be used for western blot and immunofluorescence experiments. GST-fusion constructs as well as selected peptides were presented as antigens to obtain a $\sigma 1 \mathrm{~A}$ - or $\sigma 1 \mathrm{~B}$-specific antiserum, but no specific immunoreactivity could be detected.

The gene locus for $\sigma 1 \mathrm{~B}$ on the mouse $\mathrm{X}$ chromosome was disrupted by introduction of a neomycin resistance cassette into exon 3. After electroporation of the targeting construct in ES cells, homologous recombination was found at a frequency of $10 \%$ among the neomycin-resistant clones. The injection of recombinant ES cells into blastocysts gave rise to three chimeric male mice, out of which one showed germline transmission of the mutant locus. $\sigma 1 \mathrm{~B}$-deficient mice of both genotypes were obtained by further breeding, which did not apparently differ from their wildtype littermates. Depletion of $\sigma 1 \mathrm{~B}$ RNA was confirmed by northern blot. Histological analysis of selected tissues did not detect any alteration due to $\sigma 1 \mathrm{~B}$-deficiency.

Embryonic fibroblast cell lines were established from $\sigma 1 \mathrm{~B}$-deficient mice. Protein levels of the adaptins $\gamma 1, \mu 1, \gamma 2$ and the total level of $\sigma 1$ were not changed in the $\sigma 1 \mathrm{~B}$-/- fibroblasts, suggesting either that $\sigma 1 \mathrm{~B}$ does not significantly contribute to the $\sigma 1$ population in wt fibroblasts or that $\sigma 1 \mathrm{~A}$ and/or $\sigma 1 \mathrm{C}$ compensate for the absence of $\sigma 1 \mathrm{~B}$. Consistently, $\gamma 1$ and $\mu 1$ were detected at an apparent size of 250$300 \mathrm{kDa}$ by gelfiltration, which corresponds to the size of tetrameric AP-1 or trimeric AP-1 lacking the $\sigma 1$ subunit. In both wt and $\sigma 1 \mathrm{~B}-/-$ cells, $\gamma 2$ eluted in the same 


\section{Summary}

fractions as $\gamma 1$ and $\mu 1$, indicating that it forms a complex of similar size, which is still uncharacterised. The intracellular localisation of $\gamma 1$-containing AP-1-complexes was not affected, as shown by immunofluorescence. Similarly, immunofluorescence staining with our polyclonal $\gamma 2$-antiserum, which crossreacts weakly with $\gamma 1$, suggested that there is no dramatic redistribution of $\gamma 2$.

To screen for potential compensatory mechanisms which substitute for $\sigma 1 \mathrm{~B}$ function in muscle tissue, gene expression in skeletal muscle was analysed by microarray hybridisation. About 50 genes showed differential expression in $\sigma 1 B$-deficient compared to wt tissue. Verification of these results is still in progress. Preliminary analysis of immunofluorescence labelling in muscle cryosections indicates that a decreased membrane association of $\gamma 1$-complexes in $\sigma 1 \mathrm{~B}-/$ - muscle, but these data have to be confirmed in sections of different animals and with respect to a reference staining.

Analysis of T-lymphocyte populations in thymus and spleen revealed an increase in the fraction of CD8 single-positive $\mathrm{T}$ cells in $\sigma 1 \mathrm{~B}$-deficient compared to wt thymus. However, the significance of this observation needs to be confirmed. 


\section{Bibliography}

Altschul, SF, Gish, W, Miller, W, Myers, EW \& Lipman, DJ. 1990. Basic local alignment search tool. $J$ Mol Biol, 215, 403-410. http://www.ncbi.nlm.nih.gov/BLAST/.

Ang, AL, Fölsch, H, Koivisto, UM, Pypaert, M \& Mellman, I. 2003. The Rab8 GTPase selectively regulates AP-1B-dependent basolateral transport in polarized madin-darby canine kidney cells. J Cell Biol, 2, 339-350.

Arighi, CN, Hartnell, LM, Aguilar, RC, Haft, CR \& Bonifacino, JS. 2004. Role of the mammalian retromer in sorting of the cation-independent mannose 6-phosphate receptor. J Cell Biol, 165 (1), 123-133.

Austin, C, Boehm, M \& Tooze, SA. 2002. Site-specific cross-linking reveals a differential direct interaction of class 1, 2, and 3 ADP-ribosylation factors with adaptor protein complexes 1 and 3. Biochemistry, 41 (14), 4669-4677.

Austin, C, Hinners, I \& Tooze, SA. 2000. Direct and GTP-dependent interaction of ADP-ribosylation factor 1 with clathrin adaptor protein AP-1 on immature secretory granules. J Biol Chem, 275 (29), 21862-21869.

Ausubel, FM, Brent, R, Kingston, RE, Moore, DD, Seidman, JG, Smith, JA \& Struhl, K, eds. 1994. Current Protocols in molecular biology. John Wiley and Sons, Inc.

Azzam, HS, DeJarnette, JB, Huang, K, Emmons, R, Park, CS, Sommers, CL, ElKhoury, D, Shores, EW \& Love, PE. 2001. Fine tuning of TCR signaling by CD5. J Immunol, 166, 5464-5472.

Azzam, HS, Grinberg, A, Lui, K, Shen, H, Shores, EW \& Love, PE. 1998. CD5 expression is developmentally regulated by $\mathrm{T}$ cell receptor (TCR) signals and TCR avidity. J Exp Med, 188 (12), 2301-2311. 


\section{Bibliography}

Ball, CL, Hunt, SP \& Robinson, MS. 1995. Expression and localization of $\alpha$-adaptin isoforms. J Cell Sci, 108 (8), 2865-2875.

Barlowe, C. 2000. Traffic COPs of the early secretory pathway. Traffic, 1, 371-377.

Boehm, M \& Bonifacino, JS. 2001. Adaptins: the final recount. Mol Biol Cell, 12, $2907-2920$.

Bonifacino, JS. 2004. The GGA proteins: adaptors on the move. Nat Rev Mol Cell Biol, 5, 23-32.

Bonifacino, JS \& Glick, BS. 2004. The mechanisms of vesicle budding and fusion. Cell, 116, 153-166.

Bonifacino, JS \& Lippincott-Schwartz, J. 2003. Coat proteins: shaping membrane transport. Nat Rev Mol Cell Biol, 4, 409-414.

Bonifacino, JS \& Traub, LM. 2003. Signals for sorting of transmembrane proteins to endosomes and lysosomes. Annu Rev Biochem, 72, 395-447.

Bremnes, T, Lauvrak, V, Lindqvist, B \& Bakke, O. 1998. A region from the medium chain adaptor subunit $(\mu)$ recognizes leucine- and tyrosine-based sorting signals. J Biol Chem, 273 (15), 8638-8645.

Brodsky, FM, Chen, CY, Knuehl, C, Towler, MC \& Wakeham, DE. 2001. Biological basket weaving: formation and function of clathrin-coated vesicles. Annu Rev Cell Dev Biol, 17, 517-68.

Chavrier, P \& Goud, B. 1999. The role of ARF and Rab GTPases in membrane transport. Curr Opin Cell Biol, 11, 466-475.

Chidambaram, S, Müllers, N, Wiederhold, K, Haucke, V \& von Mollard, GF. 2004. Specific interaction between SNAREs and epsin N-terminal homology (ENTH) domains of epsin-related proteins in trans-golgi network to endosome transport. J Biol Chem, 279 (6), 4175-4179.

Claussen, M, Buergisser, D, Schuller, AGP, Matzner, U \& Braulke, T. 1995. Regulation of insulin-like growth factor (IGF)-binding protein-6 and mannose 6phosphate/IGF-II receptor expressing in IGF-II-overexpressing NIH 3T3 cells. Mol Endocrinol, 9, 902-912.

Collins, BM, McCoy, AJ, Kent, HM, Evans, PR \& Owen, DJ. 2002. Molecular architecture and functional model of the endocytic AP2 complex. Cell, 109, $523-535$. 
Corvera, S, D'Arrigo, A \& Stenmark, H. 1999. Phosphoinositides in membrane traffic. Curr Opin Cell Biol, 11, 460-465.

Crottet, P, Meyer, DM, Rohrer, J \& Spiess, M. 2002. ARF1-GTP, tyrosine-based signals, and phosphatidylinositol 4,5-bisphosphate constitute a minimal machinery to recruit the AP-1 clathrin adaptor to membranes. Mol Biol Cell, 13, 3672-3682.

Crump, CM, Xiang, Y, Thomas, L, Gu, F, Austin, C, Tooze, SA \& Thomas, G. 2001. PACS-1 binding to adaptors is required for acidic cluster motif-mediated protein traffic. EMBO J, 20, 2192-2201.

Dell'Angelica, EC, Klumperman, J, Stoorvogel, W \& Bonifacino, JS. 1998. Association of the ap-3 adaptor complex with clathrin. Science, 280, 431-434.

Dell'Angelica, EC, Ohno, H, Ooi, CE, Rabinovich, E, Roche, KW \& Bonifacino, JS. 1997. AP-3: an adaptor-like protein complex with ubiquitous expression. EMBO J, $16(5), 917-928$.

DeMatteis, MA, Godi, A \& Corda, D. 2002. Phosphoinositides and the Golgi complex. Curr Opin Cell Biol, 14, 434-447.

Deneka, M, Neeft, M, Popa, I, van Oort, M, Sprong, H, Oorschot, V, Klumperman, J, Schu, P \& van der Sluijs, P. 2003. Rabaptin-5 $\alpha /$ rabaptin-4 serves as a linker between rab4 and $\gamma 1$-adaptin in membrane recycling from endosomes. EMBO J, 22 (11), 2645-2657.

Dittié, AS, Thomas, L, Thomas, G \& Tooze, SA. 1997. Interaction of furin in immature secretory granules from neuroendocrine cells with the AP-1 adaptor complex is modulated by casein kinase II phosphorylation. EMBO J, 16, 48594870 .

Doray, B, Ghosh, P, Griffith, J, Geuze, HJ \& Kornfeld, S. 2002. Cooperation of GGAs and AP-1 in packaging MPRs at the trans-golgi network. Science, 297, 1700-1703.

Doray, B \& Kornfeld, S. 2001. $\gamma$ subunit of the AP-1 adaptor complex binds clathrin: implications for cooperative binding in clathrin vesicle assembly. Mol Biol Cell, 12, 1925-1935.

Duncan, MC, Costaguta, G \& Payne, GS. 2003. Yeast epsin-related proteins required for Golgi-endosome traffic define a $\gamma$-adaptin ear-binding motif. Nat Cell Biol, 5, $77-81$. 


\section{Bibliography}

Eskelinen, EL, Meyer, C, Ohno, H, von Figura, K \& Schu, P. 2002. The polarized epithelia-specific $\mu 1 \mathrm{~B}$-adaptin complements $\mu 1 \mathrm{~A}$-deficiency in fibroblasts. EMBO reports, 3 (5), 471-477.

Faúndez, V, Horng, JT \& Kelly, RB. 1998. A function for the AP3 coat complex in synaptic vesicle formation from endosomes. Cell, 93, 423-432.

Fölsch, H, Ohno, H, Bonifacino, JS \& Mellman, I. 1999. A novel clathrin adaptor complex mediates basolateral targeting in polarized epithelial cells. Cell, 99, 189-198.

Fölsch, H, Pypaert, M, Maday, S, Pelletier, L \& Mellman, I. 2003. The AP-1A and AP-1B clathrin adaptor complexes define biochemically and functionally distinct membrane domains. J Cell Biol, 163 (2), 351-362.

Fölsch, H, Pypaert, M, Schu, P \& Mellman, I. 2001. Distribution and function of AP-1 clathrin adaptor complexes in polarized epithelial cells. J Cell Biol, 152 (3), 595-606.

Ford, MGJ, Mills, IG, Peter, BJ, Vallis, Y, Praefcke, GJK, Evans, PR \& McMahon, HT. 2002. Curvature of clathrin-coated pits driven by epsin. Nature, 419, $361-366$.

Gaidarov, I \& Keen, JH. 1999. Phosphoinositide-AP-2 interactions required for targeting to plasma membrane clathrin-coated pits. J Cell Biol, 146, 755-764.

Gaidarov, I, Smith, ME, Domin, J \& Keen, JH. 2001. The class II phosphoinositide 3-kinase $\mathrm{C} 2 \alpha$ is activated by clathrin and regulates clathrin-mediated membrane trafficking. Mol Cell, 7, 443-449.

Gan, Y, McGraw, TE \& Rodriguez-Boulan, E. 2002. The epithelial-specific adaptor AP1B mediates post-endocytic recycling to the basolateral membrane. Nat Cell Biol, 4, 605-609.

Ghosh, P, Dahms, NM \& Kornfeld, S. 2003a. Mannose 6-phosphate receptors: new twists in the tale. Nat Rev Mol Cell Biol, 4, 202-212.

Ghosh, P, Griffith, J, Geuze, HJ \& Kornfeld, S. 2003b. Mammalian GGAs act together to sort mannose 6-phosphate receptors. J Cell Biol, 163 (4), 755-766.

Ghosh, P \& Kornfeld, S. 2003a. Phosphorylation-induced conformational changes regulate GGAs 1 and 3 function at the trans-golgi network. J Biol Chem, 278, 14543-14549. 
Ghosh, P \& Kornfeld, S. 2003b. AP-1 binding to sorting signals and release from clathrin-coated vesicles is regulated by phosphorylation. J Cell Biol, 160 (5), 699-708.

Glick, BS. 2002. Can the Golgi form de novo? Nat Rev Mol Cell Biol, 3, 615-619.

Godi, A, Pertile, P, Meyers, R, Marra, P, Tullio, GD, Iurisci, C, Luini, A, Corda, D $\&$ Matteis, MAD. 1999. ARF mediates recruitment of PtdIns-4-OH kinase- $\beta$ and stimulates synthesis of PtdIns(4,5)P2 on the golgi complex. Nat Cell Biol, 1, 280-287.

Hannan, LA, Newmyer, SL \& Schmid, SL. 1998. ATP- and cytosol-dependent release of adaptor proteins from clathrin-coated vesicles: a dual role for Hsc70. Mol Biol Cell, 9, 2217-2229.

Hartmann-Stühler, C \& Prange, R. 2001. Hepatitis B virus large envelope protein interacts with $\gamma 2$-adaptin, a clathrin adaptor-related protein. J Virol, 75 (11), $5343-5351$.

Hasty, P, Crist, M, Grompe, M \& Bradley, A. 1994. Efficiency of insertion versus replacement vector targeting varies at different chromosomal loci. Mol Cell Biol, 14 (12), 8385-8390.

Higgins, D, Thompson, J \& Gibson, T. 1994. CLUSTAL W: improving the sensitivity of progressive multiple sequence alignment through sequence weighting, positionspecific gap penalties and weight matrix choice. Nucleic Acids Res, 22, 46734680. http://www.ebi.ac.uk/clustalw.

Hille-Rehfeld, A. 1995. Mannose 6-phosphate receptors in sorting and transport of lysosomal enzymes. Biochim Biophys Acta, 1241, 177-194.

Hinrichsen, L, Harborth, J, Andrees, L, Weber, K \& Ungewickell, EJ. 2003. Effect of clathrin heavy chain- and $\alpha$-adaptin specific small interfering RNAs on endocytic accessory proteins and receptor trafficking in HeLa cells. J Biol Chem, 278 (46), 45160-45170.

Hirst, J, Bright, NA, Rous, B \& Robinson, MS. 1999. Characterization of a fourth adaptor-related protein complex. Mol Biol Cell, 10, 2787-2802.

Hirst, J, Motley, A, Harasaki, K, Chew, SYP \& Robinson, MS. 2003. EpsinR: an ENTH domain-containing protein that interacts with AP-1. Mol Biol Cell, 14, 625-641. 


\section{Bibliography}

Hirst, J \& Robinson, MS. 1998. Clathrin and adaptors. Biochim Biophys Acta, 1404, 173-193.

Hofmann, MW, Höning, S, Rodionov, D, Dobberstein, B, von Figura, K \& Bakke, O. 1999. The leucine-based sorting motifs in the cytoplasmic domain of the invariant chain are recognized by the clathrin adaptors AP1 and AP2 and their medium chains. J Biol Chem, 274 (51), 36153-36158.

Höning, S, Griffith, J, Geuze, HJ \& Hunziker, W. 1996. The tyrosine-based lysosomal targeting signal in lamp-1 mediates sorting into Golgi-derived clathrin-coated vesicles. EMBO J, 15 (19), 5230-5239.

Höning, S, Sosa, M, Hille-Rehfeld, A \& von Figura, K. 1997. The 46-kDa mannose 6-phosphate receptor contains multiple binding sites for clathrin adaptors. J Biol Chem, 272 (32), 19884-19890.

Hooper, M, Hardy, K, Handyside, A, Hunter, S \& Monk, M. 1987. HPRT-deficient Lesch-Nyhan mouse embryos derived from germline colonization by cultured cells. Nature, 326, 292-295.

Huang, F, Nesterov, A, Carter, RE \& Sorkin, A. 2001. Trafficking of yellowfluorescent-protein-tagged $\mu 1$ subunit of clathrin adaptor AP-1 complex in living cells. Traffic, 2, 345-357.

Hurley, JH \& Meyer, T. 2001. Subcellular targeting by membrane lipids. Curr Opin Cell Biol, 13, 146-153.

Jahn, R, Lang, T \& Südhof, TC. 2003. Membrane fusion. Cell, 112, 519-533.

Janvier, K, Kato, Y, Boehm, M, Rose, JR, Martina, JA, Kim, BY, Venkatesan, S \& Bonifacino, JS. 2003. Recognition of dileucine-based sorting signals from HIV-1 Nef and LIMP-II by the AP-1 $\gamma-\sigma 1$ and AP-3 $\delta-\sigma 3$ hemicomplexes. $J$ Cell Biol, 163 (6), 1281-1290.

Johnson, KF \& Kornfeld, SA. 1992. A His-Leu-Leu sequence near the carboxyl terminus of the cytoplasmic domain of the cation-dependent mannose 6-phosphate receptor is necessary for the lysosomal enzyme sorting function. J Biol Chem, $267,17110-17115$.

Kaisto, T. 2003. Special features of vesicle trafficking in skeletal muscle cells. PhD thesis, University of Oulu. http://herkules.oulu.fi/isbn9514271521/.

Keen, JH, Beck, KA, Kirchhausen, T \& Jarrett, T. 1991. Clathrin domains involved in recognition by assembly protein AP-2. J Biol Chem, 266 (12), 7950-7956. 
Kent, HM, McMahon, HT, Evans, PR, Benmerah, A \& Owen, DJ. 2002. $\gamma$-adaptin appendage domain: structure and binding site for Eps15 and $\gamma$-synergin. Structure, 10, 1139-1148.

Kirchhausen, T. 2000. Clathrin. Annu Rev Biochem, 69, 699-727.

Kirchhausen, T \& Harrison, SC. 1981. Protein organization in clathrin trimers. Cell, $23(3), 755-761$.

Klumperman, J, Hille, A, Veenendaal, T, Oorschot, V, Stoorvogel, W, von Figura, K \& Geuze, HJ. 1993. Differences in the endosomal distributions of the two mannose 6-phosphate receptors. J Cell Biol, 121, 997-1010.

Klumperman, J, Kuliawat, R, Griffith, JM, Geuze, HJ \& Arvan, P. 1998. Mannose 6-phosphate receptors are sorted from immature secretory granules via adaptor protein AP-1, clathrin, and syntaxin 6-positive vesicles. J Cell Biol, 141 (2), $359-371$.

Krauss, M, Kinuta, M, Wenk, MR, Camilli, PD, Takei, K \& Haucke, V. 2003. ARF6 stimulates clathrin/AP-2 recruitment to synaptic membranes by activatin phosphatidylinositol phoshpate kinase type i $\gamma$. J Cell Biol, 162 (1), 113-124.

Lewin, DA, Sheff, D, Ooi, CE, Whitney, JA, Yamamoto, E, Chicione, LM, Webster, P, Bonifacino, JS \& Mellman, I. 1998. Cloning, expression, and localization of a novel gamma-adaptin-like molecule. FEBS Lett, 435 (2-3), 263-268.

Liu, SH, Towler, MC, Chen, E, Chen, CY, Song, W, Apodaca, G \& Brodsky, FM. 2001. A novel clathrin homolog that co-distributes with cytoskeletal components functions in the trans-Golgi network. EMBO J, 20 (1), 272-2001.

Liu, SH, Wong, ML, Craik, CS \& Brodsky, FM. 1995. Regulation of clathrin assembly and trimerization defined using recombinant triskelion hubs. Cell, 83, $257-267$.

Lui, WWY, Collins, BM, Hirst, J, Motley, A, Millar, C, Schu, P, Owen, DJ \& Robinson, MS. 2003. Binding partners for the COOH-terminal appendage domains of the GGAs and $\gamma$-adaptin. Mol Biol Cell, 14, 2385-2398.

Lundmark, R \& Carlsson, SR. 2002. The $\beta$-appendages of the four adaptor-protein (AP) complexes: structure and binding properties, and identification of sorting nexin 9 as an accessory protein to AP-2. Biochem $J, \quad 362,597-607$. 


\section{Bibliography}

Mallard, F, Antony, C, Tenza, D, Salamero, J, Goud, B \& Johannes, L. 1998. Direct pathway from early/recycling endosomes to the Golgi apparatus revealed through the study of Shiga toxin B-fragment transport. J Cell Biol, 143 (4), 973-990.

Mansour, SL, Thomas, KR \& Capecchi, MR. 1988. Disruption of the proto-oncogene int-2 in mouse embryo-derived stem cells: a general strategy for targeting mutations to non-selectable genes. Nature, 336, 348-352.

Marchler-Bauer, A, Anderson, JB, DeWeese-Scott, C, Fedorova, ND, Geer, LY, He, S, Hurwitz, DI, Jackson, JD, Jacobs, AR, Lancycki, CJ, Liebert, CA, Liu, C, Madej, T, Marchler, GH, Mazumder, R, Nikolskaya, AN, Panchenko, AR, Rao, BS, Shoemaker, BA, Simonyan, V, Song, JS, Thiessen, PA, Vasudevan, S, Wang, Y, Yamashita, RA \& Bryant, SH. 2003. CDD: a curated Entrez database of conserved domain alignments. Nucleic Acids Res, 31, 383-387. http://www.ncbi.nlm.nih.gov/entrez/query.fcgi?db=cdd.

Marks, MS, Woodruff, L, Ohno, H \& Bonifacino, JS. 1996. Protein targeting by tyrosine- and di-leucine-based signals: evidence for distinct saturable components. J Cell Biol, 135 (2), 341-354.

Martin, TFJ. 1997. Phosphoinositides as spatial regulators of membrane traffic. Curr Opin Neurobiol, 7, 331-338.

Mattera, R, Arighi, CN, Lodge, R, Zerial, M \& Bonifacino, JS. 2003. Divalent interaction of the GGAs with the rabaptin-5-rabex-5 complex. EMBO J, 22, $78-88$.

Medigeshi, GR \& Schu, P. 2003. Characterization of the in vitro retrograde transport of MPR46. Traffic, 4 (11), 802-811.

Meyer, C, Eskelinen, EL, Guruprasad, MR, von Figura, K \& Schu, P. 2001. $\mu 1 \mathrm{~A}-$ deficiency induces a profound increase of MPR300/IGF-II receptor internalization rate. J Cell Sci, 114, 4469-4476.

Meyer, C, Zizioli, D, Lausmann, S, Eskelinen, EL, Hamann, J, Saftig, P, von Figura, K \& Schu, P. 2000. $\mu 1 \mathrm{~A}$ adaptin-deficient mice: lethality, loss of AP-1 binding and rerouting of mannose 6-phosphate receptors. EMBO J, 19, 2193-2203.

Mills, IG, Praefcke, GJK, Vallis, Y, Peter, BJ, Olesen, LE, Gallop, JL, Butler, PJG, Evans, PR \& McMahon, HT. 2003. EpsinR: an AP1/clathrin interacting protein involved in vesicle trafficking. J Cell Biol, 160 (2), 213-222. 
Motley, A, Bright, NA, Seaman, MN \& Robinson, MS. 2003. Clathrin-mediated endocytosis in AP-2-depleted cells. J Cell Biol, 162, 909-918.

Müller, W, Kuhn, R \& Rajewsky, K. 1991. Major histocompatibility complex class II hyperextension on B cells in interleukin 4-transgenic mice does not lead to B cell proliferation and hypergammaglobulinemia. Eur J Immunol, 21 (4), 921-925.

Murphy, JE \& Keen, JH. 1992. Recognition sites for clathrin-associated proteins AP-2 and AP-3 on clathrin triskelia. J Biol Chem, 267 (15), 10850-10855.

Nakagawa, T, Setou, M, Seog, DH, Ogasawara, K, Dohmae, N, Takio, K \& Hirokawa, N. 2000. A novel motor, KIF13A, transports mannose 6-phosphate receptor to plasma membrane through direct interaction with AP-1 complex. Cell, 103, $569-581$.

Ohno, H, Aguilar, RC, Yeh, D, Taura, D, Saito, T \& Bonifacino, JS. 1998. The medium subunits of adaptor complexes recognize distinct but overlapping sets of tyrosine-based sorting signals. J Biol Chem, 273 (40), 25915-25921.

Ohno, H, Tomemori, T, Nakatsu, F, Okazaki, Y, Aguilar, RC, Fölsch, H, Mellman, I, Saito, T, Shirasawa, T \& Bonifacino, JS. 1999. $\mu 1 \mathrm{~B}$, a novel adaptor medium chain expressed in polarized epithelial cell. FEBS Lett, 449, 215-220.

Orzech, E, Livshits, L, Leyt, J, Okhrimenko, H, Reich, V, Cohen, S, Weiss, A, Melamed-Book, N, Lebendiker, M, Altschuler, Y \& Aroeti, B. 2001. Interactions between adaptor protein-1 of the clathrin coat and microtubules via type 1a microtubule-associated proteins. J Biol Chem, 276 (33), 31340-31348.

Owen, DJ \& Evans, PR. 1998. A structural explanation for the recognition of tyrosine-based endocytotic signals. Science, 282, 1327-1332.

Owen, DJ, Vallis, Y, Pearse, BP, McMahon, HT \& Evans, PR. 2000. The structure and function of the $\beta 2$-adaptin appendage domain. EMBO J, 19 (16), 4216-4227.

Page, LJ, Sowerby, PJ, Lui, WWY \& Robinson, MS. 1999. $\gamma$-synergin: an EH domain-containing protein that interacts with $\gamma$-adaptin. J Cell Biol, 146 (5), 993-1004.

Pearse, B \& Robinson, MS. 1984. Purification and properties of $100 \mathrm{kd}$ proteins from coated vesicles and their reconstitution with clathrin. EMBO J, 4, 2457-2460.

Peden, AA, Oorschot, V, Hesser, BA, Austin, CD, Scheller, RH \& Klumperman, J. 2004. Localization of the AP-3 adaptor complex defines a novel endosomal exit site for lysosomal membrane proteins. J Cell Biol, 164 (7), 1065-1076. 


\section{Bibliography}

Peyrard, M, Parveneh, S, Lagercrantz, S, Ekman, M, Fransson, I, Sahlen, S \& Dumanski, JP. 1998. Cloning, expression pattern and chromosomal assignment to 16q23 of the human gamma-adaptin gene (ADTG). Genomics, 50 (2), 275-280.

Puertollano, R, Aguilar, RC, Gorshkova, I, Crouch, RJ \& Bonifacino, JS. 2001. Sorting of mannose 6-phosphate receptors mediated by the GGAs. Science, 292, $1712-1716$.

Puertollano, R \& Bonifacino, JS. 2004. Interactions of GGA3 with the ubiquitin sorting machinery. Nat Cell Biol, 6 (3), 244-251.

Raiborg, C, Bache, KG, Mehlum, A, Stang, E \& Stenmark, H. 2001a. Hrs recruits clathrin to early endosomes. EMBO J, 20, 5008-5021.

Raiborg, C, Bremnes, B, Mehlum, A, Gillooly, DJ, D’Arrigo, A, Stang, E \& Stenmark, H. 2001b. FYVE and coiled-coil domains determine the specific localisation of Hrs to early endosomes. J Cell Sci, 114, 2255-2263.

Ralston, E, Lu, Z \& Ploug, T. 1999. The organization of the Golgi complex and microtubules in skeletal muscle is fiber type-dependent. J Neurosci, 19 (24), 10694-10705.

Rapoport, I, Chen, YC, Cupers, P, Shoelson, SE \& Kirchhausen, T. 1998. Dileucinebased sorting signals bind to the $\beta$ chain of AP-1 at a site distinct and regulated differently from the tyrosine-based motif-binding site. EMBO J, 17 (8), 21482155 .

Reusch, U, Bernhard, O, Koszinowski, U \& Schu, P. 2002. AP-1A and AP-3A lysosomal sorting functions. Traffic, 3, 752-761.

Reusch, U, Muranyi, W, Lucin, P, Burgert, HG, Hengel, H \& Koszinowski, UH. 1999. A cytomegalovirus glycoprotein re-routes MHC class I complexes to lysosomes for degradation. EMBO J, 18, 1081-1091.

Ricotta, D, Conner, SD, Schmid, SL, von Figura, K \& Höning, S. 2002. Phosphorylation of the AP2 $\mu$ subunit by AAK1 mediates high affinity binding to membrane protein sorting signals. J Cell Biol, 156 (5), 791-795.

Robinson, MS \& Bonifacino, JS. 2001. Adaptor-related proteins. Curr Opin Cell Biol, 13, 444-453.

Robinson, MS \& Kreis, TE. 1992. Recruitment of coat proteins onto Golgi membranes in intact and permeabilized cells: effects of Brefeldin A and G protein activators. Cell, 69, 129-138. 
Rohde, G, Wenzel, D \& Haucke, V. 2002. A phosphatidylinositol(4,5)-bisphosphate binding site within $\mu 2$-adaptin regulates clathrin-mediated endocytosis. $J$ Cell Biol, 158, 209-214.

Rohrer, J, Schweizer, A, Russell, D \& Kornfeld, S. 1996. The targeting of lamp1 to lysosomes is dependent on the spacing of its cytoplasmic tail tyrosine sorting motif relative to the membrane. J Cell Biol, 132, 565-576.

Sachse, M, Urbé, S, Oorschot, V, Strous, GJ \& Klumperman, J. 2002. Bilayered clathrin coats on endosomal vacuoles are involved in protein sorting toward lysosomes. Mol Biol Cell, 13, 1313-1328.

Schledzewski, K, Brinkmann, H \& Mendel, RR. 1999. Phylogenetic analysis of components of the eukaryotic vesicle transport system reveals a common origin of adaptor protein complexes 1, 2 and 3 and the F subcomplex of the coatomer COPI. J Mol Evol, 48, 770-778.

Schneider, WJ, Slaughter, CJ, Goldstein, JL, Anderson, RGW, Capra, JD \& Brown, MS. 1983. Use of antipeptide antibodies to demonstrate external orientation of the N-terminus of the low density lipoprotein receptor in the plasma membrane of fibroblasts. J Cell Biol, 97, 1635-1640.

Schu, P. 2001. Vesicular protein transport. Pharmacogenomics J, 1, 262-271.

Seaman, MNJ. 2004. Cargo-selective endosomal sorting for retrieval to the Golgi requires retromer. J Cell Biol, 165 (1), 111-122.

Shinotsuka, C, Yoshida, Y, Kawamoto, K, Takatsu, H \& Nakayama, K. 2002. Overexpression of an ADP-ribosylation factor-guanine nucleotide exchange factor, BIG2, uncouples Brefeldin A-induced adaptor protein-1 coat dissociation and membrane tubulation. J Biol Chem, 277 (11), 9468-9473.

Simmen, T, Höning, S, Icking, A, Tikkanen, R \& Hunziker, W. 2002. AP-4 binds basolateral signals and participates in basolateral sorting in epithelial MDCK cells. Nat Cell Biol, 4, 154-159.

Simpson, F, Peden, AA, Christopoulou, L \& Robinson, MS. 1997. Characterization of the adaptor-related protein complex, AP-3. J Cell Biol, 137 (4), 835-845.

Snouwaert, JN, Brigman, KK, Latour, AM, Malouf, NN, Boucher, RC, Smithies, O \& Koller, BH. 1992. An animal model for cystic fibrosis made by gene targeting. Science, 257, 1083-1088. 


\section{Bibliography}

Stamnes, MA \& Rothman, JE. 1993. The binding of AP-1 clathrin adaptor particles to Golgi membranes requires ADP-ribosylation factor, a small GTP-binding protein. Cell, 73, 999-1005.

Stenmark, H, Vitale, G, Ullrich, O \& Zerial, M. 1995. Rabaptin-5 is a direct effector of the small GTPase Rab5 in endocytic membrane fusion. Cell, 83 (3), 423-433.

Sugimoto, H, Sugahara, M, Fölsch, H, Koide, Y, Nakatsu, F, Tanaka, N, Nishimura, T, Furukawa, M, Mullins, C, Nakamura, N, Mellman, I \& Ohno, H. 2002. Differential recognition of tyrosine-based basolateral signals by AP-1B subunit $\mu 1 \mathrm{~B}$ in polarized epithelial cells. Mol Biol Cell, 13, 2374-2382.

Takatsu, H, Futatsumori, M, K.Yoshino, Yoshida, Y, Shin, HW \& Nakayama, K. 2001. Similar subunit interactions contribute to assembly of clathrin adaptor complexes and COPI complex: analysis using yeast three-hybrid system. Biochem Biophys Res Commun, 284, 1083-1089.

Takatsu, H, Sakurai, M, Shin, HW, Murakami, K \& Nakayama, K. 1998. Identification and characterization of novel clathrin adaptor-related proteins. J Biol Chem, 273 (38), 24693-24700.

ter Haar, E, Musacchio, A, Harrison, SC \& Kirchhausen, T. 2000. Peptide-in-groove interactions link target proteins to the $\beta$-propeller of clathrin. Proc Natl Acad Sci USA, 97, 1096-1100.

Thomas, G. 2002. Furin at the cutting edge: from protein traffic to embryogenesis and disease. Nat Rev Mol Cell Biol, 3, 753-766.

Thomas, KR \& Capecchi, MR. 1987. Site-directed mutagenesis by gene targeting in mouse embryo-derived stem cells. Cell, 51 (3), 503-512.

Tikkanen, R, Obermüller, S, Denzer, K, Pungitore, R, Geuze, HJ, von Figura, K \& Honing, S. 2000. The dileucine motif within the tail of MPR46 is required for sorting of the receptor in endosomes. Traffic, 1, 631-640.

Towler, MC, Gleeson, PA, Hoshino, S, Rahkila, P, Manalo, V, Ohkoshi, N, Ordahl, C, Parton, RG \& Brodsky, FM. 2004a. Clathrin isoform CHC22, a component of neuromuscular and myotendinous junctions, binds sorting nexin 5 and has increased expression during myogenesis and muscle regeneration. Mol Biol Cell, $15,3181-3195$.

Towler, MC, Kaufman, SJ \& Brodsky, FM. 2004b. Membrane traffic in skeletal muscle. Traffic, 5, 129-139. 
Traub, LM. 2003. Sorting it out: AP-2 and alternate clathrin adaptors in endocytic cargo selection. J Cell Biol, 163 (2), 203-208.

Umeda, A, Meyerholz, A \& Ungewickell, E. 2000. Identification of the universal cofactor (auxilin 2) in clathrin coat dissociation. Eur J Cell Biol, 79, 336-342.

Vidal, H, Auboeuf, D, DeVos, P, Staels, B, Riou, JP, Auwerx, J \& Laville, M. 1997. Quantitation of leptin mRNA in human adipose tissue by RT-competitive PCR. QIAGEN News, 2 (1).

Waguri, S, Dewitte, F, Borgne, RL, Rouillé, Y, Uchiyama, Y, Dubremetz, JF \& Hoflack, B. 2003. Visualization of TGN to endosome trafficking through fluorescently labeled MPR and AP-1 in living cells. Mol Biol Cell, 14, 142-155.

Wan, L, Molloy, SS, Thomas, L, Liu, G, Xiang, Y, Rybak, SL \& Thomas, G. 1998. PACS-1 defines a novel gene family of cytosolic sorting proteins required for trans Golgi network localization. Cell, 94, 205-216.

Wang, YJ, Wang, J, Sun, HQ, Martinez, M, Sun, YX, Macia, E, Kirchhausen, T, Albanesi, JP, Roth, MG \& Yin, HL. 2003. Phosphatidylinositol 4 phosphate regulates targeting of clathrin adaptor AP-1 complexes to the Golgi. Cell, 114, 299-310.

West, MA, Bright, NA \& Robinson, MS. 1997. The role of ADP-ribosylation factor and phospholipase D in adaptor recruitment. J Cell Biol, 138 (6), 1239-1254.

Wilde, A \& Brodsky, FM. 1996. in vivo phosphorylation of adaptors regulates their interaction with clathrin. J Cell Biol, 135.

Yasukawa, T, Kanei-Ishii, C, Maekawa, T, Fujimoto, J, Yamamoto, T \& Ishii, S. 1995. Increase of solubility of foreign proteins in escherichia coli by coproduction of bacterial thioredoxin. J Biol Chem, 270 (43), 25328-25331.

Yeung, BG, Phan, HL \& Payne, GS. 1999. Adaptor complex-independent clathrin function in yeast. Mol Biol Cell, 10, 3643-3659.

Zhang, B, Koh, YH, Beckstead, RB, Budnik, V, Ganetzky, B \& Bellen, HJ. 1998. Synaptic vesicle size and number are regulated by a clathrin adaptor protein required for endocytosis. Neuron, 21 (6), 1465-1475.

Zhu, Y, Doray, B, Poussu, A, Lehto, VP \& Kornfeld, S. 2001. Binding of GGA2 to the lysosomal enzyme sorting motif of the mannose 6-phosphate receptor. Science, 292, 1716-1718. 


\section{Bibliography}

Zhu, Y, Drake, MT \& Kornfeld, S. 1999. ADP-ribosylation factor 1 dependent clathrin-coat assembly on synthetic liposomes. Proc Natl Acad Sci USA, 96, 5013-5018.

Zizioli, D, Meyer, C, Guhde, G, Saftig, P, von Figura, K \& Schu, P. 1999. Early embryonic death of mice deficient in $\gamma$-adaptin. J Biol Chem, 274 (9), 5385-5390. 


\section{Appendix}

\section{Acknowledgements}

This work has been a very instructive experience to me, and a pleasure not only because of science but on account of many people that brightened my heart. Thanks to:

Prof. Dr. Kurt von Figura for his will to speak frankly, to clear confusion and to help with critical discussions.

PD Dr. Peter Schu for the challenging project and the constant supervision of its progress with creativity, advice and patience.

Dr. M. R. Guruprasad, Olaf Bernhard, P. N. Rekha, Angelika Knüppel, Inga Thiele, Monika Kermer, Karthikeyan Radhakrishnan and Jutta Wollenweber for their joyful spirit, for being good friends and for helpful cooperation. Especially Jutta contributed her technical skills to this work at the final stage. Thank you Guru for teaching me and for long discussions! Special thanks to Rekha who always was a great support and company.

Annegret Schneemann for the almost omniscient support in molecular biology, in particular RNA handling and Ellen Eckermann for the assistance in ES cell culture.

PD Dr. Gabriele Fischer von Mollard, PD Dr. Stefan Höning, PD Dr. Thomas Dierks, PD Dr. Bernhard Schmidt, PD Dr. Christian Körner and Dr. Christian Thiel, who were always helpful to provide detailed technical advice and reagents.

Susanne Lausmann (MPI of biophysical chemistry, Göttingen) and Prof. Dr. Renate Lüllmann-Rauch (University of Kiel) for the preparation and examination of histological sections.

Dr. Jobst Landgrebe for taking a vivid interest in the work and fortunately convincing me to use LYX for writing this thesis, which prevented all formatting trouble and produced a beautiful layout. 
Dr. Meik Dilcher and Dr. Anna Boulankina for help and lively interactions in and outside the lab.

Tina Lampe and Andrea Burgalossi, two of my practical students, who managed their projects very well and were of real support.

all the members of the institute for the pleasant atmosphere, for help and advice (without specialising too much here; but it was very important for me to talk beside the work, to get and to give feedback, and luckily I found such interactions within the institute :-)).

my family and friends outside the lab, always taking care of me in a very generous and lovable way... 


\section{Lebenslauf}

Am 10. Juni 1976 wurde ich als erstes Kind von Christine Riel, geb. Lothring und Karl Riel in München geboren. In meinem dritten Lebensjahr zogen wir nach Ismaning im Landkreis München. Von 1982-1986 ging ich in Ismaning zur Grundschule. Danach besuchte ich das Werner-Heisenberg-Gymnasium in Garching, das ich 1995 mit dem Abitur abschloss. Im November 1995 begann ich in Regensburg das Studium der Biochemie (Diplom). Die Vordiplomsprüfungen in Biologie, Organischer Chemie, Physikalischer Chemie und Biochemie legte ich im Sommersemester 1997 ab. Nach dem Hauptstudium folgten die Diplomprüfungen zu Beginn des Wintersemesters 1999/2000, die sich mit Organischer Chemie, Molekularbiologie und Biochemie beschäftigten. Anschliessend arbeitete ich am Lehrstuhl für Zellbiologie und Pflanzenphysiologie der biologischen Fakultät unter der Anleitung von Prof. Dr. Ludwig Lehle an meiner Diplomarbeit mit dem Thema "Untersuchungen zur Apoptose im Zusammenhang mit Defekten der N-Glykosylierung bei Saccharomyces cerevisiae". Nach der Abgabe der Arbeit am 22.8.2000 blieb ich noch bis zum Jahresende in der Arbeitsgruppe, um die Ergebnisse zu vervollständigen. Am 1.1.2001 begann ich in der Abteilung von Prof. Dr. Kurt von Figura im Zentrum für Biochemie und Molekulare Zellbiologie der Universität Göttingen unter der Anleitung von PD Dr. Peter Schu die Arbeit an der Dissertation mit dem Thema " $\sigma 1$-adaptin - the small subunit of the clathrin adaptor complex 1". 